\title{
3 Lebenswelten der 14- bis 17-Jährigen
}

Dieses Kapitel wurde bei Erstveröffentlichung ohne die korrekte Creative Commons Lizenz veröffentlicht. Die korrekte Lizenz finden Sie am Ende des Kapitels.

Ein Erratum zu diesem Kapitel ist verfügbar unter DOI 10.1007/978-3-658-12533-2_14

(C) SINUS Markt- und Sozialforschung GmbH 2016

M. Calmbach et al., Wie ticken Jugendliche 2016?, DOI 10.1007/978-3-658-12533-2_3 


\section{Kurzbeschreibungen der SINUS-Lebenswelten u18}

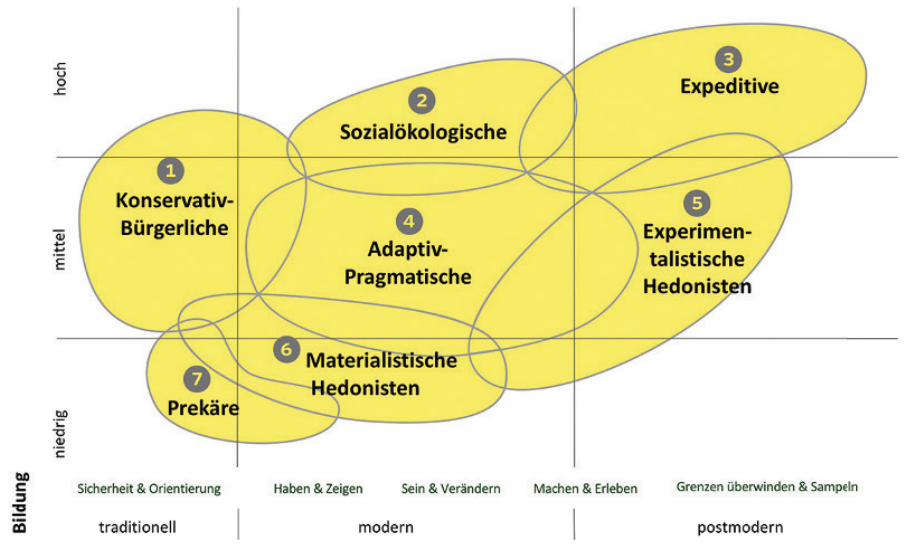

Normative Grundorientierung
(1) Die familien- und heimatorientierten
Bodenständigen mit Traditionsbewusstsein
und Verantwortungsethik.

2 Die nachhaltigkeits- und gemeinwohlorientierten Jugendlichen mit sozialkritischer Grundhaltung und Offenheit für alternative Lebensentwürfe.

3 Die erfolgs- und lifestyle-orientierten Networker auf der Suche nach neuen Grenzen und unkonventionellen Erfahrungen.

(4) Der leistungs- und familienorientierte moderne Mainstream mit hoher Anpassungsbereitschaft.

5 Die spaß- und szeneorientierten Nonkonformisten mit Fokus auf Leben im Hier und Jetzt.

6 Die freizeit- und familienorientierte Unterschicht mit ausgeprägten markenbewussten Konsumwünschen.

(7) Die um Orientierung und Teilhabe bemühten Jugendlichen mit schwierigen Startvoraussetzungen und Durchbeißermentalität.

Die soziokulturelle Landschaft der Jugendpopulation in Deutschland ist vielfältig. In beistehender Grafik sind die einzelnen Lebenswelten stichwortartig beschrieben.

Die Lebensweltanalyse zeigt, dass das im Jahr 2012 entwickelte Modell auch 2016 noch gültig ist, d. h. an der inneren Verfasstheit der Gruppen hat sich wenig geändert. Entsprechend fällt die Beschreibung der einzelnen Gruppen sehr ähnlich aus wie in der Vorgängerstudie. Zur Illustration der Befunde wurden natürlich Zitate, Wohnbilder und Auszüge aus den Hausarbeitsheften aus der aktuellen Studie verwendet. 
Werte-Universum der Konservativ-Bürgerlichen

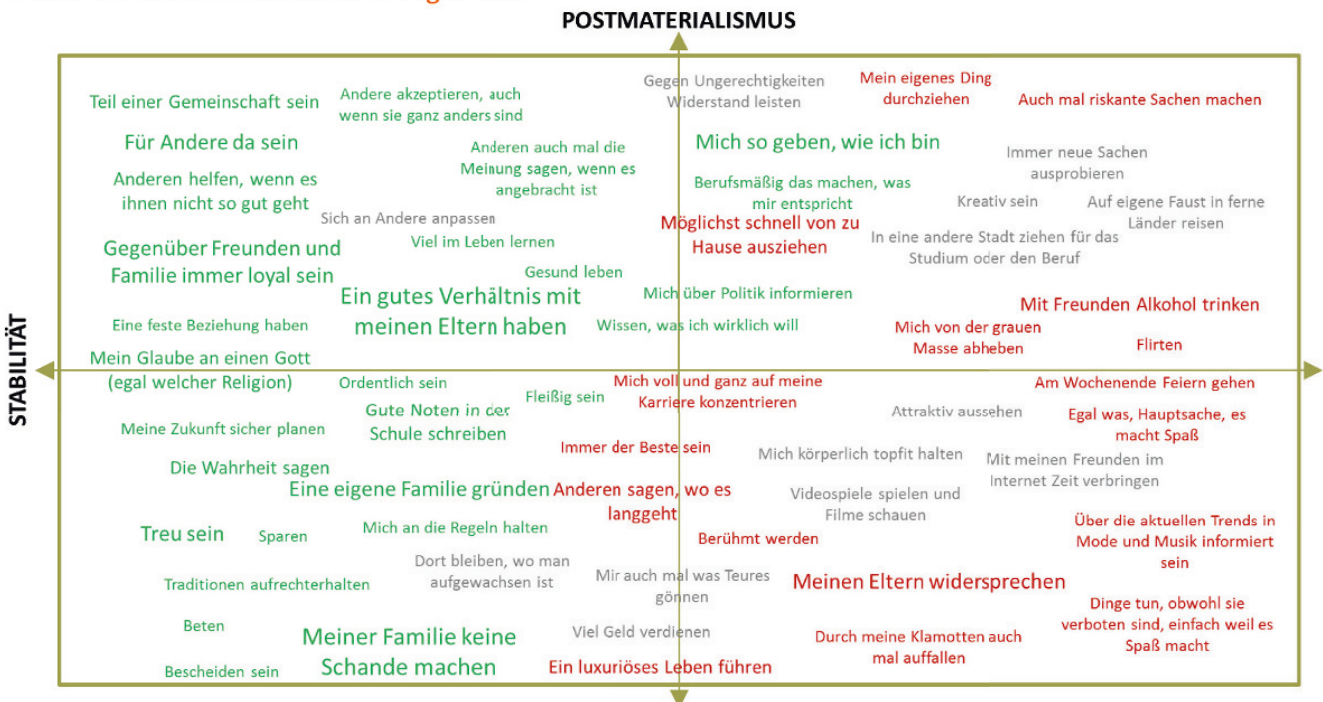

MATERIALISMUS

Hedonistische Werte sind jugendtypisch und daher auch bei Konservativ-Bürgerlichen verbreitet, allerdings rangieren sie in ihrer Bedeutung deutlich hinter einer umfassenden Liste von Werten des traditionell-bürgerlichen Tugendkatalogs: Bodenständigkeit, Vernunft, Standhaftigkeit, Sachlichkeit, Beständigkeit, Bescheidenheit, Gewissenhaftigkeit, Zielstrebigkeit, Fleiß, Treue, Gehorsam, Disziplin, Pflichtbewusstsein, Pünktlichkeit, Zuverlässigkeit, Höflichkeit, Ordnungsliebe, Sauberkeit, Harmonie.

Im Werteprofil der Konservativ-bürgerlichen Jugendlichen spiegeln sich ein ausgeprägtes Bewusstsein für die bewährte gesellschaftliche Ordnung und der starke Wunsch, an dieser festzuhalten. In diesem Sinne sind sie als konservativ zu betrachten.

Für Konservativ-Bürgerliche ist eher Selbstdisziplinierung als Selbstentfaltung charakteristisch. Entsprechend sind die Lifestyle-Affinität und die Konsumneigung in dieser Lebenswelt mit am schwächsten ausgeprägt. In dieser Lebenswelt gehen die Jugendlichen sparsam und kontrolliert mit ihrem Geld um. Die Verzichtbereitschaft ist hoch. Man möchte sein Geld "nicht zum Fenster rausschmeißen.“ 
Konservativ-bürgerliche Jugendliche sind Konventionalisten. Sie beschreiben sich selbst als unauffällig, sozial, häuslich, gesellig, ruhig und geerdet. Während diese Attribute von vielen anderen Jugendlichen als langweilig diskreditiert werden, betrachten Konservativ-Bürgerliche sie als positive Charaktereigenschaften. Als Lebensmaxime werden häufig genannt: "Nichts überstürzen" , Alles in Maßen".

Konservativ-bürgerliche Jugendliche sind sehr heimatnah und regional verwurzelt. Beispielsweise folgt man häufig den großen Sportvereinen aus der Region. Unter den Migranten und Migrantinnen dieser Lebenswelt besteht meist ein enger Draht in die Heimatregion der Eltern. Viele sind auch mit Blick auf das Herkunftsland der Eltern Lokalpatrioten. Auch die autochthonen Deutschen sind in dieser Lebenswelt patriotisch - oder haben zumindest überhaupt kein Verständnis dafür, dass andere Jugendliche es befremdlich finden, wenn man Deutschlandfahnen bei Fussballspielen schwenkt.

Von einer "No risk, no fun"-Attitüde halten Konservativ-bürgerliche Jugendliche gar nichts. Ihr Lebensmotto lautet vielmehr: „Lieber auf

Auszüge aus Hausaufgabenheften zur Frage: WAS GIBT DEINEM LEBEN SINN?

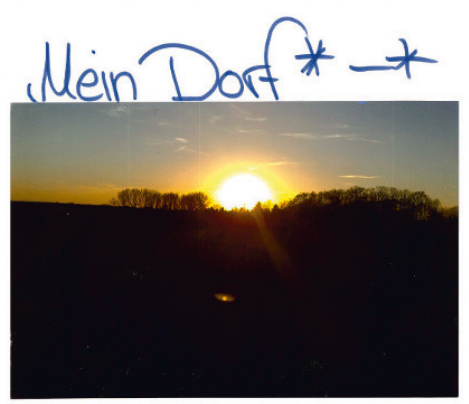

Dorflind und stolz drauf $\infty$

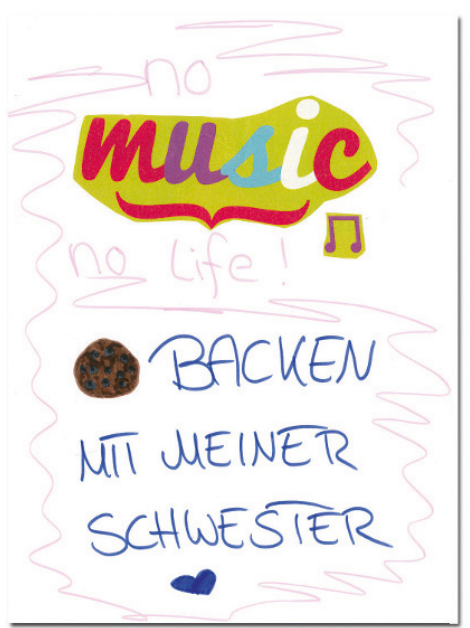


Nummer sicher gehen." Wie wichtig diesen Jugendlichen Sicherheit im Alltag ist, zeigt sich neben der Risikovermeidung in der Freizeit auch in der Betonung von materieller Absicherung (keine finanziellen Sorgen), sozialer Sicherheit (harmonische, dauerhafte Beziehungen) und Innerer Sicherheit (Deutschland vor dem Terrorismus verteidigen, und das bereits vor den Terroranschlägen in Paris im November 2015).

Dieses Sicherheitsstreben ist auch in der Alltagsorganisation erkennbar: Feste Tagesabläufe und Routinen stehen hoch im Kurs. Konservativ-Bürgerliche scheuen Veränderungen und halten sich an Gewohnheiten und Gewissheiten fest. Charakteristisch ist ihre Kontroll-Mentalität und Routineorientierung. Neuem stehen sie eher skeptisch und abwartend gegenüber. Sie orientieren sich stark an bekannten Strukturen und Umfeldern, sprechen beispielsweise mit Unbehagen darüber, dass sie im Zuge einer Ausbildung oder eines Studiums möglicherweise die vertraute Umgebung verlassen müssen.

Der Wunsch, an der bewährten Ordnung festzuhalten, zeigt sich v. a. in dem sehr deutlich formulierten Bedürfnis nach einer "Normalbiografie" (Schule, Ausbildung, Beruf, Ehe, Kinder). Im Vergleich der Lebenswelten ist der Wunsch nach einem geradlinigen, voraussehbaren Lebenslauf bei den Konservativ-Bürgerlichen mit am stärksten ausgeprägt. Kurz: Diese

Auszüge aus Hausaufgabenheften zur Frage:

WAS SIND FÜR DICH DIE WICHTIGSTEN SACHEN DER WELT?

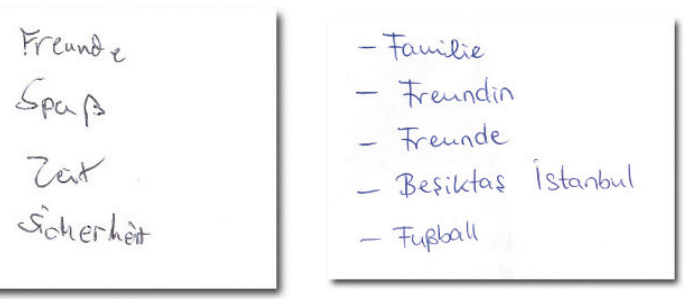

Es gibt for mich Keine wichtigen Sachen, den diese sind alle êrsetzbar, ich brauch nur meine Familic und Frounde.
Fortide, Kunstrad (Meine Hobbysi,

Einise $\sqrt{\text { Frounde }}$

meine Familie, meine

Freunde, Gesundheit, Glück clas ich in die Schule gehen darf, unser Haus, meine zukunft, mein Handy, unser tlund 
Jugendlichen sind eifrige Lebensplaner (wenn auch keine Karriereplaner) - hierzu gehört v. a. auch der Wunsch nach einer eigenen Familie. Sie betrachten Ehe und Familie als Grundpfeiler der Gesellschaft. Entsprechend deutlich werden Bindungswunsch sowie -fähigkeit und Verantwortungsbereitschaft zum Ausdruck gebracht. Dauerhaftigkeit und Treue sind für sie bereits in jungen Jahren die unverhandelbaren Wesenselemente von Partnerschaft. Ein harmonisches Familienleben wird bisweilen zum Idyll stilisiert.

Es hat für Konservativ-bürgerliche Jugendliche überhaupt nichts "Uncooles", mit den Eltern und Geschwistern Zeit zu verbringen - im Gegenteil: Man investiert gerne Zeit in die Pflege familiärer Beziehungen. Die Eltern und andere (insbesondere ältere, lebenserfahrene Familienmitglieder) werden häufig als Vorbilder genannt. Ebenso bewundert man fachliche Autoritäten (zum Beispiel Nobelpreisträger, Lehrer, Politiker) und SportStars der (in der Regel lokalen) Lieblingsvereine.

Man betrachtet einen sicheren Arbeitsplatz als wichtige Voraussetzung für die Gründung einer Familie, der Kinderwunsch wird aber nicht allein davon abhängig gemacht. In dieser Lebenswelt kann man durchaus vom "Mut zur Familie" sprechen, wohl auch, weil sich Konservativ-bürgerliche Jugendliche des Rückhalts der eigenen Familie sicher sind.

Auszüge aus Hausaufgabenheften:

Nenne eine erWachsene Person: A) Deren Lebensgeschichte Du Dir gerne erzÄhlen lassen Würdest. B) VON DER DU GERNE WAS LERNEN WÜRDEST.

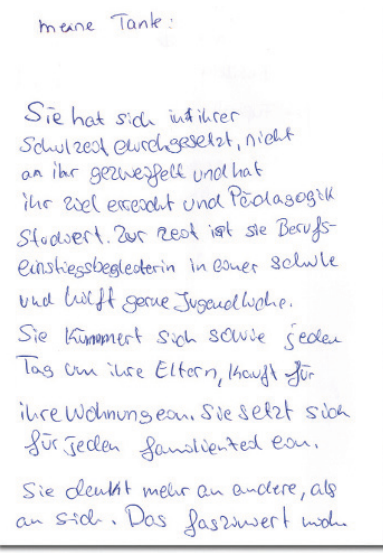

$$
\begin{aligned}
& \text { adean Informatien/Physiee lehrer } \\
& \text { b) Stephen Harking }
\end{aligned}
$$


Auszüge aus Hausaufgabenheften:

Nenne eine erwachsene Person: A) Deren Lebensgeschichte Du Dir Gerne ERZÄHLEN LASSEN WÜRDEST. B) VON DER DU GERNE WAS LERNEN WÜRDEST.

sören Bertram (Fußballer, HFC a) - wie seine karriere als Fuß-
balles gestartet hat

b) - FuBball tricks

Typisch ist ein familienintensiver Alltag mit gemeinsamen Mahlzeiten und Aktivitäten. Häufig kümmert sich die Mutter hauptsächlich um die Versorgung der Familie, pausiert in ihrem Beruf, bis die Kinder die Schule weitgehend geschafft haben oder ist Hausfrau ohne Erwerbstätigkeitsambitionen. Die Jugendlichen sind es dementsprechend gewohnt, umsorgt (und auch kontrolliert) zu werden. Mithilfe im Haushalt wird eher selten gefordert, vor allem von den Jungen nicht. Die Alltagsorganisation nach und nach ein Stück weit selbst zu übernehmen, wird von den Eltern kaum eingefordert - und die Jugendlichen finden das in Ordnung so.

Sich zu exponieren, das Innerste nach außen zu kehren, ständig den aktuellen Trends in Musik und Mode hinterherzurennen und Neues auszuprobieren ist nicht ihre Sache. Sich über Äußerlichkeiten zu definieren, liegt Konservativ-Bürgerlichen fern. Manche stresst es regelrecht shoppen zu gehen, insbesondere dann, wenn man befürchtet, sich dem Druck der Peergroup aussetzen zu müssen. Man kleidet sich „praktisch“; Kleidung soll v. a. ihren Zweck erfüllen. Der "Markenwahn“ anderer Jugendlicher wird abgelehnt. Das offene Zurschautragen von Luxus wird scharf verurteilt. Stattdessen legt man Wert auf korrekte, dem Anlass angemessene Kleidung. Man möchte es den Eltern, Lehrern und Freunden recht machen, was sich auch in höflichen, bisweilen überangepassten Umgangsformen äußert. 
Konservativ-bürgerliche Jugendliche beobachten, dass sie mit ihrer Haltung und Ästhetik zu einer soziokulturellen Minderheit zählen. Sie sind jedoch nicht ,junge ewig Gestrige“. Wenn sie sich dem schnellen Wandel von Werten und Stilen zugraden verweigern, liegt das nicht daran, dass sie intellektuell oder sozial zur Veränderung nicht in der Lage wären, sondern weil sie in ihrem Leben andere Prioritäten setzen. Von diesen Prioritäten andere zu überzeugen ist jedoch selten Anliegen Konservativ-bürgerlicher Jugendlicher.

(7) Dinge, die mir wichtig sind: für andere da sein. Gegenüber Freunden und Familie immer loyal sein. Treu sein. Die Wahrheit sagen. Mein Glaube an einen Gott. Beten. Andere auch akzeptieren, wenn sie ganz anders sind. Gegen Ungerechtigkeiten Widerstand leisten. Mich so geben, wie ich bin. (männlich, 15 Jahre)

(Das mag ein bisschen komisch klingen, aber wenn wir abends zusammen am Tisch sitzen mit meiner Familie - das ist mir sehr wichtig. Wir essen, wir reden. Wir verbringen schon den ganzen Abend mit der Familie, wir sitzen drinnen und trinken Tee. (weiblich, 16 Jahre)

[INT: WAS IST DIR WICHTIG IM LEBEN?] Sicherheit in allem eigentlich. Besonders jetzt mit den Terroranschlägen. Im Sinne von Leben gesichert, aber auch finanzielle Sicherheit, würde ich sagen. Also, Sicherheit in allem so ziemlich. (männlich, 17 Jahre)

( Sich keine Sorgen machen zu müssen, zum einen wegen der Geldnot. Und sein Leben sicher zu wissen. Man muss sich keine Sorgen machen, dass sich jede Sekunde irgendwo jemand in die Luft sprengt. (männlich, 17 Jahre)

(8) Mir ist das auf jeden Fall total wichtig, dass ich auch mit meiner Familie mal was zusammen machen. Also das ist mir richtig wichtig, und das sollte sich auch auf keinen Fall ändern. (weiblich, 14 Jahre)

(>) Lebensmotto? Ich halte mich halt immer daran höflich zu sein und mich zu benehmen, überall, wo ich halt neu bin. Und wenn ich jemanden neu kennenlerne, halt immer nett und freundlich zu sein, weil so hat mir das meine Mama beigebracht. (weiblich, 14 Jahre) 
Also ich will jetzt auch keiner werden zum Beispiel wie einer von den Geissens. Das ist so eine Millionärsfamilie. Und ich möchte aber auch keiner werden, der jetzt so arm ist und im Obdachlosenheim lebt. Also ich will eigentlich ein ganz normaler Mensch sein, so wie jetzt eigentlich auch schon. (männlich, 14 Jahre)

( Ich finde es eigentlich schrecklich, dass sich Leute nur auf die Klamotten beziehen. Es gibt Leute, die haben gar nichts an Klamotten. Mir ist das eigentlich scheißegal. Ich habe meine Klamotten, aber ich achte da nicht so drauf. Ich greife in den Kleiderschrank und ziehe einfach irgendwas an. Ich finde das mit der Mode und so gar nicht wichtig. Oder sich eine Hose bei Breuninger für über hundert Euro zu kaufen, das finde ich schrecklich. (weiblich, 17 Jahre)

( Ja, mir ist es wichtig, mich angemessen anzuziehen, wenn ich in der Schule bin oder wenn ich woanders hingehe, in ein Restaurant oder essen gehe. (männlich, 15 Jahre)

Shoppen? Überhaupt nicht oft. Mag ich nicht, ist ganz schlimm. Ich hasse Shoppen. Immer dieses Anziehen, Umziehen... [INT: UND WIE KOMMST DU DANN AN DIE KLAMOTTEN?] Da mache ich dann einen Tag mit meiner Mutter aus, und dann gehen wir halt zu Takko oder so. Und dann brauche ich wieder Hosen oder sonst was und dann geht das. Dann bin ich alleine mit meiner Mutter und nicht so mit Freundinnen. Das ist angenehmer. (weiblich, 17 Jahre)

ICh will halt nicht luxuriöses Geld verdienen, aber ich will reichlich Geld verdienen, um meine Familie zu ernähren, wenn ich groß bin, um meine Kinder glücklich zu machen, um meine Frau glücklich zu machen. Um einfach nicht im Hintergedanken zu haben, was passiert im nächsten Monat, schaff ich das mit meinem Geld oder nicht? Das wäre mein Ziel. (männlich, 15 Jahre)

(8) Aber in mir drin ist auch so ein Herz so mit Bescheidenheit und so alles Mögliche. [...] Ich finde es wichtig, meinen Freunden helfen zu können, egal in welchen Situationen. Ich würde auch, wenn sie mich um 22 Uhr anrufen, sofort aus dem Haus gehen und mit denen reden. Ich würde gern für sie immer da sein. (männlich, 15 Jahre) 
(1) Es ist schon schön, dass hier alles so geordnet und gepflegt ist, und wenn man durch die Straßen läuft, ist alles gemäht und sauber. In der Türkei ist das halt nicht so. Da liegt halt auf der Straße auch Müll. Was ich sehr gut an Deutschland finde, dass hier recycelt wird. (weiblich, 16 Jahre)

\subsubsection{Zukunftsvorstellungen}

Konservativ-bürgerliche Jugendliche machen sich bereits früh Gedanken über die Zukunft, sind bemüht, so wenig wie möglich dem Zufall zu überlassen. Gleichzeitig spüren sie jedoch auch, dass sich die Normalbiografie nur noch schwer realisieren lässt; dass Gegenwart und Zukunft ein hohes Maß an Flexibilität und Mobilität von ihnen einfordern - Werte, zu denen Konservativ-bürgerliche Jugendliche eine geringere Affinität haben als viele Altersgenossen. Das sorgt für Unbehagen, insbesondere, weil sie in Gesprächen mit Gleichaltrigen mitbekommen, dass es Jugendliche gibt, die zwar ihre Zukunftssorgen teilen, sich aber trotz vager Zukunftsvorstellungen recht unbekümmert geben und darauf vertrauen, dass sie ihren Weg schon machen werden. Dieses Selbstzutrauen haben Konservativ-bürgerliche Jugendliche kaum. Einige betrachten das Leben daher auch als "Kampf“.

Da Konservativ-Bürgerliche sicherheitsbedacht sind und nur ungern ins "kalte Wasser springen", möchten viele noch möglichst lange bei den Eltern wohnen bleiben oder zumindest in der Nähe eine eigene Bleibe finden.

Für die private Zukunft haben nahezu alle einen festen Plan: Heiraten, Kinder bekommen, Wohneigentum anschaffen. Die Geborgenheit und Sicherheit der Kleinfamilie stellen den sicheren Hafen dar, auf den man zusteuert.

"Zeit vertrödeln“ möchten Konservativ-bürgerliche Jugendliche auf keinen Fall. Sie fürchten sich regelrecht vor Lücken im Lebenslauf. Sie neigen zu einer nüchternen und realistischen Berufswahl. Selbstverwirklichung im Beruf ist zwar ein wichtiger Wert, Sicherheit steht jedoch über allem. 
Auszüge aus Hausaufgabenheften:

WiE MÖChtEst Du SPÄTER LEBEN? WAS MACHST DU DANN?

\section{Ich machte spoter \\ in elnem schonen \\ Has wohnen, mit \\ meiner tamilie und \\ einen guten Job.}

$$
\begin{aligned}
& \text { Im bester Fall: } \\
& \text { - Ein eigenes Hans } \\
& \text { - Gerine Goldnot } \\
& \text { - Familie } \\
& \text { - Sicheren Jos }
\end{aligned}
$$

ich mōchte später eire Familie heban. mitihe in eireon stören Haos whrien, för meine kinder da seinwenn siemich
brevehen.

Heffer Arbeiten damitich meinen Kinderngeden Wuasch efollenkann.

Später môchte ich eine Familie
gründen, und möglichst
2 Kinder haben.
Ohne finauzielle Probleme.
Dazu brauche ich eine gute
Berufrausbilduing und einen
guten Job,
Zurzeit ist mein Berufswunsch
einen Auwalt werden.

Später möchte ich eine Familie haben, eine gute Arbeit besitzen und in linem Houns mit garten wohnen

Die Zukunftswünsche der Konservativ-bürgerlichen Jugendlichen sind von Bescheidenheit, Nüchternheit, und Realismus gekennzeichnet. Alles, was man will, ist ein anständiges Leben ohne Not in harmonischen familiären Verhältnissen. Als Referenz dient den Konservativ-Bürgerlichen dabei oft die eigene familiäre Gegenwart.

Eine Familie zu gründen begreifen Konservativ-Bürgerliche nicht nur als einen Wunsch und ein Zukunftsziel, sondern auch als eine Leistung, die sie erreichen wollen.

Den Konservativ-bürgerlichen Jugendlichen ist ein geordneter beruflicher Aufstieg wichtig - allerdings nicht um jeden Preis. Man hofft darauf, dass sich mit gewissenhafter, pflichtbewusster und fleißiger Erledigung der Aufgaben die entsprechenden Erfolgserlebnisse automatisch einstellen werden. Doch sicher ist man sich nicht. Karrieresprünge zulasten eines harmonischen Familienlebens betrachten v. a. Konservativ-bürgerliche Mädchen skeptisch, wohl auch weil man den emotionalen Halt v. a. in der Familie und nicht im Beruf eingelöst sieht.

Bei den Berufswünschen der Konservativ-bürgerlichen Jugendlichen ist auffällig, dass häufig Berufe genannt werden, von denen man sich 
Sicherheit bzw. Abgesichert-Sein verspricht, v.a. Beamtenlaufbahnen. Sowohl von Jungen als auch Mädchen wird v. a. beispielsweise die Polizei als attraktiver Arbeitgeber genannt, auch die Bundeswehr wird (von den Jungen) erwähnt. Die Berufswünsche sind tendenziell geschlechtertypisch und traditionell ("ehrliche Berufe"). Die Jungen sehen sich künftig in handwerklichen Berufen (Steinmetz, Polizei, Feuerwehr, Maler, Gärtner, Schlosser etc.), die Mädchen in pädagogischen und Pflegeberufen sowie im medizinischen Bereich. Über die Vielfalt der neueren Ausbildungsberufe wissen Konservativ-Bürgerliche wie viele Jugendliche eher wenig. Man orientiert sich v. a. an etablierten Berufen. Unter den besonders ambionierten Vertretern dieser Lebenswelt spielt auch das gesellschaftliche Ansehen des Berufes und der anvisierten Universität eine wichtige Rolle.

Wichtig für die berufliche Orientierung sind die Eltern und weitere erwachsene Personen im sozialen Nahumfeld. Daraus erklärt sich auch die Tendenz, eher traditionelle Berufe als Ziele zu benennen. Wichtig ist, dass die berufliche Laufbahn planbar und absehbar ist. Es muss ersichtlich sein, wohin der Weg führt. Angebote zur beruflichen Orientierung, die im Rahmen des Schulunterrichts gemacht werden, nimmt man pflichtbewusst in Anspruch.

Zukunftsbezogene Ängste beziehen sich v.a. darauf, dass sich später "vielleicht alles ändert", dass die Freunde wegziehen und die Routinen wegbrechen werden. Auch in der Schule abzurutschen ist eine Sorge, die viele teilen. Der Abschluss gilt als harte Währung auf dem Ausbildungsund Arbeitsmarkt, den man als umkämpft und unsicher wahrnimmt. Und auch spätere Weiterbildung scheint vielen unerlässlich, um auf diesem Markt zu bestehen.

Die eigenen Chancen auf dem Arbeitsmarkt sieht man zum einen von der eigenen Leistung abhängig. Sich anzustrengen ist daher eine absolute Selbstverständlichkeit; „wer das nicht tut, wird es auch zu nichts bringen". Die Jugendlichen beobachten jedoch in der Familie und dem Verwandten- und Bekanntenkreis der Eltern, dass dies heute oft nicht ausreicht, weil "Fleiß und Ehrlichkeit" nicht mehr alleine entscheiden. 
Auszüge aus Hausaufgabenheften: WAS GIBT DeINEM LeBEN SINN?
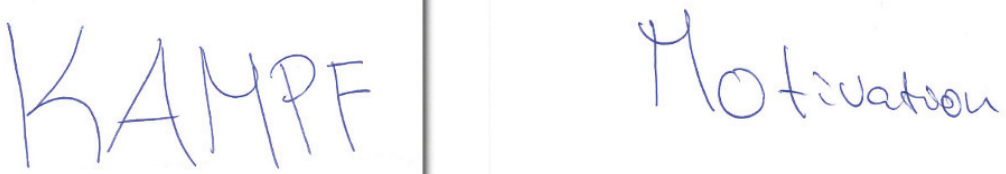

Un Zuele as erreschen.

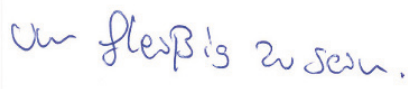

Typische

Zitate zur

|llustration

( Mit 32 will ich auf jeden Fall schon mal einen richtig ordentlichen Job haben und auf jeden Fall schon ausgezogen sein und ein normales Leben führen. (männlich, 14 Jahre)

(1) Ich hoffe natürlich immer noch, dass meine Familie immer noch bei mir ist, sie in meiner Nähe ist. Bisher habe ich auch noch nicht den Plan, hier so wegzuziehen. Und dass wir natürlich immer noch das Traditionelle machen, so zu Weihnachten oder so treffen. (weiblich, 14 Jahre)

( Also wenn ich sehe, das Gehalt von meinem Ehemann reicht für uns beide aus, für unsere Familie, dann würde ich es eher bevorzugen, zu Hause zu sein, Zeit mit meiner Familie zu verbringen, den Haushalt zu erledigen. (weiblich, 16 Jahre)

( Also mir ist natürlich nicht so wichtig, dass ich später mal total reich werde oder jetzt total reich bin, dass ich später mal in einer übelsten Luxusvilla lebe oder so. Das ist mir eigentlich total Wurst. Und natürlich dass ich hier bei mir im Dorf bleibe, also jetzt will ich halt noch hier bleiben. (weiblich, 14 Jahre)

( Und mit 35 habe ich vielleicht eine Familie und wohne in meinem eigenen Haus, nicht so weit weg von hier. Ich will schon gerne hier bleiben eigentlich. Das ist so schön ruhig. (weiblich, 17 Jahre) 
( Ich kann mir vorstellen, woanders hinzugehen, aber ich wei $\beta$, die TU ist in den Top Ten der weltweit besten Unis. Wieso sollte man woanders hingehen, wenn man auch dort sein kann? (männlich, 17 Jahre)

(7) Spiele programmieren oder irgendwas im Bereich wirtschaftliches Programmieren [...]. Das wäre eher der etwas langweiligere Weg, aber wahrscheinlich auch der, der am sichersten ist. (männlich, 17 Jahre)

( Ich würde gern zur Polizei gehen. Ich denke mal, ich werde hier in der Nähe wohnen, also nicht so weit weg. (weiblich, 15 Jahre)

\subsubsection{Kulturelle Orientierung, Freizeit}

Konservativ-Bürgerliche beschreiben ihre kulturellen Präferenzen als "normal", "nicht besonders ausgefallen". So mögen sie beispielsweise v. a. diejenigen Songs und Filme, die derzeit die Hitlisten anführen. Eine nähere Beschäftigung mit Musik und Kino findet aber eher weniger statt.

Die Konservativ-bürgerlichen Jugendlichen haben zwar keine ausgesprochene Nähe zu "trivialer" oder volkstümlicher Kultur (z.B. Volksmusik, Schlager), sie distanzieren sich jedoch auch nicht ausdrücklich davon (im Gegensatz zu fast allen anderen Jugendlichen). Migranten dieser Lebenswelt hören auch populäre wie folkloristische Musik aus den Herkunftsregionen, einige sind auch in ethnischen Vereinen aktiv.

Der eigene Kleidungsstil wird nicht an den Musikgeschmack rückgekoppelt. Popmusik besitzt für sie keine ideologische Aufladung.

Das Hochkulturinteresse ist sehr schwach ausgeprägt. Eine deutliche Distanz besteht gegenüber kulturellen Produktionen, die tradierte Formen künstlerischen Ausdrucks aufbrechen. Zu abstrakter bzw. sperriger oder radikaler Kunst haben Konservativ-bürgerliche Jugendliche wenig Zugang. Sie fühlen sich hier bisweilen sogar eingeschüchtert, und manche sehen sich in ihrem Kulturverständnis regelrecht "angegriffen", so dass sie hier nicht von Kunst sprechen mögen. Auf Kultur mit einer volkstümlichen Note hingegen können sie sich einlassen, wenngleich nur die 
Auszüge aus Hausaufgabenheften: WAS HÖRST DU GERNE FÜR MUSIK?

Ich höre total gerne Schlager

(z. B.: Helene Fischer) aber

auch Rap (2.B: Fand

Bang)

Aber am allerliebsten

mag ich das olktuellste

(was z.B.: in den Charts

lommt) aktuelle Musik and

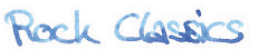

- Pop

- türkische Charts

\section{Electio}

EDM

House

hin und wieder Metal

Wenigsten und zudem nur sehr selten entsprechende Veranstaltungen besuchen.

Auch Diskothekenbesuche und Partys spielen für Konservativ-Bürgerliche eine untergeordnete Rolle. Man fühlt sich dort bisweilen unsicher oder fürchtet, mit dem eigenen Auftreten bzw. dem geringem Interesse an dem, was derzeit als cool oder uncool gilt, "blöd aufzufallen“. Diese Jugendlichen stehen eher am Rand der Tanzfläche, statt sich in der Mitte zu exponieren. Insbesondere wenn Partys "zügellos" werden ("zu viel gesoffen wird“, "Randale gemacht wird”, ,wild geknutscht wird", "es zum Saufgelage ausartet"), kommt bei den Konservativ-bürgerlichen Jugendlichen Unbehagen auf. Vielen ist es schon fast peinlich, dass sie zu den "Kontrollfreaks" und "Partybremsen" zählen. Aber sie können "nicht aus ihrer Haut" und wollen "lieber schnell weg, bevor es Ärger gibt".

Konservativ-bürgerliche Jugendliche mögen „eher" die "geordnete" Fröhlichkeit und Geselligkeit von Stadt(teil)festen und die Atmosphäre von Vergnügungs- und Tierparks - nicht zuletzt, weil man hier oft mit der ganzen Familie zusammen ist. Auch gemeinsame Abende mit Familie oder Freunden zählen in dieser Lebenswelt zu beliebten Freizeitgestaltungen. 
Hoch im Kurs stehen zudem unmittelbare Naturerfahrungen wie Zelten mit Lagerfeuer, wobei insbesondere gemeinschaftsstiftende Momente positiv erwähnt werden (wenn "alle am Feuer sitzen“, wenn „man schön beisammen sitzt"). Die Natur ist ein Symbol für Heimat, Ruhe und Harmonie und für christlich-gläubige Konservativ-Bürgerliche außerdem ein Teil der göttlichen Schöpfung.

Viele dieser Jugendlichen haben zwar kein breites (pop)kulturelles Wissen, dafür oft ein sehr bereichsspezifisches. Man kniet sich in eine Sache "richtig rein", wird zum Experten oder zur Expertin. Interessant sind oft Nischen-Themen, wie zum Beispiel Survival, Modellfiguren, Wrestling oder Automobile. Themen, die Möglichkeiten zum Sammeln bieten, stehen bei Konservativ-bürgerlichen Jugendlichen hoch im Kurs.

Während Konservativ-bürgerliche Mädchen Computer- und Konsolenspiele fast durchweg ablehnen, greifen Jungen (wie auch in den meisten anderen Lebenswelten) gerne zum Gamepad, um in Actionspielen (z. B. Call of Duty), aber auch in Wissens- und Quizspielen ("Wer wird Millionär?") ihr Können und Wissen zu testen. Man grenzt sich aber bewusst von den "Zockern" ab, indem man betont, sich selbst Grenzen zu setzen, um nicht zu viel Zeit vor der "Kiste" zu verbringen.

Auszüge aus Hausaufgabenheften: Was GiBt DeInEM LebEN SinN?

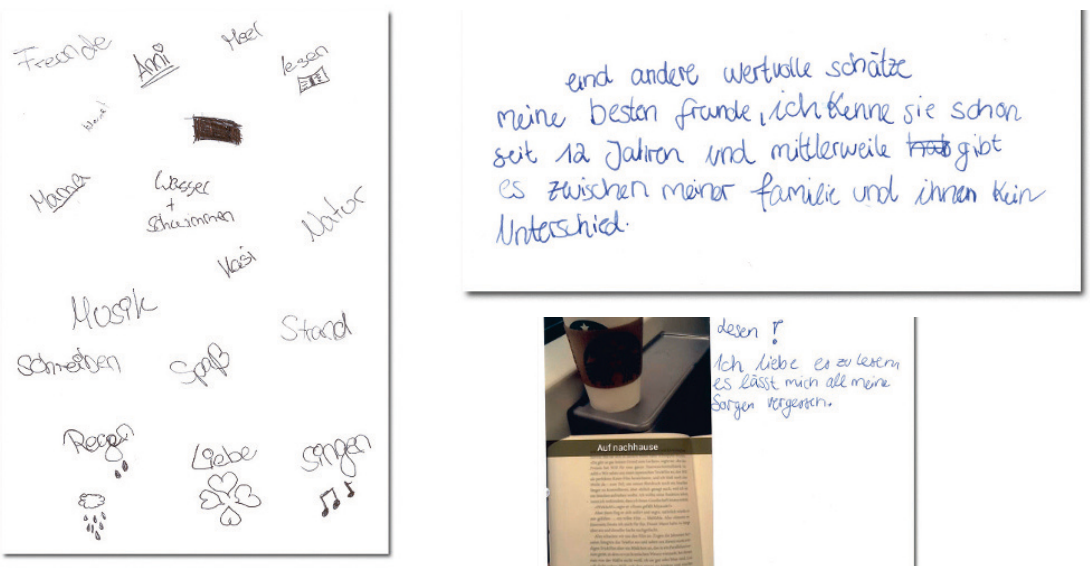


Diese Jugendlichen sehen gerne fern. Vor allem Infotainment-Angebote (Dokumentationen, Wissenshows) und Comedyserien (How I met your Mother, Big Bang Theory) gehören für die meisten zum Tagesprogramm. Sowohl nationale als auch regionale Nachrichten werden interessiert und auch regelmäßig verfolgt. Man schaut zudem gerne gemeinsam mit der Familie fern (v.a. Quizsendungen, gemeinsamer Tatort-Abend, Sport-Veranstaltungen). Im TV-Abendprogramm oder auf DVD stehen neben den üblichen Action-(Fast \& Furious), Fantasy-(Die Tribute von Panem) und Comedy-(Der Kindergarten Daddy) Blockbustern auch deutsche Produktionen wie beispielsweise der "Tatort ", „Fack Ju Göhte 2" und "Rico, Oskar und das Herzgebreche" hoch in der Gunst.

Freizeit mit der Vor- und Nachbereitung von „Unterrichtsstoff" zu verbringen ist auch für viele Konservativ-Bürgerliche nicht wirklich eine Option. Allerdings ist man darauf bedacht, mehr über diejenigen Themen zu erfahren, für die man sich interessiert. So nimmt man ein Buch zur Hand, um sich zu bilden und seinen Wissenshunger zu stillen. Auch regionale und überregionale Zeitungen und Nachrichtenmagazine (Der Spiegel) werden neben Krimis (Edgar Wallce, Die drei ???), Fantasybüchern (Der Herr der Ringe) und Sportmagazinen (Bravo Sport) häufig gelesen.

Typische Zitate zur Illustration
( Am Wochenende gibt es eigentlich nichts Besonderes. Da sitze ich nur zu Hause herum und habe nichts zu tun. (...) Partys mag ich nicht so. Auf solchen Veranstaltungen wäre mir das zu viel Alkohol und auch zu laut. Ich mag es leise. Da sind auch zu viele Leute. (weiblich, 17 Jahre)

(2) So bei uns die ganzen Feste vom Verein natürlich. Da muss ich ja mit hin. Dann die Kerwe hier in [DoRf IN SüdDEUTSCHLAND] ist immer ganz lustig jedes Jahr. Das ist auch das Einzige, wo ich mehr oder weniger mit auf die Party gehe abends. In [KLEINSTADT IN SÜDDEUTSCHLAND] ist ja immer dieses Sommerfest, da gehe ich auch mit hin. Und hier auch Sommerfest. Das sind eigentlich so die Feste, wo ich hingehe. Mehr auch nicht wirklich. (...) Ich bin nicht so die Partymaus. Das ist nicht so meins. (weiblich, 17 Jahre) 
Wenn ein Dorffest ist, dann gehe ich da vielleicht mal mit meiner Mutti oder meinem Bruder hin, vielleicht mit ein paar Kumpels. (männlich, 14 Jahre)

Eher so chartmäßig. Ich lebe es jetzt nicht, aber es ist für mich schon etwas Wichtiges, die Musik. (männlich, 17 Jahre)

( I I höre am liebsten das Topaktuellste, was in den Charts so läuft.Und dann mag ich auch so gerne Schlager, also Helene Fischer, das mag ich auch total gerne. (weiblich, 14 Jahre)

( Mein Geschmack ist wie bei allen anderen auch. (männlich, 14 Jahre)

( Und Musik ist einfach alles mögliche rauf und runter. Kommt immer darauf an, wie man sich gerade fühlt. Wenn es mir scheiße geht, dann höre ich eher Rammstein oder Volbeat oder sowas. Und wenn es mir gut geht, Pharrell Williams "Happy" oder sowas. Wenn ich mit meiner besten Freundin zusammen bin, hören wir mit ihrem Bruder immer Techno. Das ist auch ganz lustig im Auto. (weiblich, 17 Jahre)

(7) Ich singe im Verein, also im Chor mehr oder weniger. [INT: WAS SINGT IHR DA SO?] Ganz alte Lieder, so Oma-Lieder. Ein bisschen neuer als der Kirchenchor, aber dann auch nicht mehr so neu. Außer an der Winterfeier, da machen wir unseren Next-Generation-Teil. Und da singen wir dann die neueren Lieder. (weiblich, 17 Jahre)

(1) Ich treffe mich lieber mit meinen Freunden, als dass ich in die Disco gehe oder so. Zum Beispiel pokern oder halt Zeit verbringen irgendwie. Man geht irgendwie in den Park und verbringt gemeinsam Zeit. Einfach so herumhängen, chillen. (männlich, 17 Jahre)

( Ich bin nicht so ein Fanatiker, aber ich mag es, so über Politik zu reden. [INT: SCHAUSt DU AUCH NACHRICHTEN, WelChE?] Ja. Eher auf ARD, Tagesschau, Tagesthemen. (männlich, 15 Jahre)

( Draußen zu sein, klar. Aber den ganzen Tag weg zu sein, so lange wie möglich außer Haus zu sein, ist irgendwie nicht mein Ding. (männlich, 17 Jahre) 


\subsubsection{Vergemeinschaftung}

In der Wahrnehmung Konservativ-bürgerlicher Jugendlicher zeichnen sich ihre Freundschaften vor allem durch Beständigkeit und Verbindlichkeit aus. Sie mögen es nicht, sich „immer auf neue Leute einstellen zu müssen" und erklären entsprechend, dass sie mit ihren engsten Freunden schon seit dem Grundschulalter oder noch länger befreundet sind. Ihre Freundschaften sind zumeist geschlechterhomogen strukturiert.

Konservativ-Bürgerliche betonen, dass ihnen ein fester, überschaubarer, sozial homogener Freundeskreis wichtig ist. Sie legen großen Wert auf Gemeinschaft und meinen damit in erster Linie "Offline-Gemeinschaft" ("im echten Leben“). Sie denken und sprechen kaum in neudeutschen Begriffen wie "Networking" und "Communities", sondern erzählen eher von der guten Gemeinschaft oder vom festen Freundeskreis. So akzeptiert man in virtuellen Social Communities, insofern diese überhaupt genutzt werden, nicht ohne Weiteres Freundschaftsanfragen von Jugendlichen, die man gar nicht oder nur wenig kennt.

Den Konservativ-Bürgerlichen ist bewusst, dass viele Jugendliche ihnen in Bezug auf popkulturelle Wissensbestände um Welten voraus sind und sie sich auf diesem Feld kaum profilieren können. Sie gehen aber mit ihrer geringen Affinität zu modernem Lifestyle durchaus selbstbewusst um, indem sie sich beispielsweise demonstrativ von den „Hipstern" und den "Stylern" sowie deren aus ihrer Sicht oberflächlichem Trendkult und substanzloser Selbstinszenierung distanzieren.

Wegen ihrer geringen Affinität zum zeitgeistigen Lifestyle ist die Teilhabe Konservativ-bürgerlicher Jugendlicher am jugendkulturellen Kosmos eingeschränkt. Die Wechselhaftigkeit, Kleinteiligkeit, Widersprüchlichkeit, Unübersichtlichkeit, Veränderungsdynamik und der oft ungezügelte Hedonismus von Jugendszenen läuft dem Wunsch nach Ordnung, Eindeutigkeit, Ernsthaftigkeit und Beständigkeit dieser Jugendlichen zuwider. Entsprechend grenzt man sich auch von den „Rebellen“ und "Störenfrieden" ab, bezeichnet sich selbst (leicht ironisch) eher als brave Schüler.

Sie fühlen sich dort aufgehoben, wo die Gruppe und nicht der/die Einzelne im Vordergrund steht; wo sie nicht das Gefühl haben, "anders", 
"besonders", „,auffällig" sein zu müssen, um respektiert zu werden. Dementsprechend haben sie mit devianten, ästhetisch provokanten Jugendszenen "nichts am Hut". Auch sehr introvertierte Jugendliche werden in dieser sehr geselligen Lebenswelt nicht geschätzt. Fallen ästhetische Extrovertiertheit und soziale Introversion bzw. demonstrative Passivität zusammen (wie zum Beispiel "bei den Emos“), gehen Konservativ-Bürgerliche besonders schnell auf Distanz.

Attraktiv für diese Jugendlichen sind Vergemeinschaftungsformen, bei denen sie nicht das Gefühl haben, einem Wettbewerb ausgesetzt zu sein ("Wer ist der Coolste", "Wer kann was am besten“, „Wer hält am meisten aus", "Wer ist am krassesten"), sondern die einen vor dem „Individualitätswahn der Ich-Gesellschaft"' geschützten, berechenbaren Raum bieten, in dem man keine Masken aufsetzen muss. Solche Räume findet man beispielsweise in Vereinen und Kirchengemeinden. Viele Jugendliche in dieser Lebenswelt sind von der Anforderung permanenter Selbstdarstellung und Profilierung abgestoßen, manche auch überfordert.

Konservativ-Bürgerliche sehen sich selbst aber nicht als "überangepasste" oder "langweilige" Jugendliche. Sie beschreiben sich als "Freunde, mit denen man mal Pferde stehlen kann", die "auch mal was Verrücktes machen“. Allerdings halten sich ihre "Ausbrüche“, „Frechheiten" und "Verrücktheiten" im Rahmen - ganz zu schweigen davon, dass sie nicht in Konflikt mit Autoritäten oder gar dem Gesetz geraten möchten. 
Typische Zitate zur Illustration
( Ich habe hier Freunde in der Gegend, die wohnen nur eine Tür weiter, die kenne ich seit meiner Geburt und die liebe ich auch so wie meine Brüder. Mit denen bin ich auch oft zusammen. (männlich, 15 Jahre)

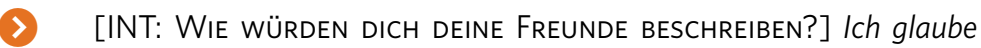
ruhig, lustig, interessiert. Mehr fällt mir gerade nicht ein. (männlich, 17 Jahre)

( Ich gehe meistens auch zur Jungen Gemeinde bei uns im Dorf, die Kirche, die gleich um die Ecke ist. (männlich, 14 Jahre)

( Also ich bin in so einer Fan-Gruppe vom Fußball-Verein, von so einem kleinen, unserem Nachbardorf $R$. Wenn da halt immer ein Heimspiel ist, fahre ich da halt immer hin, und dann, wenn dann noch Zeit ist, spiele ich halt mit Kumpels draußen Fußball. (männlich, 14 Jahre)

( Ich bin ja eher so ein Mensch, der harmonisch mit anderen Menschen zusammensitzt und sich unterhält. Streit geht bei mir gar nicht. (weiblich, 17 Jahre)

(1) Eingebildete, Arrogante hasse ich nicht, aber da bin ich ein bisschen so fern. (männlich, 15 Jahre)

(7) [INT: WIE SIND DIE LEUTE SO, DIE DU NICHT MAGST?] Wenn sie denken, sie sind geil, sie sind die Besten. Im besten Falle auch noch, sie kriegen alle Mädchen. (männlich, 17 Jahre)

Lieblingsorte? Ich bin gerne unten auf dem Schulhof. Da sitzen wir oft auf dem Klettergerüst. Oder halt im Verein im Vereinshaus. Mehr gibt es halt nicht wirklich. Oder halt bei meiner Großtante. Da ist es auch cool. Da hat man auch seine Ruhe. (weiblich, 17 Jahre) 


\subsection{Adaptiv-Pragmatische}

Der leistungs- und familienorientierte moderne Mainstream mit hoher Anpassungsbereitschaft

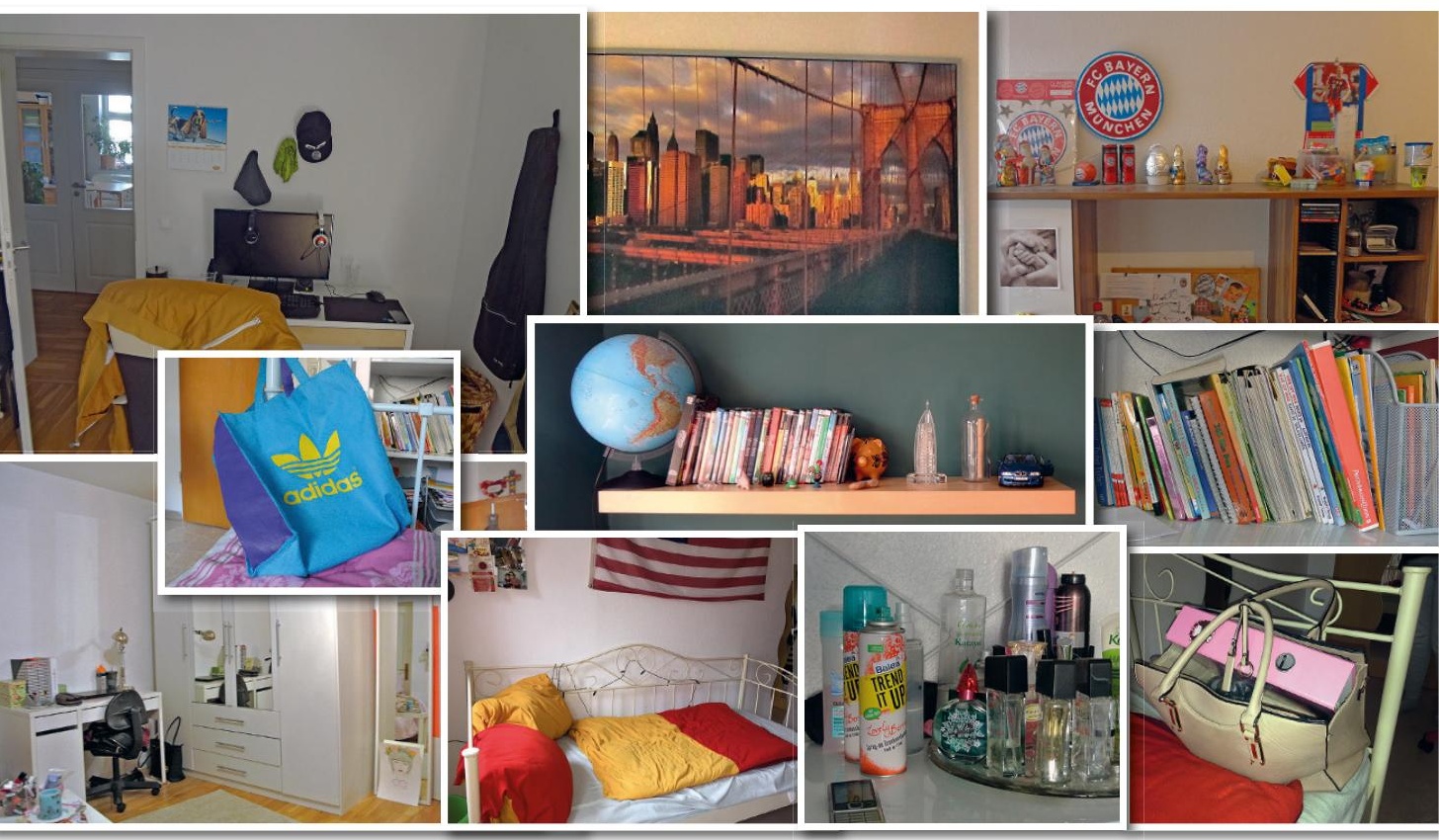

\subsubsection{Lebensweltliche Basisorientierungen}

Adaptiv-pragmatische Jugendliche kombinieren die bürgerlichen Grundwerte und Tugenden wie Ehrlichkeit, Respekt, Vertrauen, Pünktlichkeit und Fleiß mit modernen und hedonistischen Werten wie Freiheit, Offenheit, Unvoreingenommenheit, Spaß und Humor.

Die Familie gibt dem Leben Sinn. Die wichtigsten Menschen im Leben - und oft auch die eigenen Vorbilder - sind die Mitglieder der eigenen Familie. Dies gilt auch dann, wenn die Familie durch die Trennung der 
Werte-Universum der Adaptiv-Pragmatischen

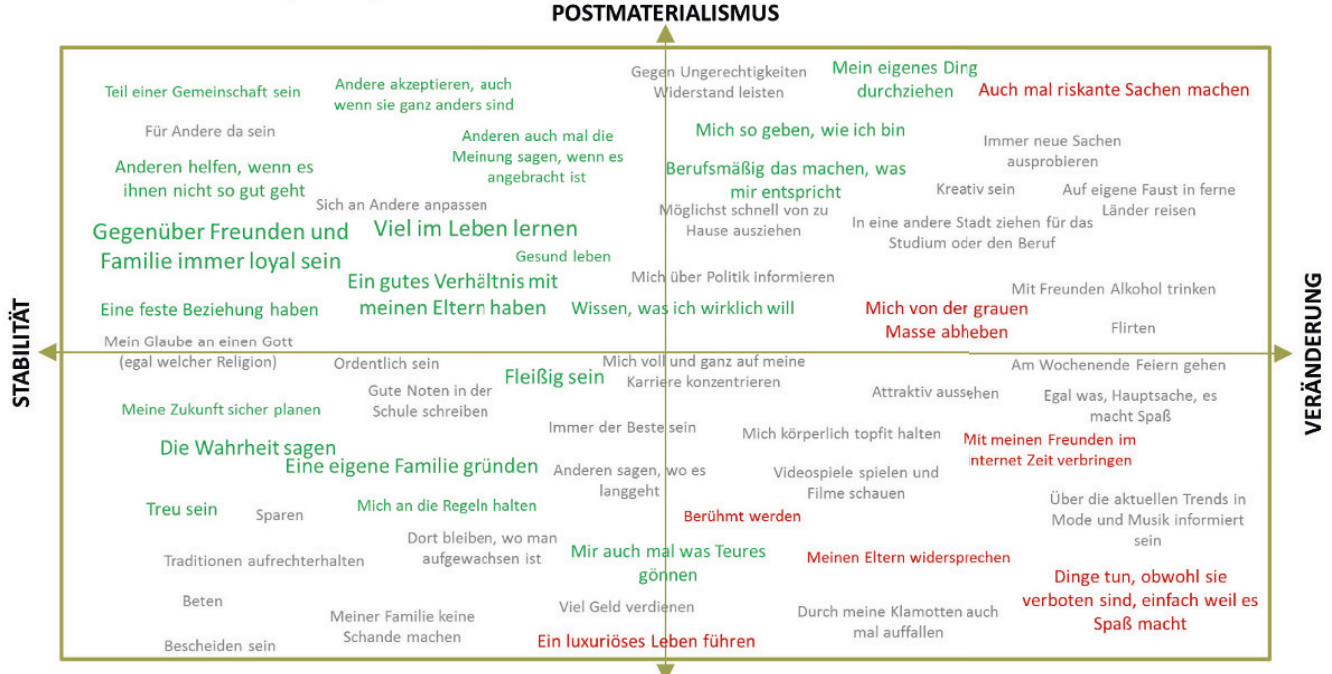

MATERIALISMUS

Eltern oder andere Umstände aktuell nicht zusammenlebt. Zu dieser Familie gehören - insbesondere bei Jugendlichen mit Migrationshintergrund - neben Eltern und Geschwistern auch Großeltern, Tanten und Onkel, Cousins und Cousinen, Nichten und Neffen. Die Familie ist der Ort, wo man Schutz erhält, Unterstützung bekommt und Geborgenheit erfährt. Auch wenn der Abnabelungsprozess von den Eltern beginnt, bleibt Familie ein wichtiger Bezugspunkt, allerdings fordert man von sich selbst dann mehr Selbständigkeit und Eigenverantwortung.

Anpassungs- und Kompromissbereitschaft sowie Realismus bezeichnen sie als ihre Stärken. Ideologien stehen diese Jugendlichen skeptisch gegenüber. Ihre Werte und ihr Lebensstil sind der Maßstab für Normalität. Sie orientieren sich nicht an Utopien, sondern am Machbaren. Sie basteln keine Entwürfe für eine "bessere Welt", sondern versuchen ihren Platz in der Mitte der Gesellschaft zu finden und mit den Gegebenheiten zurecht zu kommen. Sie möchten ein sicheres und geordnetes Leben, nehmen gleichzeitig aber wahr, dass ihnen in Zukunft ein hohes Maß an Flexibilität und Selbstmanagement abverlangt werden wird. Man klagt 
Auszüge aus Hausaufgabenheften: WAS GIBT DEINEM LEBEN SINN?
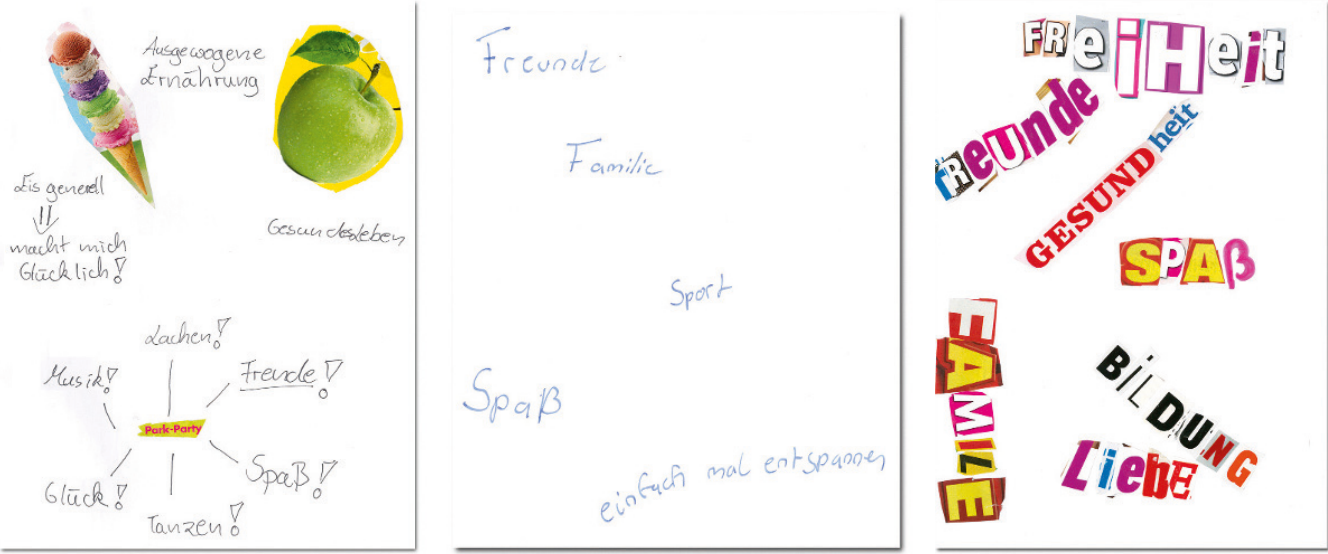

aber nicht, sondern findet sich damit ab. Das gilt auch für den Aufwand, den man in die Schule steckt. Gerade die Jüngeren dieser Gruppe erkennen, dass für sie nun immer mehr der Ernst des Lebens beginnt.

Soweit es möglich ist, orientiert sich das Leben der Adaptiv-pragmatischen Jugendlichen an den gültigen Normen und Regeln. Wer Regeln

Auszüge aus Hausaufgabenheften:

Nenne eine erwachsene Person: A) Deren Lebensgeschichte Du Dir Gerne ERZÄHLen LAsSen WüRdest.

B) VON DER DU GERNE WAS LERNEN WÜRDEST.

Mein Ur, Ur Gropvater den ich nur von einem fots kenne)

Con meiner Tante, weil wir nur 9 jahre altessunterschied haben und sie zurzeit Studiert.

Sie nehme ion ouch als Corbild! a) ich wurde gerne von meinem verstorbenen opa ertahren, wie es damals furr inn war als er alleine nach peutschland kam.

a. Konnd Zuse

b) von meiner untter 
verletzt, bekommt eine gerechte Strafe. Wer seine Aufgabe besonders gut erfüllt, verdient Lob und Anerkennung. Sie bejahen die gesellschaftliche Ordnung und schätzen das deutsche Wirtschafts- und Sozialsystem - insbesondere im Vergleich zu anderen Ländern.

Adaptiv-pragmatische Jugendliche legen Wert auf einen sozial rücksichtsvollen Umgang. Man gibt sich nett und liebenswürdig, eckt möglichst nicht an, schreit nicht oder verhält sich gar hinterhältig. Man versteht sich als solide, aber nicht langweilig. Man ist heimatverbunden, aber flexibel, wenn sich dies aus familiären oder beruflichen Gründen ergeben sollte.

Ihr Auftreten ist selbstbewusst, aber unaufdringlich. Wenn Adaptiv-Pragmatische aus ihren Routinen ausbrechen und "mal was Verrücktes machen", übertreiben sie es nicht, sondern sind auf die brave Art ein bisschen wild. In keinem Fall würden sie etwas Gesetzeswidriges tun.

Adaptiv-pragmatische Jugendliche sehen sich als verantwortungsbewusste Bürgerinnen und Bürger, die künftig pünktlich Steuern zahlen und dem Staat nicht auf der Tasche liegen wollen. Vermittelt über die Tischgespräche zuhause nimmt man auf, dass man immer mehr zwischen Eliten ("Banker", "Bonzen“), die sich auf Kosten anderer bereichern, und "Leistungserschleichern" eingezwängt ist. Es findet eine deutliche Abgrenzung gegenüber "faulen Menschen" statt. Man möchte zu den Menschen gehören, die im Leben viel erreichen, sich Ziele setzen und diese konsequent, fleißig und selbständig verfolgen. Man ist sich sicher, mit Ehrgeiz und Selbstvertrauen sehr viel erreichen zu können. Der Maßstab sind dabei die Etappenziele der bürgerlichen Normalbiografie, d. h. erfolgreicher Einstieg in das Berufsleben, Familiengründung und Aufbau eines Zuhauses.

Der Besitz von Dingen - z. B. ein Auto, ein Haus oder eine schöne Wohnungseinrichtung - hat eine hohe Bedeutung. Geiz wird als unsympathisch empfunden. Ihr Konsuminteresse ist durchaus ausgeprägt, unterliegt aber stark rationalen Entscheidungen. Kleidung soll modisch, aber auch funktional sein. Die Adaptiv-pragmatischen Jugendlichen folgen den aktuellen Trends der großen Modeketten (H\&M, Zalando, Hollister, ZARA). Es ist wichtig "gut angezogen" zu sein. 
Auszüge aus Hausaufgabenheften: WAS GIBT DeInEM LeBEN SinN?
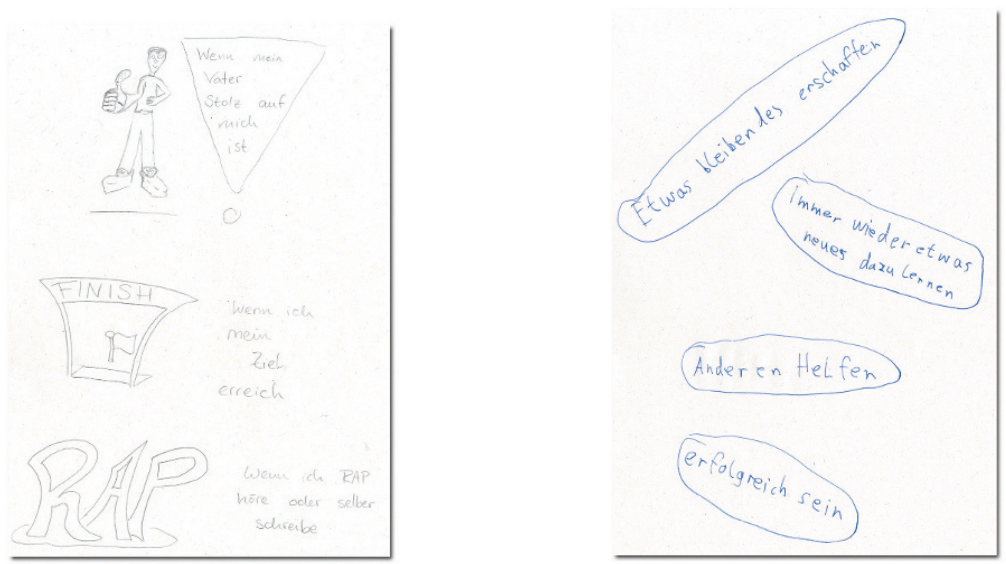

Adaptiv-pragmatische Jugendliche mit Migrationshintergrund zeigen einen deutlichen Integrationswillen. Es gibt eine große Wertschätzung für Deutschland und seine Vorteile im Bildungs- und Sozialsystem, man sieht die persönlichen Chancen zur Zugehörigkeit und Teilhabe. Ebenso werden aber auch die Vorteile und Werte der Herkunftskultur gesehen, z. B. der engere soziale Zusammenhalt, mehr Offenheit unter den Menschen und mehr Lebensfreude. Man erkennt die bi- oder multikulturellen

Auszüge aus Hausaufgabenheften: Wofür INTERESSIERST Du DICH?
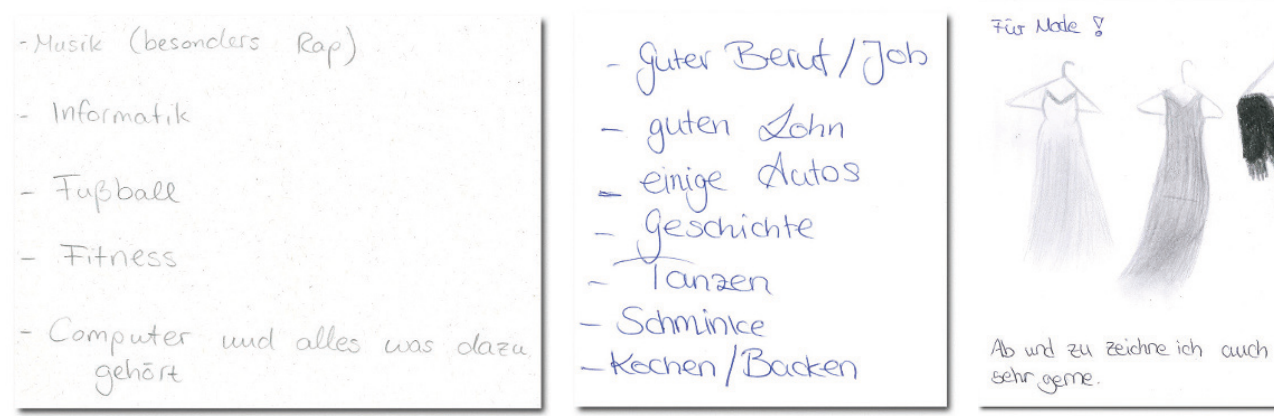

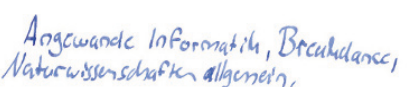


Wurzeln als Ressourcen im Hinblick auf Sprache, interkulturelle Kompetenz und beruflichen Erfolg. Eine doppelte Staatsbürgerschaft würde man begrüßen, weil sie der eigenen Identität am ehesten entspricht.

Typische Zitate zur Illustration
Am wichtigten im Leben: Wissen, was ich wirklich will. Meine Zukunft sicher planen. Mich körperlich topfit halten und Teil einer Gesellschaft sein. (männlich, 14 Jahre)

( I I versuche, mich allen anzupassen. Das gelingt mir hoffentlich. (männlich, 16 Jahre)

( Mein Geschmack ist nicht wirklich außergewöhnlich. Ich höre das, wie alle anderen auch. Ich will mich da jetzt auch nicht irgendwie abheben. Ich will jetzt nicht sagen, ich höre nur das, damit ich etwas anderes höre. Eigentlich wie jeder, ich passe mich an. Nicht komplett, aber ich höre halt das, was jedem in dem Alter eigentlich gefällt. (männlich, 14 Jahre)

( Ich finde, man sollte zuerst etwas erreichen. Und danach kann man sich vergnügen. Aber dann auch nicht extrem vergnügen. (männlich, 16 Jahre)

( Ich will jetzt kein luxuriöses Leben, ich brauch nicht in jedem Land eine Villa usw. Und Privatjet und alle Sachen aus Gold, so was brauch ich überhaupt nicht. Einfach, dass ich das, was ich will, auch haben kann. (männlich, 15 Jahre)

$>\quad$ Ich finde, es läuft relativ gut in Deutschland. Es läuft besser als in Griechenland auf alle Fälle. Die Arbeitslosenquote ist nicht anders als sonst auch. Ich finde, es läuft nicht schlechter als sonst. (weiblich, 17 Jahre)

$>$ Deutschland ist ein relativ wohlhabendes Land im Gegensatz zu anderen, deswegen ist es gut, dass man abgesichert ist, Versicherung und so. Dass alles funktioniert, gutes Gesundheitswesen. (männlich, 14 Jahre)

I Ich würde sagen, dass ist so ziemlich das, was im Moment jedes Mädchen trägt. Es ist keine spezielle Richtung, sondern ich kaufe das, was mir gefällt. Aber das ist meistens auch das, was gerade in den Geschäften ist. Ich muss dafür nicht in Spezialgeschäfte gehen. (weiblich, 14 Jahre) 
( Ich lege Wert auf Klamotten, aber nicht so extrem, aber schon ein bisschen. H\&M, Zara, so die Standardläden. (weiblich, 16 Jahre)

( I Ch habe verschiedene Kleidungsstücke aus verschiedenen Richtungen. Es gibt natürlich Leute, die auf Kleidung achten und die andere Leute über die Kleidung beurteilen. Mir ist Kleidung aber relativ egal. Dass sich die Hip-Hop-Szene mit einer bestimmten Kleidung identifiziert und nur bestimmte Stile bevorzugt, ist mir eigentlich egal. Ich muss es ja nicht tragen. Ich höre nur die Musik gern. (männlich, 16 Jahre)

( Es ist nicht wichtig, aber zum Beispiel ein paar Marken, Hollister oder so, das sind halt coole Marken, die machen halt schöne T-Shirts, finde ich. Aber es ist nicht so, dass du bestimmte Marken tragen musst, das ist total egal. (männlich, 15 Jahre)

( Kleidung an sich ist schon wichtig, weil man sich ja auch wohl fühlen will. Aber ich finde, man muss jetzt nicht die 50-€-Socken tragen oder die 60-€-Unterhose. (männlich, 14 Jahre)

( Wenn man da sieht, wie manche Leute in Deutschland wohnen, oder generell selbst HartzIV-Empfänger, wenn man manchmal guckt, was die sich alles leisten können, dann finde ich das nicht unbedingt berechtigt. (weiblich, 17 Jahre)

( Es gibt schon viele Dinge, die gerecht sind in Deutschland, vom Finanziellen und so und von den Rechten. Es gibt aber auch Dinge, wo man sagt, das geht überhaupt nicht, das muss man unbedingt ändern. Auch mit Hartz IV, dass manche es überhaupt fast gar nicht verdient haben, weil sie nichts aus ihrem Leben machen und dann trotzdem noch Geld bekommen. Und wie die dann leben, und dann bekommen die das und das. (männlich, 14 Jahre)

I Ich versuche, mich mehr in der Schule anzustrengen. Früher war es mir eigentlich ein bisschen egal. Jetzt wird alles ernster. Das merkt man dann auch voll. Bald bin ich mit der Schule fertig. Die Zeit geht ganz schnell vorbei. (weiblich, 14 Jahre) 


\subsubsection{Zukunftsvorstellungen}

Adaptiv-pragmatische Jugendliche haben einen Plan für ihr Leben. Sie wollen eine gesicherte Zukunft, ein wohlgeordnetes Leben mit einem guten Beruf, einer netten Familie und einem schönen Zuhause. Sie streben nach Wohlstand und Status, jedoch nicht nach übertriebenem Luxus. Ausreichend Geld für ein schönes Leben ist das Lebensziel. Wünschenswert ist, sowohl heute als auch in der Zukunft, einen angenehmen Rückzugsort zu haben, an dem man sich von den Herausforderungen des Alltags erholen kann.

Adaptiv-pragmatischen Jugendlichen ist es wichtig, vorausschauende und sinnvolle Entscheidungen zu treffen. Man steckt sich Ziele, die es zu erreichen gilt. Man macht sich "richtig Stress" bei der Planung der nächsten Jahre, möchte unbedingt die richtigen Entscheidungen treffen, nichts dem Zufall überlassen. Das erste Etappenziel nach der Schule ist eine gute Ausbildung in einer möglichst krisensicheren Branche. Gedanklich stehen ihnen dabei viele Optionen offen, letztendlich lassen sie sich weniger von ihrer Fantasie denn von Vernunft und einem Nutzenkalkül

Auszüge aus Hausaufgabenheften:

WiE MÖCHTEST DU SPÄTER LEBEN? WAS MACHST DU DANN?
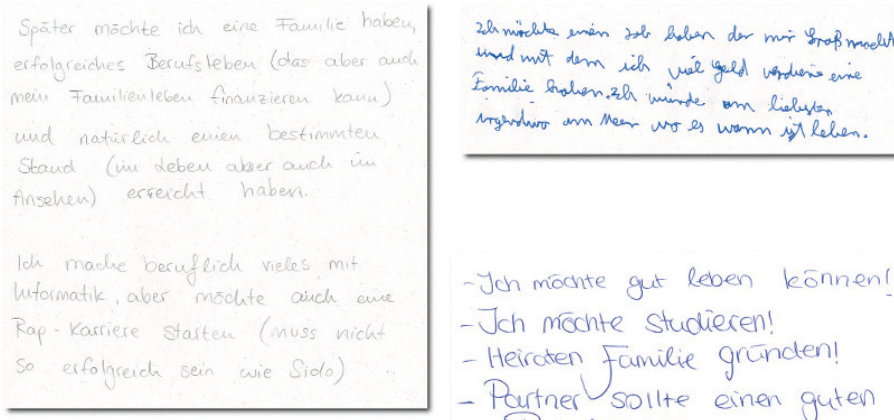

Ich möchte späterin einem eigenem Haus oder einer Wohnung leben, ein Auto haben und genag Geld, unalles zu bezahlen. AuBerdem mochte ich meinen Kindern Dinge ermöglichen, die sie sich wünschen, ohne dabei immer autdas Geld achten zu massen. ich möchte auch mir selbst sachen kau fen können, ohne Monate lang zusparen. AuBerdem möchte ich einen guten job haben, den ich gerne mache, von dem man jedoch auch gut leben kann, da ich nicht guf Hilfe angewiesen sein mochte. zudem hätte ich gerne einen Frend oder Mann und zumindest ein kind. 
leiten. Sicherheit rangiert vor Selbstverwirklichung. Man wird sich flexibel zeigen und den Weg gehen, der die meisten Chancen verspricht, auch wenn dies der bescheidenere Plan B wäre. Man sieht dies jedoch nicht als Einknicken vor sich selbst, sondern als die rational richtige Entscheidung für die "vernünftige Alternative".

Für die Zukunft wünscht man sich in jedem Fall eine romantische Beziehung, ein schönes Zuhause und eigene Kinder. Eine Beziehung und insbesondere Kinder sind jedoch erst dann vorgesehen, wenn mit einem sicheren Arbeitsplatz und einem ausreichenden Einkommen die notwendigen finanziellen Voraussetzungen dafür geschaffen sind. Man weiß, dass die Vereinbarkeit von Familie und Beruf eine große Herausforderung darstellt, denkt diese aber mit Unterstützung der Familie und einer stabilen Partnerschaft meistern zu können. Mädchen wie Jungen möchten später mit Kindern berufstätig sein - v. a. für die Frauen ist eine gelungene Vereinbarkeit ein wichtiger Modernitätsmarker.

Der Entscheidung für den richtigen Beruf, $d$. h. einen Beruf, den man ein Leben lang ausüben kann und ausüben will, wird große Bedeutung beigemessen. Der Beruf soll zwar auch Spaß machen, in erster Linie jedoch mit einem guten Einkommen und einem sicheren Arbeitsplatz verbunden sein. Er soll regelmäßige Arbeitszeiten bieten und im besten Fall nahe zum Wohnort liegen. Außerdem soll der Job familienverträgliche Aufstiegsoptionen bieten.

Jugendliche mit Migrationshintergrund spielen häufiger mit dem Gedanken, nach der Schule eine längere Reise in ihr Herkunftsland oder eine Weltreise zu unternehmen. Auch längere Aufenthalte im Ausland für die Ausbildung, zum Studium oder zum Arbeiten sind für Jugendliche mit Migrationshintergrund eine häufiger genannte Option. Sie wollen ihre verschiedenen kulturellen und sprachlichen Ressourcen optimal nutzen. Damit sind sie deutlich mobiler und internationaler orientiert als die Adaptiv-pragmatischen Jugendlichen ohne Migrationshintergrund. 
Typische Zitate zur Illustration

Wenn alles so läuft, wie ich es mir vorstelle, bin ich mit 22 gerade mit dem Studium fertig. Und ich habe höchstwahrscheinlich einen guten Job. Ich bin von meinen Eltern weggezogen. Vielleicht wohne ich mit meinem Freund in einer WG. Ich führe eigentlich so ein alltägliches Berufsleben. Das wäre im Alter von 22 zu erwarten. Da fängt gerade der Berg an zu steigen im Leben. [...] Ich möchte mit 28 finanziell auf gutem Boden sein. Ich habe also schon das erste Ziel im Leben erreicht dann. (männlich, 16 Jahre)

( Wenn ich mit 19 anfange zu studieren, und ich überlege Medizin, da studiere ich ja alleine 6 Jahre Medizin. Dann bin ich in der Facharztausbildung mit 28. Dann wäre ich gerade fertig mit der Facharztausbildung oder gerade in der Mitte. Mit 28 hört man sich schon so alt an, weil man auf die 30 zugeht. (weiblich, 17 Jahre)

( Ich wohne mit 20 dann wahrscheinlich in einer WG, ich denke aber, noch nicht in einer anderen Stadt, immer noch hier in der Nähe. (männlich, 15 Jahre)

(7) Ich finde, die Beziehung ist nicht das Wichtigste. Man muss keine Beziehung haben, um im Leben etwas zu erreichen. Da gibt es Wichtigeres. Jetzt zum Beispiel, wenn man jung ist, muss man zuerst etwas erreichen, und erst danach kann man eine Beziehung eingehen. Deswegen steht eine Beziehung zur Zeit bei mir noch ganz hinten. Erst wenn man den Grund aufgebaut hat, den Boden, auf dem man stehen kann, erst dann spielt die Beziehung eine wichtige Rolle. (männlich, 16 Jahre)

( Ich muss erst mit der Schule fertig werden. Mich interessiert zur Zeit die Liebe nicht. (weiblich, 14 Jahre)

( Erst mal die Schule fertig, dann Studium und dann einen Job finden. Irgendwann auch Freundin finden und die richtige, und, und, und. (männlich, 15 Jahre)

( Es gibt ja diese Diskussion, ist es besser wenn man früher Mutter wird, ist es besser, wenn man später Mutter wird, dann kann man davor Karriere machen. Ich möchte auf jeden Fall nicht so früh Mutter werden. Ich bin auch nicht die Art von Frau, die sagt, ich möchte unbedingt drei Kinder haben. (weiblich, 17 Jahre) 


\subsubsection{Kulturelle Orientierung, Freizeit}

Adaptiv-pragmatische Jugendliche orientieren sich kulturell am populären Mainstream: Sie hören die Musik, sie sehen die Sender und sie schauen die Filme, die scheinbar "alle gut finden“. Sie verbinden mit Kultur in erster Linie Unterhaltungs-, Erlebnis- und Entspannungsansprüche. Die Teilhabe am popkulturellen Geschehen und der modernen Freizeitkultur ist ihnen wichtig. Eine konzentrierte, intellektuelle Auseinandersetzung mit Kultur ist jedoch die Ausnahme. Weil sie sich nicht vertieft für kulturelle Entwicklungen und Strömungen interessieren, sind für sie starre kulturelle Dichotomien wie "Underground versus Mainstream" oder "Hochkultur versus Popkultur" eher bedeutungslos.

Bei Kino-Filmen (Action, Liebesfilme, Komödien) und Fernsehserien (Vorabendserien, amerikanische Serien, Comic-Serien) folgen Adaptiv-pragmatische Jugendliche dem aktuellen Programmangebot. Am liebsten geht man mit der Clique gemeinsam ins Kino. Multiplex-Kinozentren werden dabei ebenso wenig gegen „kleine Programmkinos“ wie Privatsender gegen öffentlich-rechtliche Sender ausgespielt. Nicht die Location oder der Sender ist entscheidend, sondern das Angebot - es soll vor allem unterhalten und nicht anstrengend sein. Eher unbeliebt sind problemorientierte, sehr brutale oder komplexe Filme ( ${ }_{\text {"I }}$ it offenem

\section{Auszüge aus Hausaufgabenheften: WAS HÖRST DU GERNE FÜR MUSIK?}

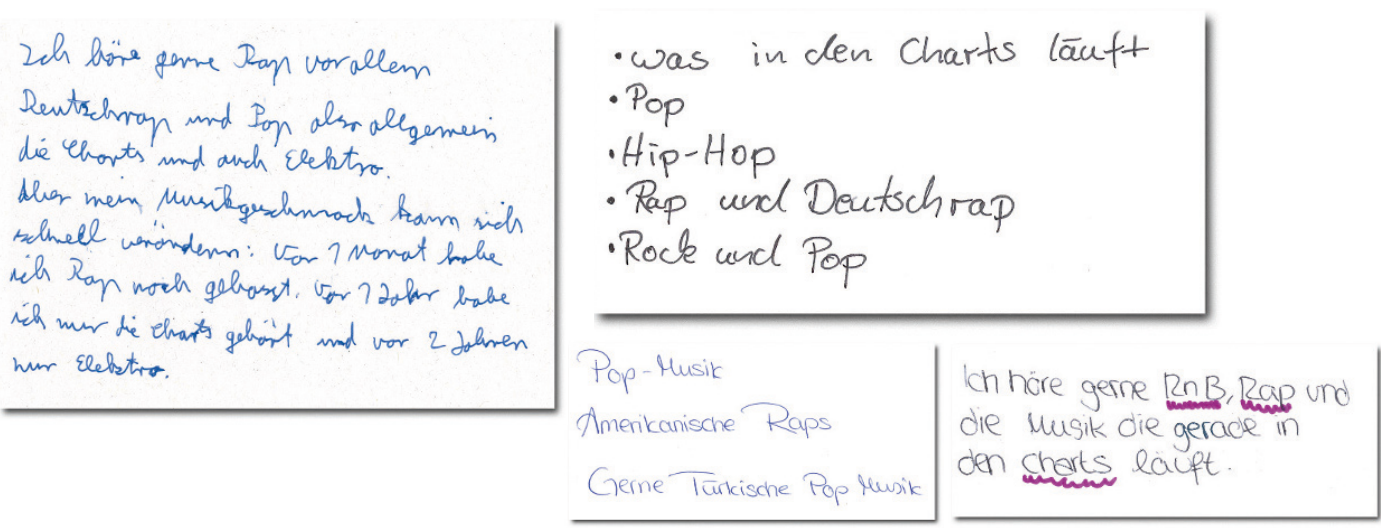


Ende"). Ebenso wird das Theater eher distanziert betrachtet, weil es als „übertrieben" und schwer verständlich wahrgenommen wird. Eine beliebte Ausnahme beim Bühnenprogramm bilden Musicals.

Musik zu "besitzen“ ist für die Adaptiv-pragmatischen Jugendlichen kaum von Relevanz. Vieles wird weder gekauft noch getauscht, sondern über populäre Musikplattformen, z. B. Spotify, Livestream und YouTube konsumiert. Besitz liegt überwiegend in Form von Livestreams vor, die man selbst heruntergeladen oder von Freundinnen und Freunden bekommen hat.

Hin und wieder werden Pop-Konzerte, eine Disko oder Partys besucht, dies hat aber keine besonders hohe Bedeutung und ist begrenzt durch die altersbedingte Immobilität (vor allem auf dem Land), die mangelnden finanziellen Ressourcen und die Regeln der Eltern.

Die Mädchen lesen insgesamt deutlich häufiger, vor allem Romane, Fantasy und andere populäre Bücher (z. B. Twilight, Harry Potter). Jungen lesen nicht so häufig, bei ihnen sind ebenfalls Fantasy-Bücher (Eragon) und Sachbücher beliebt. Bücher sind gut, wenn sie unterhalten oder wenn man "etwas verstehen und lernen kann". Zeitschriften werden sowohl von Mädchen (Mode) als auch von Jungen (Auto) gelegentlich durchgeblättert. Die Zeitung wird in die Hand genommen, wenn man sich - aus eigenem Interesse oder für die Schule - über das Tagesgeschehen informieren will.

Adaptiv-pragmatische Jugendliche haben häufig Hobbies, wobei auch dies bei den Mädchen deutlicher ausgeprägt ist als bei den Jungen: Klavierunterricht, Schlagzeug, Singen, Reiten, Tanzen. Diese Hobbies stehen aber immer nur an zweiter Stelle und werden im Zweifelsfall zugunsten des Schulerfolges aufgegeben. In der Regel finden diese Aktivitäten in einem organisierten (Musikschule, Tanzstunde, Chor) oder privaten (eigener Musiklehrer), aber immer angeleiteten Umfeld statt.

Unter den Hobbies und Freizeitbeschäftigungen spielt Sport eine besonders wichtige Rolle: Fitness, Fußball, Leichtathletik, Mannschaftssport, u.v.m. Die Motive für den Sport sind vielfältig. Den einen geht es um die Gesundheit, den anderen um das gute Aussehen. Oft wird der Sport nur zum Spaß, vereinzelt aber auch als Leistungssport betrieben. Wenn man 
Auszüge aus Hausaufgabenheften: WAS LIEST DU GERNE?

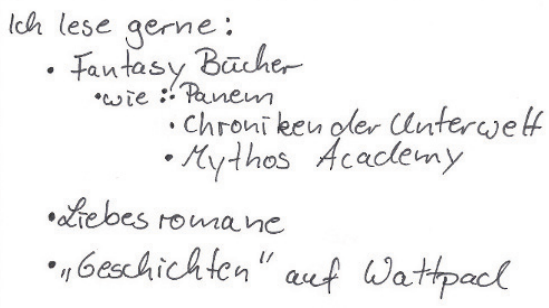

- Liebes romane

"Geschichten" auf Wattpad

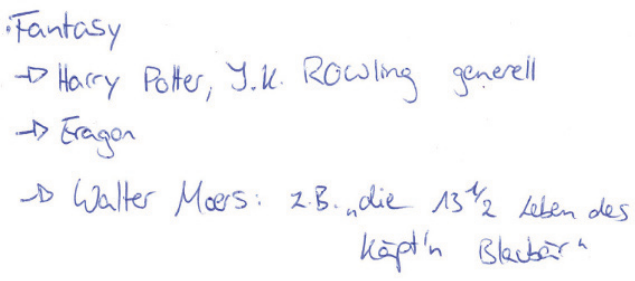

Trendsportarten wie Snowboard oder Surfen betreibt, beobachtet man die dazugehörigen Szenen und Leitfiguren zwar mit Faszination, aber aus der Distanz. Man selber hat zumeist entweder nicht das Können oder keinen Ehrgeiz, zum engeren Zirkel einer Szene dazuzugehören. Zum sportlichen Interesse gehört auch der Besuch von Sportereignissen, z. B. ein Spiel der heimischen Mannschaft im Fußballstadion oder die Fahrt zu einem Eishockey-Match.

Insgesamt haben Adaptiv-pragmatische Jugendliche durch Schule, Familie und Hobbies viele feste Termine im Wochenablauf und einen entsprechend verplanten und vollen Alltag, in dem die Zeit manchmal knapp wird. Zwar werden auch Pausenzeiten in der Schule oder die Zeit mit der Familie als Freizeit gesehen, Freizeit im Sinne von "ungeplanter Zeit" beschränkt sich für die meisten Jugendlichen jedoch auf den späten Nachmittag nach den Hausaufgaben, den Abend und die Wochenenden. Diese wird dann mit Freunden, mit Bummeln und Kaffee trinken, dem Internet, Fernsehen, DVD, Musik hören oder Spielen zugebracht. Wichtig ist, dass etwas Interessantes und Lustiges in der 
Freizeit passiert. Nur Jugendliche in ländlichen Regionen klagen hin und wieder über mangelnde Freizeitmöglichkeiten.

Für Mädchen gehört Mode zu den häufiger genannten Interessenschwerpunkten. Auch für Gesundheit und Fitness interessieren sie sich.

\subsubsection{Vergemeinschaftung}

Der soziale Nahraum mit Familie und Freundinnen und Freunden bildet den Mittelpunkt des Alltags der Adaptiv-pragmatischen Jugendlichen. Innerhalb eines überschaubaren und verlässlichen Umfeldes ist man über Internet und Handy gut eingebunden und vernetzt. Hier sind die Menschen, mit denen man auf einer Wellenlänge ist, die ähnliche Interessen, Ansichten und "die gleichen Träume" haben. Es wichtig, dass die eigene Freundinnen und Freunde freundlich, humorvoll und "gut drauf" sind.

Freundinnen und Freunde hat man vor allem aus der Schule, aus der Nachbarschaft ("Sandkastenfreunde“) und dem Vereinsleben. Eine Handvoll Menschen zählen üblicherweise zum engsten Freundeskreis. Außenherum gibt es eine größere Anzahl von "Bekannten“, die man allerdings deutlich von den Freundinnen und Freunden unterscheidet. Grundsätzlich möchte man mit allen gut auskommen.

Soweit es der voll geplante Alltag zulässt, sieht man die Freundinnen und Freunde fast täglich. Freundschaft hat einen hohen Wert, der sich darin zeigt, dass man füreinander da ist, sich hilft und gegenseitig vertraut. Man trifft sich mit der ganzen Clique, gerne aber auch mal nur zu zweit mit dem besten Freund oder der besten Freundin. Dann chillt man gemeinsam, tauscht Neuigkeiten aus, spielt Brettspiele oder unternimmt etwas miteinander (z. B. Ausflüge, Kinobesuche oder einen Stadtbummel). Auch diese Aktivitäten werden vorab geplant und organisiert, wie die meisten Dinge im Leben der Adaptiv-pragmatischen Jugendlichen.

Adaptiv-pragmatische Jugendliche nehmen wahr, dass es Außenseiter und Mobbing in der Schule gibt, erzählen jedoch, weder selber gemobbt 
zu werden noch am Mobbing beteiligt zu sein. Gemobbt werden ja nur die, "die irgendwie komisch sind. Die verhalten sich anders und sehen anders aus, sind nicht so normal". Adaptiv-pragmatische Jugendliche bezeichnen sich selbst als eher unauffällig, halten sich ausreichend fern von Szenen und sind bemüht, keinen Angriffspunkt für Mobbing zu bieten. Es sind höchstens die Jugendlichen mit Migrationshintergrund, die schon die Erfahrung gemacht haben, „angepöbelt" worden zu sein. Trotzdem formulieren auch sie keine Angst vor Diskriminierung und kein Gefühl der Benachteiligung.

Adaptiv-pragmatische Jugendliche grenzen sich betont von "Asozialen" ab. Sie thematisieren dabei weniger die niedrige soziale Herkunft, sondern unhöfliche oder aggressive Umgangsformen oder geringere Leistungsbereitschaft. Ebenso werden „Angeber", "Besserwisser", „arrogante und zickige Leute" abgelehnt. 
Typische Zitate zur Illustration

(I) In meiner Klasse gibt es einen, der ist so ein richtiger Besserwisser, das mag ich überhaupt nicht. Der tut sich überall einmischen, obwohl er überhaupt keine Ahnung hat. Dann hat er eine andere Meinung. Alle haben gerade einen Film geguckt, alle fanden ihn toll. Dann sagt er, er hat ihn gar nicht gesehen, und dann tut er so: Der Film war richtig schlecht! Irgendwie hat er eine Kritik gelesen. Das nervt mich halt, so Sachen. (männlich, 15 Jahre)

( Also ich hatte ein paar asoziale Freunde. Die waren halt öfters mal Schule schwänzen oder haben nie die Hausaufgaben gemacht. Ich habe jetzt Freunde, die sehr sozial sind. Die sind sehr fleißig, haben immer die Hausaufgaben. Ich glaube nicht, dass die mal Schwänzen waren. Sie sind respektvoll gegenüber älteren Menschen. Die älteren Freunde, die Asozialen, die waren schon ein bisschen anders. Das habe ich auch mit der Zeit gemerkt. Jetzt bin ich mit denen nicht mehr so eng befreundet wie früher. Wir sprechen nur mal so in der Schule. (weiblich, 14 Jahre)

Arrogant, hochnäsig, solche mag ich gar nicht. Die denken, sie wären was Besseres, obwohl das ja gar nicht so ist. Schon wie die laufen eigentlich und wie die reden, die sind so, wie soll ich sagen, anders halt als andere. (weiblich, 16 Jahre) 
Werte-Universum der Prekären

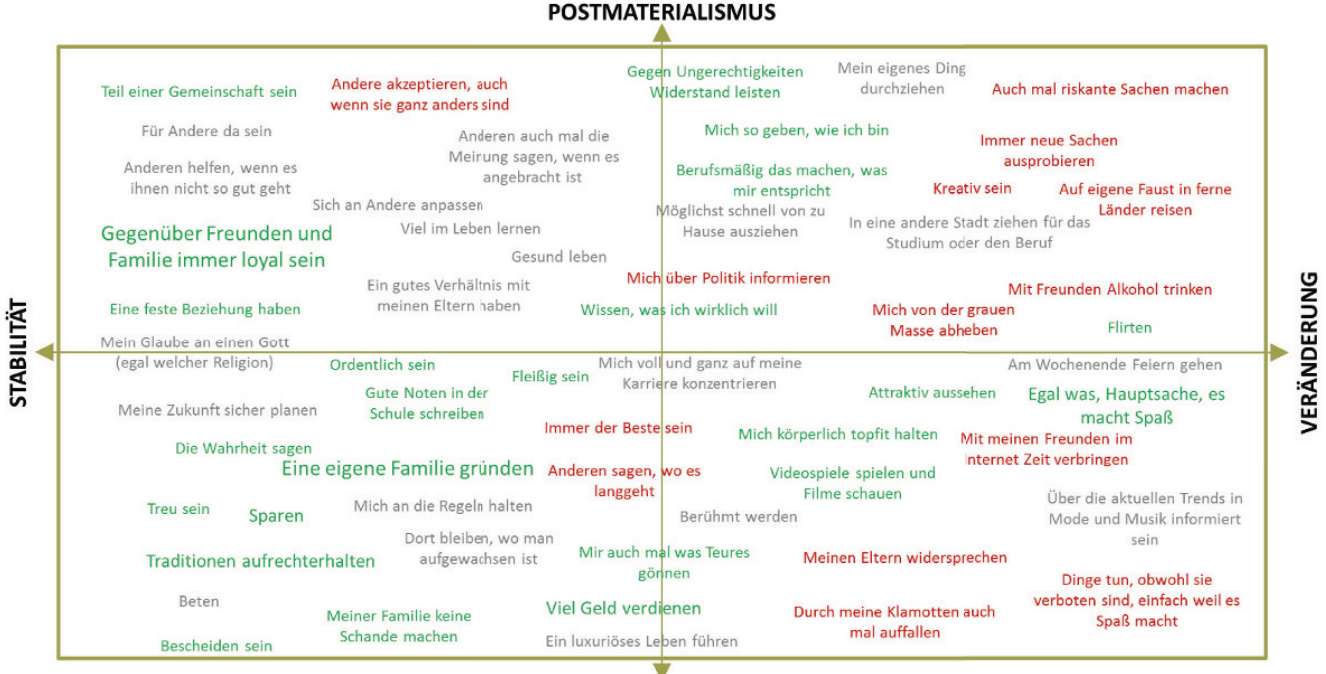

MATERIALISMUS

Während viele Anzeichen dafür sprechen, dass die meisten dieser Jugendlichen sich dauerhaft in der Prekären Lebenswelt bewegen werden, weil sich bei ihnen verschiedene Risikolagen verschränken (bildungsfernes Elternhaus, Erwerbslosigkeit der Eltern, Familieneinkommen an oder unterhalb der Armutsgrenze, schlechte Aussichten einen Schulabschluss zu erreichen, problematische Peergroup), ist bei manchen aber auch vorstellbar, dass es sich nur um eine krisenhafte Durchgangsphase handelt, insbesondere wenn die feste Absicht besteht, „alles zu tun, um hier raus zu kommen".

Viele sind sich ihrer sozialen Benachteiligung bewusst und bemüht, ihre Situation zu verbessern, sich nicht (weiter) zurückzuziehen und entmutigen zu lassen. Aber das Gefühl, dass Chancen strukturell verbaut sind, oder auch dass man sie sich selbst verbaut (z. B. durch Drogenkonsum, Kriminalität, schlechte Schulleistungen), und die daraus resultierende Angst vor geringen Teilhabemöglichkeiten sind in dieser Lebenswelt dominant.

Familie nimmt im Werteprofil der Prekären Jugendlichen eine zentrale Stellung ein. Dass es sich hier um eine idealisierte Vorstellung von Familie 
Auszüge aus Hausaufgabenheften: WAS GIBT DeInEm Leben SinN?

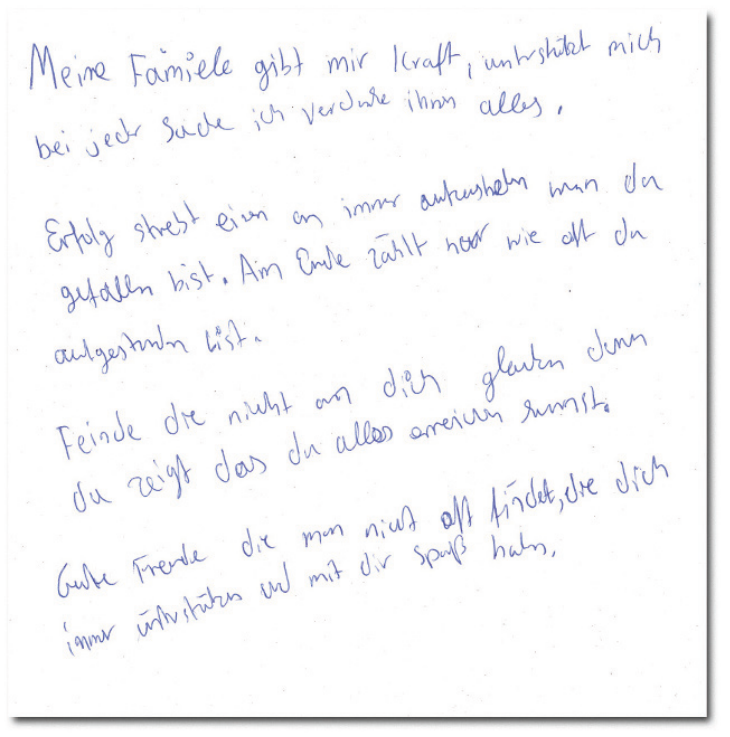

handelt, die oft kaum etwas mit dem zu tun hat, was die Jugendlichen tatsächlich erleben, ist bezeichnend. Eine eigene Familie zu gründen, mit vielleicht "nur zwei" Kindern, "ein Dach über dem Kopf" zu haben und ein harmonisches Familienleben zu führen, bestimmt häufig die Zukunftsträume dieser Jugendlichen.

Man hat den starken Wunsch dazuzugehören und "auch mal etwas richtig gut zu schaffen", nimmt jedoch wahr, dass das nur schwer gelingt. Viele orientieren sich am Geschmack der Peergroup, um nicht weiter aufzufallen.

Gerechtigkeit und Fairness sieht man in der Gesellschaft kaum verwirklicht. Viele sind sehr anfällig für die gängigen rechtspopulistischen Klischees ("Ausländer nehmen die Arbeitsplätze und Frauen weg“, „unter den Ausländern finden sich viele Terroristen" etc.). In der Prekären Lebenswelt (bei den Jugendlichen ohne Migrationshintergrund) sind die Ressentiments gegenüber Ausländern mit Abstand am stärksten ausgeprägt. Auch bei den Jugendlichen mit Migrationshintergrund finden sich Hinweise auf extreme politische Positionen. 
Die subjektive Wahrnehmung geringer Aufstiegsperspektiven resultiert bei einigen in dem Gefühl, dass sich Leistung nicht lohnt. Andere haben eher unrealistische, fast kindlich-naiv anmutende Zukunftsträume und hoffen, später als Fußballstar, Musiker, Gewinner von "DSDS" o. ä. Karriere zu machen. Man sucht sich oft Vorbilder, die aus ähnlich widrigen Verhältnissen stammen und es mit viel Durchsetzungsvermögen "nach oben" geschafft haben („Kämpfen und niemals aufgeben“). Nicht von ungefähr nennen die Jungen häufig Boxer als Vorbilder.

Von allen Lebenswelten berichten die Prekären am häufigsten und recht selbstverständlich von physischen Gewalterfahrungen; als Täter und Opfer. Auch kriminelle Aktivitäten und Auseinandersetzungen mit der Polizei sind bei einigen Alltag.

\section{Auszüge aus Hausaufgabenheften:}

Nenne eine erWachsene Person: A) deren Lebensgeschichte Du Dir gerne ERZÄHLEN LASSEN WÜRDEST. B) VON DER DU GERNE WAS LERNEN WÜRDEST.

Ich wurde mir gerne Ronaldos lebengesutiatte erzachlen lassen.

Weil er hat nie aufgegeben, er hatte immer Seine Liele im Ange
Christiano Ronaldo Das ist mein Traum

a) Wic er daza gekommenist Fubballer zu werden and wie er das geschaft hat

b) Er soll mich unterstuteen und Tipps geben dass ich ein Propiwerde

- Polizist

Jchohabe baldein Praktikum bei der Polizei und ichworde Er Fahrungen sameln um Polizist zu werdon

a) $2 P A C$

a) a) Mnammed Al:

b) Mike Tyson

hichael Jackson 
Auszüge aus Hausaufgabenheften: WAS GIBT Deinem LebEn SinN?
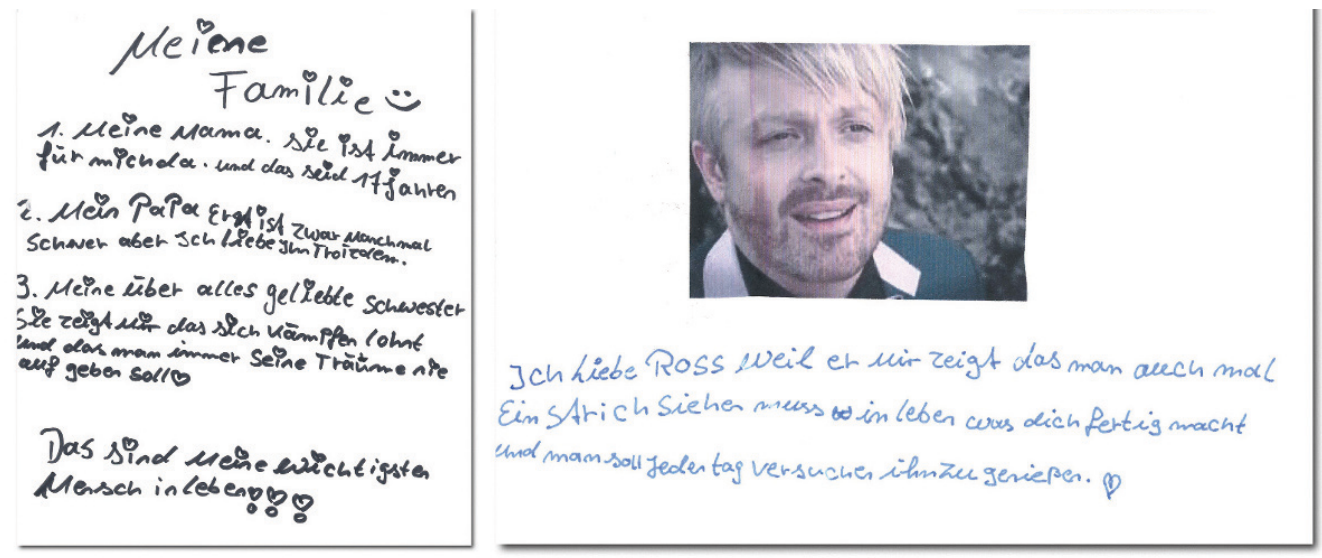

( Ich kümmere mich nicht so viel um die Gesellschaft, denn die kümmert sich ja auch nicht so um mich. Das Interessante sind ja die Freunde und die Familie. (männlich, 16 Jahre)

Typische

Zitate zur

Illustration

(1) Ja, ich hatte davor schon Stress mit meinem Vater. Mein Vater ist Alkoholiker. Er geht jetzt nämlich auch in eine Kur. Zum Glück. (...) Viel Kontakt habe ich eigentlich nicht mehr. (...) Ich ruf Mama und Papa an und sie gehen nicht ran. Warum ist mir auch egal. Ja, weil meine Eltern gesagt haben, ich bin eine Schlampe, also sozusagen haben sie das gesagt, weil ich am Bahnhof so einen Ruf habe, dass ich eine Schlampe bin, obwohl das gar nicht stimmt. (weiblich, 14 Jahre)

(1) ICh muss sagen, ich habe mal Marihuana genommen, aber nicht lange. Ich habe es mal ausprobiert. (...) Aber was Scheiße ist, ich habe es mal mit meinem Vater gemacht. Mein Vater hat es mir erlaubt, weil mein Vater selber davor schon bekifft und angetrunken war, dann hat er mir einfach nur seine in die Hand gedrückt und gesagt, zieh. Und das war auch so ein starkes Zeug. (weiblich, 14 Jahre)

(1) Über Zukunft habe ich mir eigentlich noch gar keinen Kopf gemacht. Ich will erst einmal meine Jugendzeit genießen, sozusagen so viel Scheiße wie möglich machen. Jetzt bin ich noch nicht strafmündig, das heißt 
ich bin schon strafmündig, aber ich kann nicht in den Knast kommen. (weiblich, 14 Jahre)

( Meine Schwächen und Fehler? Dass ich so zuhaue. (...) Ja, erst mal reden und dann, wenn es eskaliert, dann zuhauen. (...) Ich weiß nicht, wenn einer meine Mutter beleidigt, dann weiß ich nicht mehr, was ich mache und dann schlage ich die einfach. (männlich, 15 Jahre)

$>$ Mein Lebensmotto ist: Egal wie oft man hinfällt, es kommt immer darauf an, wie oft man aufsteht. (männlich, 16 Jahre)

[INT: Also WAS WÜRDEST DU SO SAGEN, WAS IST DIR DAS WICHTIGSTE IM LEBEN] Religion, beten, Geld verdienen, Familien gründen, Arbeit, so halt. (männlich, 15 Jahre)

( Ich schwöre, die Polizisten übertreiben immer voll. Leute machen eine Anzeige und die Polizisten übertreiben direkt voll mit, keine Ahnung, mit Sozialstunden, alles übertreiben die, voll unnötig. [...] Gegen mich läuft ein Strafverfahren. Ich habe ein Mädchen, sie ist größer als ich und breiter als ich, und ich habe ihr eine Ohrfeige gegeben und keine Ahnung, sie ist auf den Boden gefallen. Und dann hat meine Freundin gegen die noch getreten, wo die auf dem Boden lag. Und deswegen habe ich jetzt eine Anzeige bekommen. Zum Gerichtstermin bin nicht hingegangen. Pech gehabt, ich habe einen neuen bekommen. (weiblich, 14 Jahre)

Ich bin mit Ross Antony ein bisschen privat befreundet, und wenn ich die dann so angucke, obwohl die schwul sind, was die alles meistern, das gibt uns auch nochmal Kraft, die große Kraft. Meine Schwester, die ist auch ein Vorbild für mich, gerade, was das angeht zu kämpfen und nicht aufzugeben. (weiblich, 17 Jahre)

(Die Ausländer können hier machen, was sie wollen. Und das geht eigentlich nicht. Wir sind in Deutschland. Ich mag es zum Beispiel nicht, wenn ich jetzt in der Bahn sitze mit so Kopftuchträgern. Da würde ich am liebsten die Bahn wechseln. (männlich, 15 Jahre) 


\subsubsection{Zukunftsvorstellungen}

Die Wahrnehmung von Armut(sgefährdung) in der Familie und die oft mit den Eltern geteilten Erfahrungen eigener Überflüssigkeit und Nutzlosigkeit behindern die Entwicklung von Selbstvertrauen, Selbstwirksamkeit und Stärke - wodurch der weitere Lebensweg negativ beeinflusst wird. Andererseits wird gerade von den Prekären Jugendlichen - quasi in einer kompensatorischen Reflexion auf die eigene Schwäche - betont, dass man selbst für die eigene Zukunft verantwortlich sei und „sich durchboxen" müsse.

Wenn sich Jugendliche aus anderen Lebenswelten die Frage stellen „Was wird aus mir?", so haben sie zumindest eine vage Vorstellung davon, welche beruflichen Optionen die wahrscheinlich erzielten Schulabschlüsse ermöglichen. Den Prekären Jugendlichen fehlt in der Regel dieses Orientierungswissen. So zeigen sie sich teils sehr pessimistisch hinsichtlich ihrer Ausbildungsperspektiven, teils jedoch auch unrealistisch optimistisch und aufstiegsorientiert. Die Traumberufe verweisen auf ein klares Dilemma zwischen Wunsch und Wirklichkeit: Ingenieur, Fußballprofi, Arzt, Anwalt oder Star würde man gerne werden. Wie eine Ausbildung zu einem solchen Beruf verläuft, welche Voraussetzungen dafür notwendig sind, oder wie genau das Berufsbild aussieht, wissen aber nur die wenigsten. Erkannt haben diese Jugendlichen jedoch, dass solche Berufe zum einen ausreichend Geld und zum anderen Prestige bedeuten. Sollte es mit dem Traumberuf nichts werden, dann will man "wenigstens nicht auf HartzVI sein". Den Jugendlichen dieser Lebenswelt mit einer realistischeren Einschätzung ihrer Situation ist bewusst, dass sie aufgrund schulischer Defizite Probleme beim Übergang in das Berufsleben erwartet. Man versucht diese durch Fleiß, Verlässlichkeit und Motivation auszugleichen.

Wenige der Prekären Jugendlichen nehmen Angebote zur beruflichen Orientierung wahr: Man weiß nicht wo, auch nicht so recht warum, und vor allem möchte man nicht selbst um Hilfe bitten. Dagegen bieten massenmediale Repräsentationen von Berufen (Fußballstar, Anwalt, Polizist, Arzt etc.) scheinbar Orientierung. Vor allem die Jungen zeigen sich sehr empfänglich für die medial präsentierten männlichen Vorbilder. 
Wie die meisten Jugendlichen in ihrem Alter wissen die Prekären, dass sozialer Aufstieg eng an Bildungserfolge gekoppelt ist, dass man also ohne Schulabschluss und Ausbildung kaum eine Chance hat. Gleichzeitig bekommen sie von älteren Freunden gespiegelt, dass selbst mit einem Schulabschluss der Ausbildungsplatz nicht sicher und sogar mit einer abgeschlossenen Ausbildung eine Festanstellung nicht garantiert ist. Das verunsichert massiv und führt bei manchen zu der resignativen Frage: Warum denn dann eigentlich?

Dass man selbst eine Familie gründen will, steht außer Frage. Man wünscht sich (nicht zu viele) Kinder und hofft, für diese gut sorgen und ihnen auch einmal etwas Besseres bieten zu können. Letztlich ist die Familiengründung auch ein Feld, in dem die Aussichten auf Erfolg vielversprechender sind als beispielweise in der Erwerbswelt. Die Chance, hier auch einmal weiter zu sein als andere, bestimmte Etappen früher zu erreichen, ist reizvoll.

Auszüge aus Hausaufgabenheften:

WIE MÖCHTEST DU SPÄTER LEBEN? WAS MACHST DU DANN?

Ich mochte wie jador Mensh etwos erreiven also will ich spater wohl hasume sain

ICh weils nook nicht was ich vor habe aber ich will ontiedon foll nicut mit Fupbull anthón

ich wiel eigendlich min eigenes gescheftauf machen alsersanst mach icn michals Mahler.

- Erfolgreich, Fran Fran, Kinder

$$
\begin{aligned}
& \text { Wit meinen Jetztigen Freume } \\
& \text { eine Familie grinden. } \\
& \text { Das Juhmeines Berof's unsures } \\
& \text { lemer durf }
\end{aligned}
$$

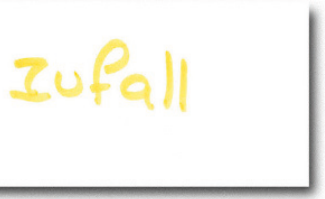


( Im Leben ist mir wichtig, dass ich meine Schule fertig mache, also auf jeden Fall die Mittlere Reife habe. Dann eine Ausbildung anfange. Dass es meiner Familie gut geht, dass ich eine Frau habe und Kinder und dass ich mit Freunden auch gut bin. (männlich, 16 Jahre)

Bei mir ist noch alles offen, was ich werden will und so. Aber im Moment läuft es in der Schule auch nicht so gut. Ich muss jetzt ein bisschen mehr Gas geben. Und das meint auch mein Lehrer. Aber er hat gesagt, wenn ich dazu bereit bin, unterstützt er mich, und dann schaffen wir das auch. Und wenn das klappt, hole ich vielleicht noch meinen Realschulabschluss nach. (männlich, 16 Jahre)

( Also, wenn es klappt, dann bin ich mit 25 Fußballprofi. (männlich, 16 Jahre)

Ja, Arbeit so, Polizist oder so. [INT: UND UM DIE SCHULE, MACHST DU DIR DA SORGEN, OB DAS KLAPPT?] Ja. Weil ich schlecht in der Schule bin, so Faxen mache. Ich muss mich bessern. (männlich, 15 Jahre)

( Mit 25? Da feiere ich mein Leben richtig durch, weil nach 25 bin ich dann nicht mehr so wirklich jung. Weil, dann werde ich jetzt langsam älter. Ja, da genieße ich halt meine Zeit so stark wie es geht. Und versuche auch ein bisschen hoch zu kommen mit der Arbeit und so, oder irgendwie was Besseres hinkriegen oder mal eine eigene Firma, das wäre eigentlich so am besten. Vielleicht so Baustelle oder so. Ich weiß nicht, also eigentlich erst mal eine Ausbildung als Maler. (männlich, 15 Jahre)

Zuverlässlichkeit, das habe ich jetzt drauf, sage ich jetzt mal. Und dass ich halt meine Arbeit halt immer gut mache und sorgfältig bin. (...) Ich wollte immer mal so Chef von irgendwas Großem sein. Ich überlege ja jetzt die ganze Zeit, ob ich zur Bundeswehr gehen soll, da mein Ding mache. (männlich, 15 Jahre) 


\subsubsection{Kulturelle Orientierung, Freizeit}

Prekäre Jugendliche sind popkulturell interessiert, vor allem Hip Hop steht hoch in der Gunst. Vielen bieten die Texte von Rap Songs zahlreiche Identifikationspunkte. Das Interesse regt jedoch selten zur aktiven Suche nach Neuem an, man begnügt sich mit dem, was man kennt oder über den Freundeskreis mitbekommt. Eine tiefere Auseinandersetzung mit Musik (Musik sammeln, Konzertbesuche, selbst musizieren) ist eher untypisch. Beliebte Künstler sind z. B. Haftbefehl, Bushido, Fard, Farid Bang, Rihanna, Massiv, Sido, K.I.Z..

Hat es Berührungspunkte mit Theater, Oper oder klassischer Musik gegeben, sind diese in schlechter Erinnerung geblieben. Die klassische Hochkultur wirkt befremdlich, langweilig und überfordert sprachlich bzw. intellektuell. Die Jugendlichen dieser Lebenswelt sind es kaum gewohnt, einer Darbietung über einen längeren Zeitraum ihre ungeteilte Aufmerksamkeit zu schenken.

Die Angebote des Privatfernsehens sind der Hauptbezugspunkt zum „kulturellen Überbau“. Scripted Reality oder Pseudo-Doku-Soaps sind beliebt, weil sich hier die Möglichkeit bietet, die eigene soziale Lage zu relativieren und Familienbeispiele zu sehen, bei denen es entweder

Auszüge aus Hausaufgabenheften: WAS HÖRST DU GERNE FÜR MUSIK?

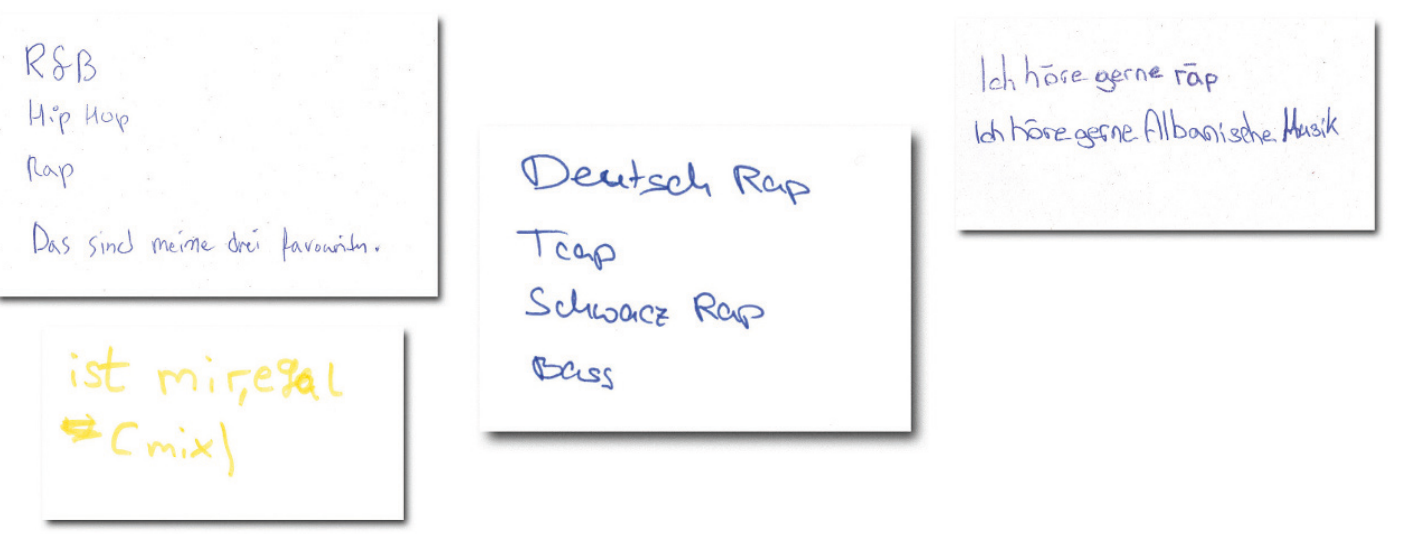


"noch viel schlimmer zugeht", oder die ganz ähnliche Probleme im Alltag haben. Castingshows und Daily-Soaps findet man unterhaltsam, weil „es immer was Neues ist", aber in einem gewohnten Setting präsentiert wird, das für viele eine Struktur bietet, die im Familienalltag fehlt.

Lesen ist laut Aussage dieser Jugendlichen prinzipiell "nicht so ihr Ding". Nicht selten fällt jedoch auf, dass diejenigen, denen nicht das Lesen an sich Schwierigkeiten bereitet, Leseangebote begeistert angenommen und in guter Erinnerung behalten haben. Die mangelnde Verfügbarkeit von Büchern im heimischen Umfeld spielt daher eine nicht unwesentliche Rolle für die Selbstattribution von "Lesefaulheit" in dieser Lebenswelt.

Das Freizeitverhalten der Prekären Jugendlichen oszilliert zwischen Rückzug und Delinquenz. Da sind jene, die „zur Schule, nach Hause, dann schlafen" gehen und jene, die "eigentlich direkt raus, oder halt direkt nach der Schule raus" gehen. Von letzteren werden nicht selten auch Erfahrungen mit Drogen(-handel), gewalttätigen Auseinandersetzungen und kleinkriminellen Delikten berichtet. Die Freizeitgestaltung bewegt sich bisweilen am Rande der Legalität oder bereits darüber hinaus.

Diejenigen, die sich eher zurückziehen, haben oftmals bereits seit Jahren massive Mobbingerfahrungen in der Schule und im "Freundeskreis"

Auszüge aus Hausaufgabenheften: WoFÜR INTERESSIERST DU DICH ÜBERHAUPT NICHT?

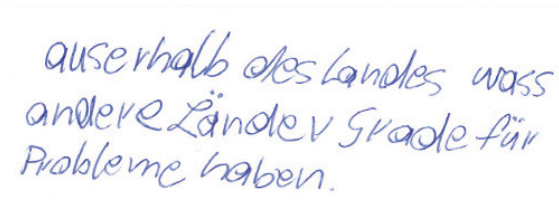

Ichlese rich

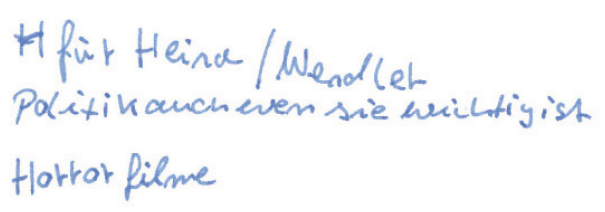


Auszüge aus Hausaufgabenheften: WofüR INTERESSIERST Du DICH?
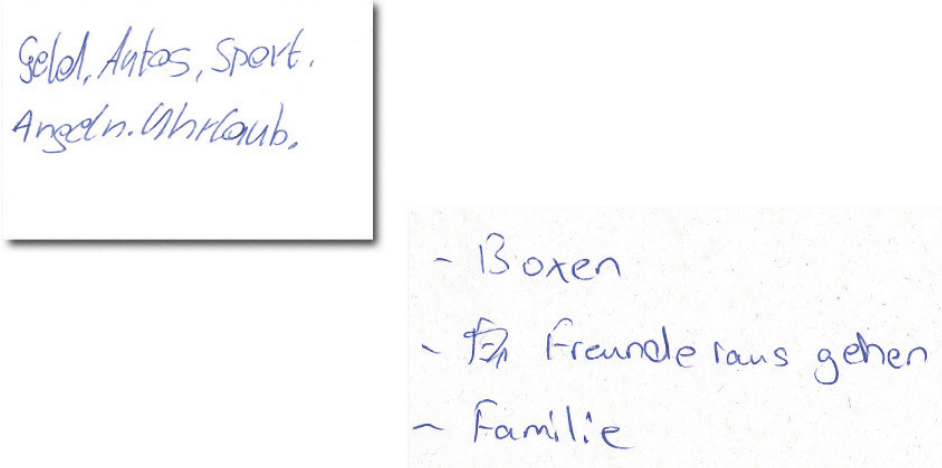

Fußbale

Famicle

Mivis

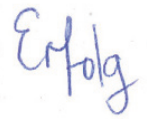

erlebt. Sie haben zu wenig Selbstvertrauen, um sich „draußen“ behaupten zu wollen, oder spüren einfach, dass sie "nicht so richtig dazu gehören". Neben der Wohnung wird von diesen Jugendlichen häufig auch die Natur als intakter, harmonischer und sicherer Rückzugsort beschrieben.

Im Vergleich der Lebenswelten sind Computer- und Konsolenspiele bei Prekären Jugendlichen am beliebtesten - auch bei den Mädchen. Hier findet man eine Beschäftigung, der man auch alleine nachgehen kann. Und ähnlich wie beim Fernsehkonsum gibt die Wiederholung bzw. Wiederholbarkeit Sicherheit. Man bewegt sich auf weitgehend bekanntem Terrain, wird dabei unterhalten, muss sich nicht auf vollkommen neue Strukturen oder Unwägbarkeiten einlassen. Die virtuellen (Spiele-)Welten bieten die Möglichkeit, sich unabhängig von den sozialen und familiären Rahmenbedingungen zu präsentieren und zu bewähren, was zu sonst eher seltenen Erfolgserlebnissen führen kann. Voller Stolz erwähnen einige auch, dass sie besonders gute Gamer sind. „Zocken“ ist für diese Jugendlichen eine Quelle für Bestätigung und Selbstbewusstsein. Auffällig ist der explizite Hinweis darauf, dass gewalthaltige Spiele eine gute Möglichkeit zum Frustabbau bieten.

Auch Sport ist ein Gebiet, in dem sie die Anerkennung suchen, die ihnen in anderen Lebensfeldern oft verwehrt bleibt. Bei den männlichen Jugendlichen steht eindeutig Fußball und Kampfsport an erster Stelle, 
sowohl als aktiver Spieler als auch als Fan und Zuschauer eines bestimmten Vereins. Von Mädchen wird gelegentlich Tanzen oder Fitness-Training genannt.

Jugendliche aus der Prekären Lebenswelt nutzen nicht selten Angebote der offenen und mobilen Jugendarbeit oder werden in ihrer Freizeit durch Jugendsozialarbeit begleitet. Diese Angebote werden in der Regel dankbar angenommen, weil sie Freizeitmöglichkeiten eröffnen, die alleine nicht zu realisieren wären.

In der freien Zeit nach der Schule und den Hausaufgaben sieht man keinen Raum mehr für weitere Bildungsanstrengungen. Den Unterricht bereitet man nur vor oder nach, wenn es absolut notwendig ist, um die Versetzung nicht zu gefährden. Ansonsten hat man weder Lust dazu, noch sieht man ein, warum man sich in der Freizeit "bilden" sollte, da dies nicht direkt erkennbar belohnt wird und man so bloß seine Zeit "verschwendet".

( Ich spiele beim Fußball - egal ob ich mich verletzt habe - trotzdem weiter. Ich kämpfe beim Fußball nur. (weiblich, 14 Jahre)

Und überhaupt müsste ich in der B-Jugend spielen von meinem Alter her. Aber ich spiele in der A-Jugend wegen meinem Freund. Da sind halt auch 17- und 18-Jährige dabei. Aber ich versuche da mitzuhalten. Und das ist ja auch eine Herausforderung. (männlich, 16 Jahre).

( Ich mache auch Turniere, Wettkämpfe und alles. Thaiboxen. Also mit Vollkontakt. Macht auch Spaß. Das mache ich schon seit fünf Jahren, und bin da jetzt einer der Ältesten in dem Boxverein, einer der Besten. (männlich, 15 Jahre)

( Klassische Musik, das finde ich abscheulich. Das ist nichts für mich. (männlich, 15 Jahre)

(7) Musik? So Rap eher, Rap und ja, nur das. Bushido. Weil Andere gegen ihn rappen und er ist besser als die. (männlich, 15 Jahre)

(1) So Sido oder sowas gefällt mir. [INT: UND WAS GEFÄLLT DIR DARAN?] Die Texte, allgemein so. (männlich, 15 Jahre) 
(7) Aber ich habe auch öfters was mit der Polizei zu tun. Ich bin in Klamottenläden rein und habe da Sachen geklaut. (...) Eigentlich wurde ich bisher nie erwischt. Und es ist richtig oft passiert, muss ich sagen. (...) Klamotten, Kaugummis, ich habe selbst für meine Freundin schon mal Wodka geholt. Das war auf jeden Fall sehr schwer, muss ich sagen. Der ganze Laden war voll. Das war echt schwer, aber ich habe es geschafft. Ich mache es manchmal noch, wenn ich Sachen brauche, aber nur manchmal. Irgendwie, weil manche Sachen sind sehr einfach, aber manche Sachen, die sind ein bisschen größer und schwerer. Selbst beim Media Markt habe ich schon mal Kopfhörer hingekriegt zu klauen, aber das war übelst schwer, weil über uns war eine Kamera und wir haben sie nicht gesehen. (weiblich, 14 Jahre)

( PlayStation zocke ich gerne, weil da Ballerspiele drauf sind. (...) Da kann ich meine Wut rauslassen. (...) Und es macht einfach Spaß, zum Beispiel "Call of Duty", das zocke ich am meisten. (weiblich, 14 Jahre)

[INT: UND GIBT ES SO EIN THEMA, WO DU DICH BESONDERS GUT AUSKENNST, WAS ANDERE VIELLEICHT NICHT KÖNNEN, WO DU SAGST, DU BIST eIn EXPerte WIE, KeIne Ahnung, Mathematik?] Ja, also bei der PlayStation. Also nicht der Beste jetzt, aber einer von den Besten. [INT: BEI eINEM Bestimmten Spiel?] Dieses Waffenspiel, AW. [INT: IST DAS AB 18 ODER DARF MAN DAS AUCH SCHON...?] Ab 18. [INT: UND WAS IST SO COOL AN DEM SPIEL?] Man kann da mit Freunden reden, man kann gucken, wer besser ist, wer schneller ist. (männlich, 15 Jahre)

\subsubsection{Vergemeinschaftung}

Prekäre Jugendliche machen häufig Ausgrenzungserfahrungen, sei es in der Schule, in der Öffentlichkeit oder auch innerfamiliär. Weil Integration im Rahmen der klassischen Institutionen für diese Jugendliche oft kaum möglich ist, ist die Anerkennung in der Peergroup zentral. Während viele berichten, dass ihre Freunde "wie Familie" seien, gibt es aber mindestens ebenso viele, die als völlige Außenseiter im sozialen Rückzug bleiben. Freunde findet man oft in den Soaps und Serien der Privatsender - auf die ist Verlass, die "kommen“ täglich. 
Auseinandersetzungen mit Freunden bzw. im Freundeskreis haben bei vielen einen bleibenden Eindruck hinterlassen. Man hat das Gefühl, hier "echt schlechte Erfahrungen" gemacht zu haben. Trotzdem wird die Bedeutung von Freunden mit idealisierendem Gestus immer wieder betont.

Bestimmte Jugendszenen üben eine Faszination auf Prekäre Jugendliche aus (vor allem Hip Hop). Man fühlt sich den (medial präsenten) Protagonisten und Protagonistinnen verbunden, bei denen man oft biografische Parallelen erkennt. Die Teilhabemöglichkeiten an solchen Jugendszenen (Kleidung, Technik, Platten auflegen, Texte schreiben und selber Rappen) sind jedoch eher gering.

Vergemeinschaftung findet bei Prekären zu einem großen Teil im öffentlichen Raum statt, v. a. Jugendhäuser sind beliebt. Aufgrund der elterlichen Herkunftsmilieus wachsen diese Jugendlichen häufig in schwierigen Wohnumfeldern auf, im Zentrum sogenannter sozialer Brennpunkte. Sich auf der Straße zu behaupten, kostet nicht selten einiges an Mut und Durchsetzungsvermögen. Auch deshalb ist "die Gruppe" so wichtig: Allein kann man nicht viel ausrichten, in der Gruppe fühlt man sich sicher. Vor allem die männlichen Vertreter dieser Lebenswelt haben vergleichsweise häufig bereits Gewalterfahrungen gemacht - als Opfer wie als Täter. 
Typische Zitate zur Illustration
( Ja, ich bin auch nett und so. Also, wer nett zu mir ist, dann bin ich auch nett zu ihm. Und wer aggressiv zu mir ist, dann bin ich auch zu ihm aggressiv. So! (männlich, 15 Jahre)

( Jeden Tag gehe ich ins Jugendhaus. Ich komme hier hin, weil ich habe keine Lust, nach Hause zu gehen. Ich mag das hier. Hier hat man halt keine Langeweile. Hier weiß man, was man machen kann, und hier hat man auch Freunde, die man auch kennt noch aus der Schule. (männlich, 14 Jahre)

(7) Wir sind dann meistens immer hier in der Stadt und laufen die ganze Zeit herum in N. und gucken uns die Gegend an. Manchmal bauen wir auch Scheiße, ich mit meinen anderen Gruppenkameraden. In der Stadt sind wir auch öfters, und meistens haben wir ein bisschen randaliert. (weiblich, 14 Jahre)

(Dann gibt es noch "Hilf mir", ist auch eine Serie bei RTL2 "Jung, verzweifelt und pleite", da erklären die das so. Da klauen auch welche Geld, und dann erklären die das halt, wie viel Strafe, was da auf dich zukommt, was es da gibt. Das finde ich halt auch sehr interessant. (weiblich, 17 Jahre) 


\subsection{Materialistische Hedonisten}

Die freizeit- und familienorientierte Unterschicht mit ausgeprägten markenbewussten Konsumwünschen.

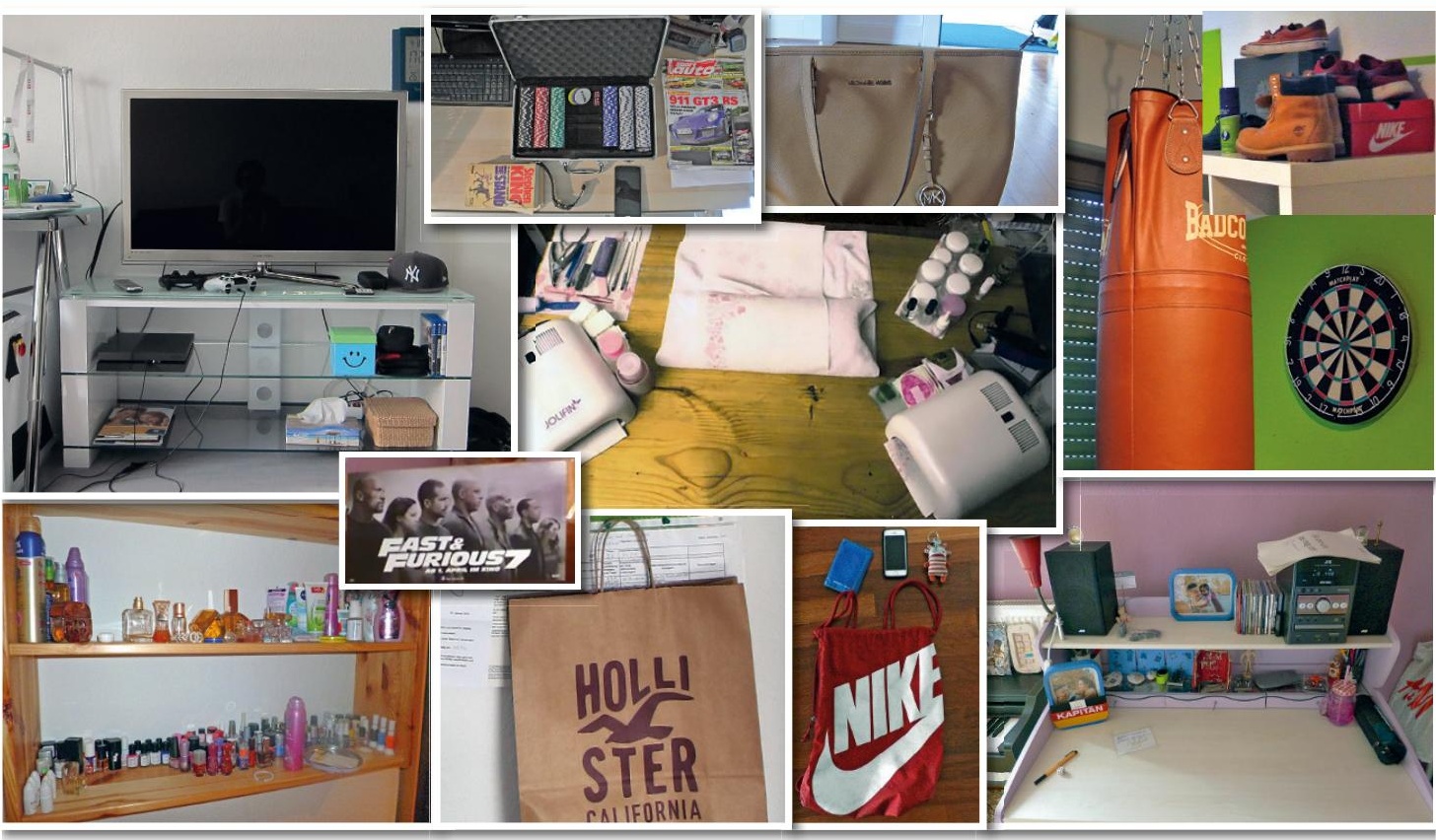

3.4.1 Lebensweltliche Basisorientierungen

Unter den Materialistischen Hedonisten legen die Jungen wie Mädchen großen Wert auf die Repräsentation von (angestrebtem) Status: Konsum kommt klar vor Sparsamkeit. Bescheidenheit liegt innen fern. Der Umgang mit Geld ist überwiegend unkontrolliert. Kurzfristige Konsumziele haben einen hohen Stellenwert - neue, moderne Kleidung und Schuhe sowie Modeschmuck sind ihnen äußerst wichtig. Mit Äußerlichkeiten Eindruck zu hinterlassen, bezeichnen sie als eigene Stärke. 
Werte-Universum der Materialistischen Hedonisten

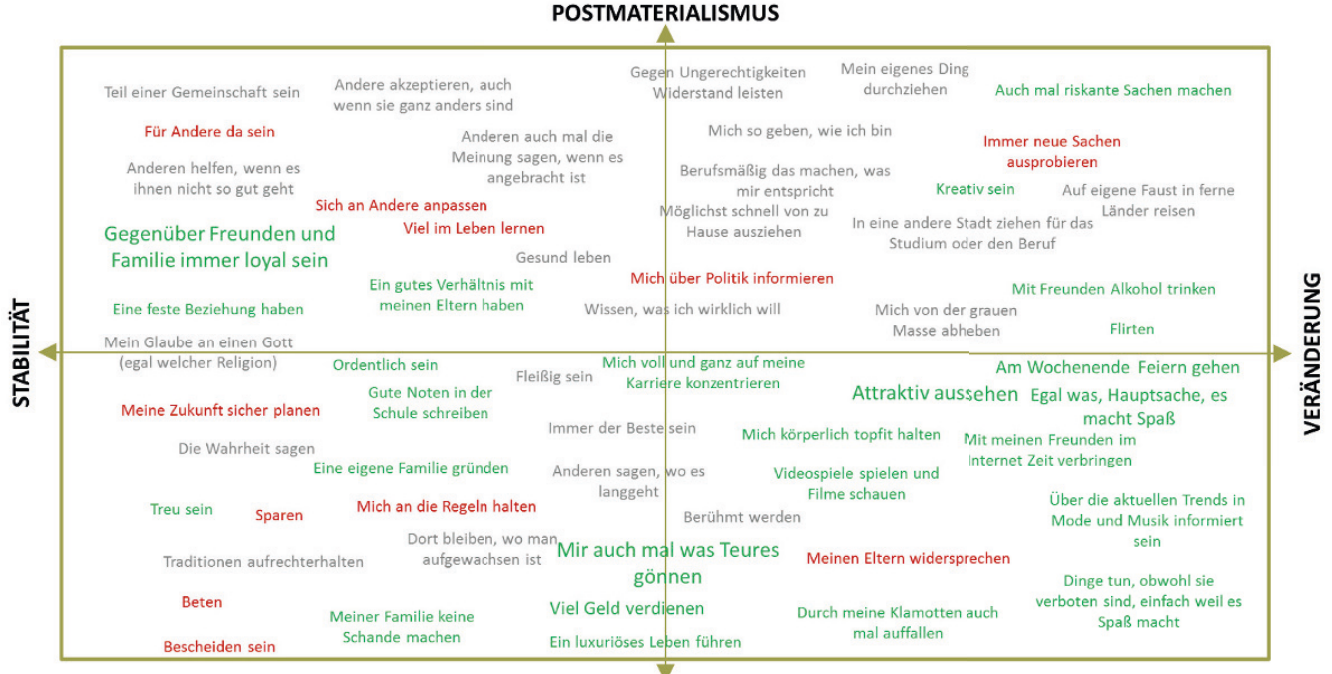

MATERIALISMUS

Von schlecht gekleideten Personen - noch dazu, wenn sie einen generell ungepflegten Eindruck machen - grenzt man sich deutlich ab.

Die Konsumwünsche sind daher auch von einer starken Markenorientierung geprägt, weil Marken in den Peer-Kontexten der Materialistischen Hedonisten Anerkennung abwerfen. Sie haben entsprechend ein feines Gespür dafür, welche Brands derzeit angesagt sind. Markenlogos müssen auffällig positioniert sein, sonst erfüllen sie ihren Zweck nicht: das Kommunizieren der Botschaft "Schaut her, was ich mir leiste". Materialistische Hedonisten fühlen sich auf den großen Shoppingmeilen wohl, weil sie dort "ihre" Läden finden: z. B. Streetstyle-Stores, Pimkie, New Yorker, H\&M, Orsay, Zara, Bijou Brigitte, Nike. Besonders wichtig ist es innen, immer mal wieder ganz besondere Teile aus dem Luxusgüter-Bereich zu ergattern (Dolce\&Gabbana, Michael Kors), z. B. über Ebay oder "Sachen, die vom Laster gefallen sind". Sie wissen auch darüber Bescheid, wo man Schnäppchen machen kann: Restpostenläden, Outlets etc. Auch Fake-Produkte (wenn sie "gut gefälscht" sind) stehen in der Gunst ganz oben (z. B. Louis-Vuitton-Handtaschen). 
Auszüge aus Hausaufgabenheften: Was GIBT DeInEM Leben SinN?
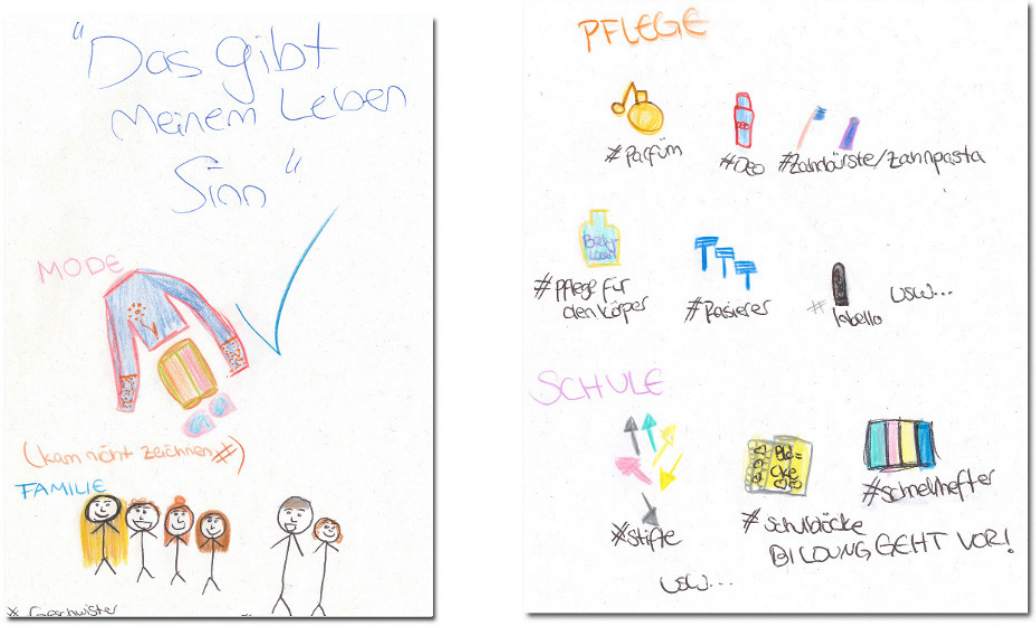

Für Materialistische Hedonisten sind v.a. Shoppen, Party, Geld und Urlaub die coolsten Sachen der Welt. Man möchte Spaß und ein „gechilltes Leben" haben. Sie beklagen keinen Mangel an Freizeit im Sinn von freier Zeit, sondern bemängeln eher hin und wieder die Langeweile des Alltags.

Auszüge aus Hausaufgabenheften: WAS GiBt DeInEm Leben Sinn?
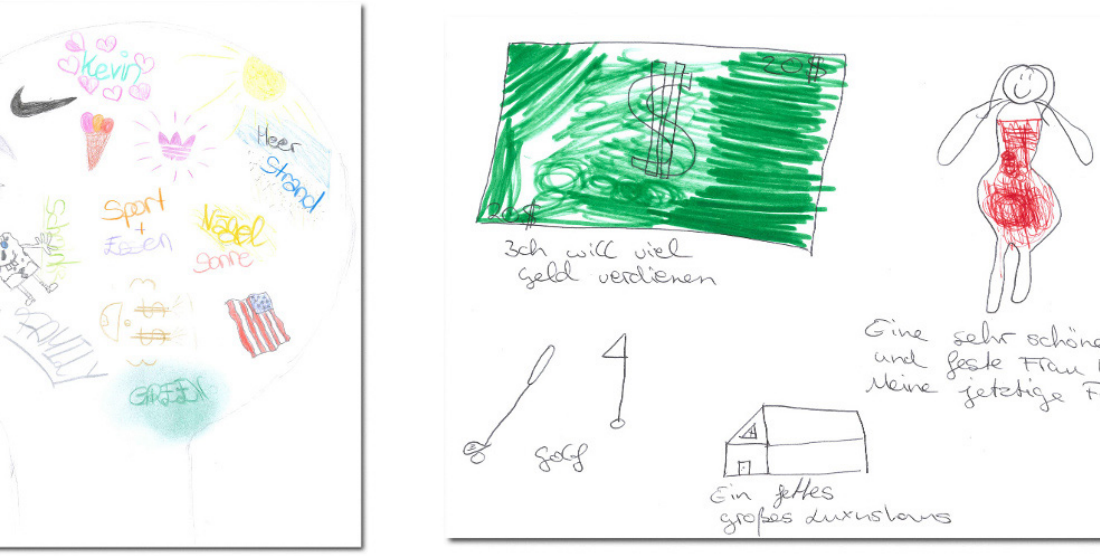

Gine selw schöne

und geste Fran heiraten. Meine jetetige Freundin 
Materialistische Hedonisten erzielen meist niedrige formale Bildungsabschlüsse. Darunter leiden sie. Insbesondere die Hauptschüler und Hauptschülerinnen berichten davon, dass die Hauptschule in der Öffentlichkeit einen schlechten Ruf genießt und man deswegen "komisch angesehen" wird. Zu Bildung im Sinne von schulischem Lernen hat man eine geringe Affinität; man ist froh, "wenn man da raus ist". Entsprechend spielt die Schule in der Freizeit kaum eine Rolle. Viele setzen darauf, in Zukunft ihre Bildungsdefizite durch Fleiß bei der Arbeit wett zu machen.

Auch wenn man mehr Zeit mit der Schule und dem Freundeskreis verbringt, stellen Eltern und Familie, inklusive Großeltern und Verwandtenkreis (v. a. bei den Jugendlichen mit Migrationshintergrund), den zentralen Bezugspunkt im Leben dar. Gemeinsame Mahlzeiten, zusammen Fernsehen oder ins Kino gehen, Ausflüge an erlebnisreiche Orte wie Centerparks, Väter- und Söhne-Ausflüge und ähnliche Aktivitäten gehören zum Familien-Programm. Das häufig traditionelle Familienmodell der Eltern dient vielen als Vorbild. Entsprechend werden im familiären Umfeld - und mit Blick auf eine eigene Partnerschaft bzw. Familie - traditionelle Werte wie Harmonie, Zusammenhalt, Treue, Hilfsbereitschaft, Ehrlichkeit und Anstand als bedeutsam erachtet, da sie stellvertretend für einen respektvollen Umgang miteinander stehen.

Auszüge aus Hausaufgabenheften: WoFÜR INTERESSIERST DU DICH ÜBERHAUPT NICHT?

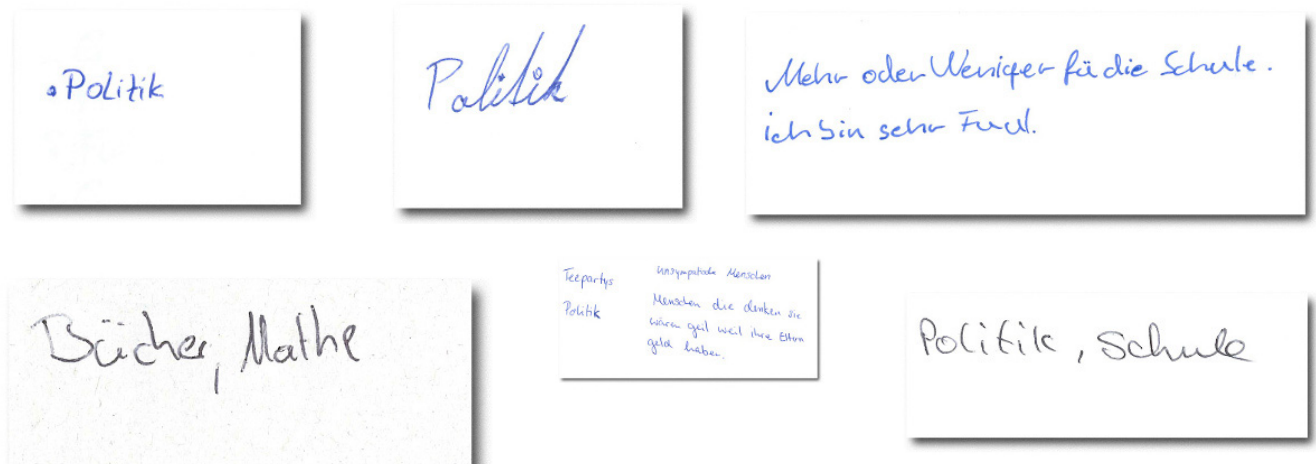


Während die Familie Geborgenheit und Sicherheit gibt, steht der Freundeskreis für Fun und Action. Es gehört fest zum täglichen Rhythmus, mit den Freundinnen und Freunden rauszugehen, abzuhängen und etwas zu erleben. Dazu nutzt man gelegentlich auch das Raumangebot der mobi-

Auszüge aus Hausaufgabenheften: WAS SIND für DICH DIE WICHTIGSTEN SACHEN DER WeLt?

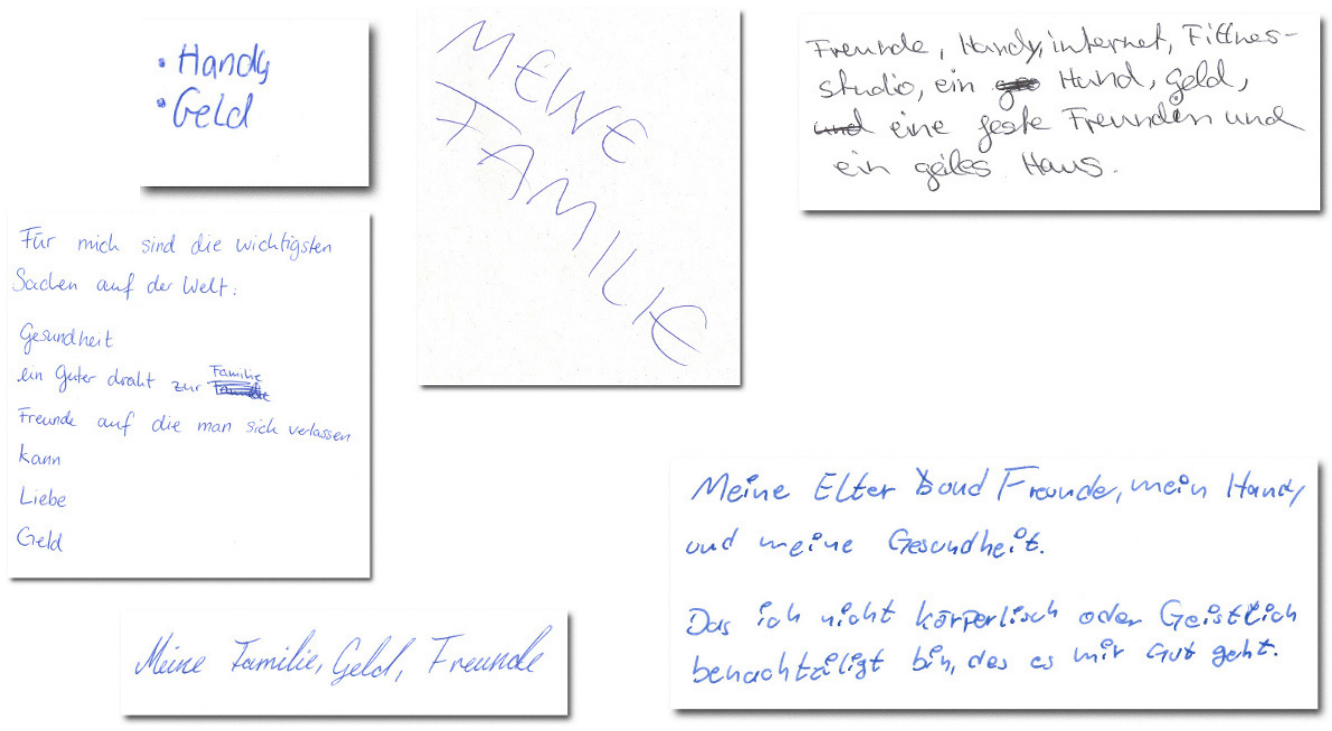

len oder offenen Jugendarbeit.

Vandalismus, Aggressivität gegenüber den Peers und der Konsum illegaler Drogen sind in den Alltagserzählungen dieser Jugendlichen immer wieder Thema. Während sich insbesondere die muslimischen Jugendlichen dieser Lebenswelt davon teilweise demonstrativ abgrenzen, gehören die (aggressive) Verteidigung der eigenen Rechte und exzessives Feiern zum Lebensstil vieler anderer Materialistischer Hedonisten. Sie zeigen tendenziell eine Ablehnung gegenüber Kontroll- und Autoritätswerten. Rigide Regeln werden deutlicher als in den anderen Lebenswelten als begrenzend, entmündigend und abstrafend erlebt. 


\section{Auszüge aus Hausaufgabenheften:}

Nenne eine erwachsene Person: A) Deren Lebensgeschichte Du Dir Gerne ERZÄHLEN LASSEN WÜRDEST. B) VON DER DU GERNE WAS LERNEN WÜRDEST.

a) Dwayne Johnsen b) Dwayne Johnsen

\section{Mein Vater}

Weil mein Vater

viel von dieser Welt

mit belommen und es

avch mit erlebt hat,

und er zugleich auch

Seine Erfahrungen Mirteilen Mann.

Wie man sich in

Schwierigen situationen

verhalten sollse und was

man Machen Sollte.

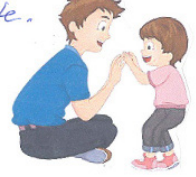

- Cristiano Ronaldo

- Mohammed Ali

-

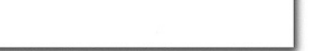

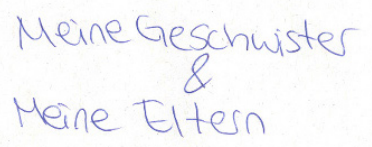

Ich wä̈rde mit qean die hebensgeschichtevon Pud Walten erzüiblen lassen wollen.

Esintorssint wich einfach wie er schaspieler evurde and evic er es sohoch geschuft hut. And hemen eviendichceuch gern von ihm.

Jugendliche mit Migrationshintergrund schwärmen von dem Land, aus dem ihre Eltern kommen, betonen aber, dass das Leben in Deutschland viele Vorteile hat. Bei ihnen wiegt Identifikation mit der Herkunftskultur in der Regel gleich stark oder stärker als die Identität als Deutsche oder Deutscher. Deutschland ist das Land für den Alltag und zum Arbeiten, das Herkunftsland ist das Land für Lebensqualität, Urlaub und Genuss.

Die Jugendlichen bewundern neben den eigenen Eltern v. a. die Stars der Entertainment- und Sportlandschaft, insbesondere die besonders glamourösen Vertreter/innen. Man sucht sich oft Vorbilder, die aus sozial prekären Verhältnissen kommen, aber dennoch viel im Leben erreicht haben - trotz bzw. gerade wegen der ungünstigen Ausgangsbedingungen Reichtum und Berühmtheit erlangt haben.

Typische Zitate zur Illustration
(1) Die drei wichtigsten Sachen? Mich so geben, wie ich bin. Mir auch mal was Teures gönnen. Viel Geld verdienen. Meiner Familie keinen Schaden machen. (weiblich, 14 Jahre) 
( Wirklich wichtig im Leben ist, dass es mir und meiner Familie gut geht. Und auch meiner Freundin. Und dass ich mich mit allen verstehe, mit meinen Freunden, meiner Freundin und meiner Familie. Und dass ich glücklich bin. Und alle anderen auch. Also ein Auto ist zwar für mich auch sehr, sehr, sehr wichtig. Und ein Handy auch und so weiter. Aber das ist so erst mal das Wichtigste. (männlich, 15 Jahre)

(7) Lebensmotto? Das ist schwer. Vielleicht yolo [ANM.: You ONLY LIVE ONCE ]. Also nicht jetzt so, dass man macht, was man will. Man muss natürlich schon die Gesetze und sowas einhalten. Aber dass man Spaß hat. (männlich, 16 Jahre)

( Wobei eigentlich interessiert mich Schule jetzt nicht wirklich viel, also eigentlich überhaupt nicht. Ich mache es halt nur, dass meine Eltern nicht erfahren, dass ich, keine Ahnung, die Hausaufgaben zum Beispiel, ich habe keinen Bock, dass die Lehrer jeden Tag anrufen und sich beschweren über irgendwas. (männlich, 15 Jahre)

Ich würde wollen, dass es in der Schule besser wird, dass ich mich mehr für die Schule interessiere. (...) Ich gehe jeden Morgen dahin und sage, ich habe keinen Bock, ich will schlafen. Mit so einer Einstellung, also dass diese Einstellung besser wird. (männlich, 17 Jahre)

( Ich mag schon lieber Markensachen als so H\&M, aber es ist meistens einfach viel zu teuer. Aber ich mag schon so eher, also wenn ich feiern gehe, mag ich es schick. (...) Die Hosen von Hollister sind ganz gut und so Superdry. Michael Kors, aber da habe ich nur eine Tasche von, weil es so teuer ist. Und sonst halt so die ganz normalen Standardmarken, die irgendwie jeder ganz gut findet. Adidas, Nike. (weiblich, 17 Jahre)

( Ich mag Schuhe sehr gerne, aber Schuhe, die ich mir halt nicht leisten kann. Nike Yeezys, das sind meine absoluten Lieblingsschuhe, also die Red October, aber die kosten halt richtig viel. Aber ich überlege mir, vielleicht gefälschte Schuhe zu holen irgendwo. (männlich, 15 Jahre)

( Manchmal gehe ich bei ZARA shoppen oder halt bei Peek \& Cloppenburg. Das kommt auf die Laune an, oder ob es mir gefällt (...). Also jeden zweiten Tag gehe ich mal so gucken, was es so gibt und was nicht. Dann gehe ich auch manchmal so etwas holen. (männlich, 16 Jahre) 
( Mit 35 möchte ich ein schönes Auto. Einen Mercedes, einen schönen CLS. (männlich, 17 Jahre)

Ich habe jetzt aber nicht so eine bestimmte Stylerichtung. Natürlich gibt es Sachen, die ich nicht tragen werde, zum Beispiel Emo-Sachen oder Punk-Sachen. (männlich, 15 Jahre)

( Wenn ich so gegen halb vier zu Hause bin, dann mache ich mir meistens erst mal etwas zu Essen und gucke dann ein, zwei Stunden fern. Und dann gehe ich raus mit meinen Freunden. Wenn ich abends wiederkomme, gibt es Abendbrot. Und vielleicht zocke ich danach noch ein paar Stunden oder mache Sport. (männlich, 15 Jahre)

( Ich bin ja in Berlin aufgewachsen (... ). Also man hat ja immer so einen Migrationshintergrund, würde ich sagen. Man ist ja Deutscher, sozusagen. Man ist ja hier geboren, aber hat halt sozusagen so einen türkischen Hintergrund, auch durch die Familie. Und da würde ich dann sagen, dass ich mich eher als Türke fühle, aber auch so ein bisschen deutsch. Das ist halt so ein bisschen kompliziert. (männlich, 16 Jahre)

( Lebensmotto? Da hatte ich mal so ein Motto. Ich habe das gerade vergessen. Es gibt ja so ein Motto "Lebe und denke nicht an morgen." Dann denkt man so: Aber man sollte halt mit Geschmack sozusagen mit begrenzter Zeit leben. Man sollte an viele Orte reisen und etwas erleben. (männlich, 16 Jahre)

> Von wem ich gerne die Lebensgeschichte hören würde? Von Evelyn Gerz. Das ist eine professionelle Nageldesignerin. Sie hat ganz früh mit Nägeln angefangen. Und ich gucke die immer auf YouTube. Ich finde die einfach cool. (weiblich, 15 Jahre)

I Ich bin gerne mit Leuten, die auch gern feiern gehen oder Gras rauchen oder so. So die Kiffer-Szene würde ich sagen. (weiblich, 17 Jahre)

\subsubsection{Zukunftsvorstellungen}

Die Materialistischen Hedonisten folgen dem bürgerlichen Lebenstraum von Beruf, Ehe, Kindern, schönem Zuhause und dann „irgendwie 
Auszüge aus Hausaufgabenheften:

Wie MöChtest Du spÄter LEBEN? WAS MACHSt DU DANN?

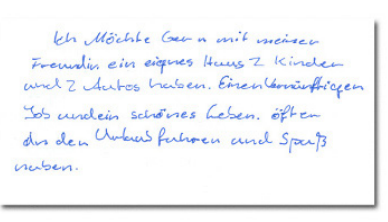

Ich möble einen gaten Job ein Haus und eine eigene Tamilie.

Donnmochle ich das leba gerieben

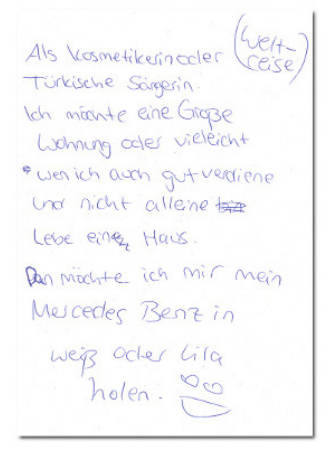

ich will spate- eine Familic haben und guictlich und whieden sein. ich mockle einen gulen Job haben mit dem ich for meine Familie sorgan tann und sie ebentalls glüchlics

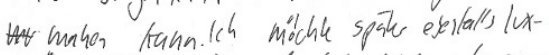

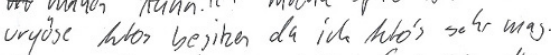
eine auch noch sche wichige Sach fïs dic zertuntt ist das ich 1.2 Kinde haber will.

glücklich werden“. Diesen Traum will man in der Nähe zum bisherigen Heimatort, gerne in einem Neubaugebiet realisieren. Aus eigener Erfahrung, dass es unter Jugendlichen soziale Probleme, Gewalt und Drogen gibt, möchte man seinen Kindern ein besseres Umfeld bieten. Eine liebevolle Erziehung und eine schöne Kindheit für sie sind wichtige Zukunftsvorstellungen. Insgesamt ist sozialer Aufstieg über einen guten Beruf ein wichtiges Lebensziel für Materialistische Hedonisten. Vor allem Jungen dieser Gruppe träumen teilweise auch von einem luxuriösen Leben. Die Zukunftswünsche der Mädchen haben hier mehr Bodenhaftung.

Schnell finanziell unabhängig sein und möglichst früh eine Familie gründen sind wichtige Ziele. Man strebt einen sicheren Ausbildungsberuf an, der ein gutes Einkommen und - vor allem bei Mädchen - Kontakt mit Menschen bietet. Meist hat man aber noch keine konkreteren Vorstellungen, was man werden möchte und werden kann. Hat man sich näher mit den realistischen Möglichkeiten auseinandergesetzt, mündet die Berufswahl oft in eher gering entlohnten, statusarmen Berufen. Für Materialistische Hedonisten bleibt der Traumberuf ganz klar ein "Traum": 
Fußballer (Jungen) oder Musiker (Jungen und Mädchen). Man verweist aber gleichzeitig darauf, dass die Chancen vermutlich eher schlecht stünden und man daher auch einen realistischen Plan verfolgt.

Sorgen und Ängste kreisen darum, keinen Ausbildungsplatz zu bekommen, damit den gesellschaftlichen wie den selbst gesteckten Anforderungen nicht gerecht zu werden, dem Druck der Leistungsgesellschaft nicht standhalten zu können. Man fürchtet auch, dass der eigene Abschluss mit der Zeit nichts mehr wert ist. Lebenslanges formales Lernen ist dabei keine attraktive Vorstellung.

Unsicherheit entsteht auch dann, wenn mit der Ausbildung neue und fremde Herausforderungen verbunden sind, denen man sich nicht sicher gewachsen fühlt (z. B. eine längere Abwesenheit vom vertrauten Umfeld).

Typische Zitate zur |llustration
Ich habe Angst, dass dieser Kfz-Mechatroniker nicht klappt oder ich meinen Abschluss nicht schaffe. Ich habe aber gehört, dass man das auch nachholen kann. Trotzdem stelle ich mir das manchmal so vor. Ich habe gehört, dass man beim MSA [ANM.: MitTleren SCHULABSCHLUSS] zwei Versuche hat. Und ich stelle mir so vor, dass ich den ersten Versuch nicht schaffe und dann den zweiten auch nicht. (männlich, 15 Jahre)

(7) Aber ich würde jetzt schon gerne eine Ausbildung machen, weil ich auch langsam arbeiten und Geld verdienen will, mein eigenes Geld verdienen. (männlich, 17 Jahre)

(1) Es macht mir Sorgen, dass ich später vielleicht mal nicht den besten Job habe. (weiblich, 16 Jahre)

Ich würde gerne gut Geld verdienen. Ich brauch jetzt nicht $x$-facher Millionär, Milliardär sein, aber ich würde schon gern gut verdienen und auch später eine Familie haben und die gut ernähren können. Auch ein schönes Haus haben, einen schönen Garten, perfekt natürlich mit einem schönen Auto. (männlich, 15 Jahre) 
Wenn ich mit meiner Schule und meiner Ausbildung fertig bin, dann will ich natürlich heiraten. Heiraten und dann Kinder kriegen, das will ich natürlich. Ich liebe Kinder. (weiblich, 15 Jahre)

( Und mit 25 bin ich schon bereit zum Heiraten. Ich glaube mit 35 da habe ich schon Kinder bekommen und lebe mit meiner Frau auch schon in der Türkei (...). Ich habe einen Job gefunden als Grafik-Designer und arbeite in einer Werbeagentur oder in einer hohen Firma. (männlich, 16 Jahre)

(7) Ausbildung? Ich schaue mal, was mir so gefällt. Und wenn ich nichts finde, gehe ich noch ein Jahr zur Schule. [INT: KANN MAN DAS NAGELDESIGN AUCH ALS AUSBILDUNG MACHEN?] Nein, das nicht. Das ist kein... Wie heißt das? [INT: AusBiLdungsberuf?] Ja, genau. Man muss sich dafür selbstständig machen. Und vorher kann man nur ein Praktikum machen. [INT: UND WIE WÄRE ES MIT KOSMETIKERIN?] Mein nächstes Praktikum - ich habe ja noch eines - mache ich dann beim Friseur. Und vielleicht mache ich dann eine Ausbildung zum Friseur. Oder ich war auch mal beim Blumenladen. So Floristin finde ich auch ganz gut. Mal schauen. (weiblich, 15 Jahre)

(7) Eigentlich bin ich mir nur selber wichtig. Und dass ich alles bestens hinkriege. Und wie gesagt, ich möchte auf jeden Fall etwas richtig richtig Großes schaffen, egal was. Also zum Beispiel Basketballer oder Rapper oder irgend so etwas. (männlich, 17 Jahre)

( Ich möchte eine kleine Wohnung, aber wenn ich mal einen Freund habe, dann vielleicht in ein Haus. Und ich möchte einen Mercedes-Benz in Weiß oder in Lila. (weiblich, 14 Jahre)

(1) Das weiß ich jetzt gar nicht so, was ich jetzt werden will, aber halt einen gut bezahlten Job. Dann hätte ich gerne eine Familie. (männlich, 17 Jahre)

(Das kann man ja nicht wissen, wie das wird in der Zukunft, deswegen reden wir auch nicht so viel darüber. (männlich, 17 Jahre) 
Auszüge aus Hausaufgabenheften: WofüR INTERESSIERST Du DıCH?

- Autos

- Kousden

- Freandinl Freunde

- Geld

- Klamonoten

-Spout. Fìr's Golfen und Framen,
geld

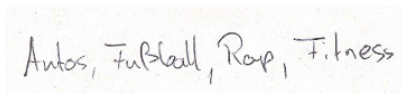

1

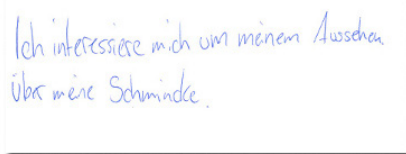

Tiere, Klamotten, Geld, Musik aB LPas da er eine becondere Vergangenhert hat.

Marchimal zeichne sh weh gerne.

\&'was in meinen värden gerade posient.

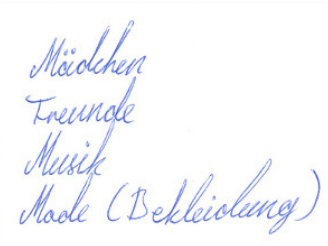

Freunde

Gerüchte

gut ancisehende

Mode
Drogen

Partys

\subsubsection{Kulturelle Orientierung, Freizeit}

Typische Freizeitaktivitäten der Materialistischen Hedonisten sind Freundinnen und Freunde treffen, abends weggehen, chillen, Games zocken, Shisha rauchen, Public Viewing und Stadionbesuche, etwas trinken, DVD schauen, PC und Internet, Schwimmen gehen. Auch Fast Food steht hoch in der Gunst. Man geht oft und viel aus, gerne in Diskotheken und kommt dann erst spät in der Nacht nach Hause. Alkohol gehört zum Feiern „irgendwie dazu, damit man locker wird", "übertriebenes Saufen" wird aber abgelehnt.

Von großem Interesse sind die aktuellsten Neuigkeiten aus dem sozialen Nahumfeld. Via Handy und über soziale Netzwerke werden topaktuelle Informationen über die Aktivitäten der Clique oder Ereignisse im Wohnumfeld bezogen und weitergegeben.

Das Leben von Stars und Sternchen begleitet vor allem die Mädchen durch ihren Alltag (Schwärmereien). Mit Fernsehen, Internet und Zeitschriften hält man sich auf dem Laufenden und tauscht sich untereinander aus. 
Auszüge aus Hausaufgabenheften: WAS GIBT DEINEM LeBEN SinN?
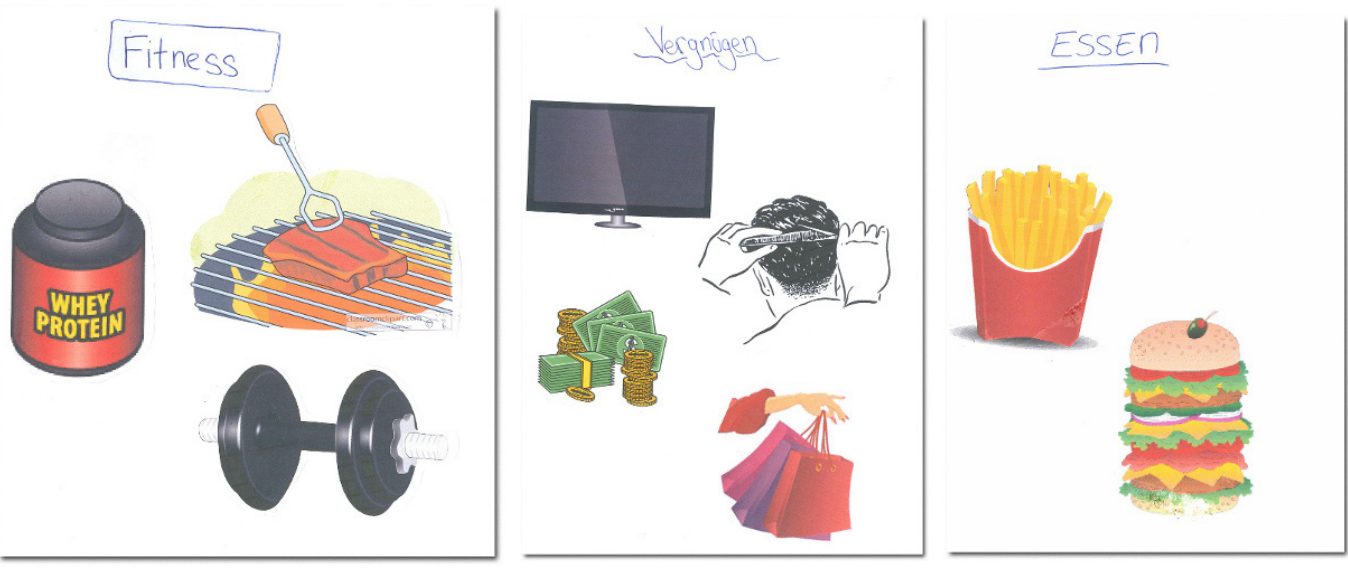

Für eine längere Zeit und mit gewisser Regelmäßigkeit bei einer Sache zu bleiben, fällt den meisten schwer bzw. ist langweilig. Wenn es eine regelmäßige Teilnahme an (vereinsmäßig) organisierten Angeboten gibt, dann im Bereich Sport. Motivation ist, dass anders als in der Schule die Jugendlichen hier oft die Erfahrung machen, zu den Besten zu gehören. Vor allem Jungen sind in Mannschaftssporten - insbesondere Fußball - aktiv und genießen die Anerkennung aus Turniersiegen und Medaillen. Sportlichen Aktivitäten gehen viele auch abseits von Vereinen nach. Einen "guten“ Körper zu bekommen („Body-Tuning“), spielt dabei eine wichtige Rolle.

Materialistische Hedonisten stehen der Hochkultur sehr distanziert gegenüber; sie haben hiermit in ihrem Alltag in der Regel kaum Berührungspunkte. Die wenigen Jugendlichen, die mit "hoher Kunst" in Kontakt kommen, verstehen nicht, "wie man sowas gut finden kann“ - zu langweilig (klassische Musik) und zu altbacken (Gemälde).

Materialistische Hedonisten orientieren sich musikalisch klar am Mainstream. Es ist ihnen nicht wichtig, sich einen besonders exklusiven Geschmack zu attestieren. Im Gegenteil: Man findet in der Regel das gut, was die anderen gut finden und will auf dem Laufenden sein. Dennoch ist 
Auszüge aus Hausaufgabenheften: WAS HÖRST DU GERNE FÜR MUSIK?

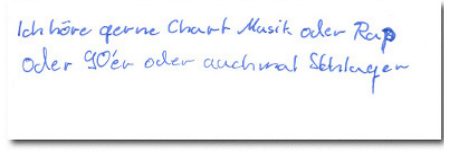

- Rap (Deutschrap)

- Englisch (pop)

- Franzosich (Rap)

- Turkisch (pop)
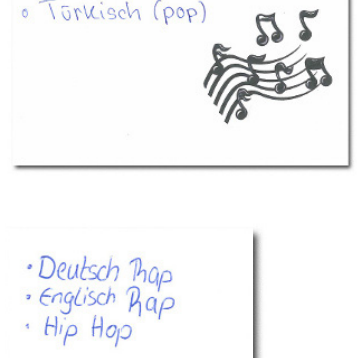

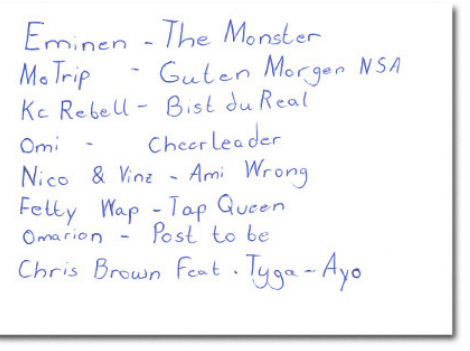

- Hip-lop

- Clup- Musík

- Pop

- Deutscher - Rap
Ich hive geme Bluck, R\&B, Rap

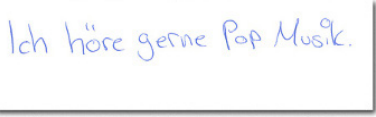

$R \cap B$

Rap, Hip- Hop, House

Maistans English Rap und Deutsch Rap

Hin and wieder Hoase Musile und Charts

man aber der Überzeugung, dass der bevorzugte Star etwas ganz Besonderes ist. Jungen und Mädchen hören beispielsweise häufig die neuesten Hits der internationalen und regionalen Stars, v. a. aus dem Bereich Hip-Hop und R'n'B. Texte über Liebe und Themen aus dem eigenen Alltag sind gut, deutsche Texte sind besser zu verstehen als englische Texte. Wichtig ist Glaubwürdigkeit, wer über den „Knast" rappt, sollte diese Erfahrung auch real bzw. glaubhaft vorweisen können.

Materialistische Hedonisten sorgen dafür, dass sie "coole", aktuelle Klamotten im Schrank haben. Bei den Jungs geht dies häufig in Richtung Hip-Hop-Style, wobei die Stars des deutschen Gangsta-Rap (wie z. B. Bushido) oder aktuell erfolgreiche Fußballer als Vorbilder dienen. "Ghetto-Style" und "Bling-Bling" ist angesagt: sportlich bis schick, die Kleidung muss immer sauber und faltenfrei sei, auch die Schuhe müssen immer sauber sein, Jungen wie Mädchen mögen Modeschmuck und auffällige Parfüms. Hygiene spielt eine sehr große Rolle (Deodorants und bei jenen, die bereits Bartwuchs haben in jedem Fall frische und teilweise recht 
aufwendige Rasuren). Trägt man nicht gerade ein Cap, werden die Haarschnitte "perfekt" gestylt.

Bei den Mädchen gehören High Heels, Hair- und Bodystyling, Make-up, Schmuck und andere Accessoires zur täglichen Routine bzw. Ausstattung. Bevorzugt wird körperbetonte Kleidung in oft auffälligen Farben.

Computer- und Konsolenspiele finden die Mädchen weit weniger interessant als die Jungen. Letztere verbringen teilweise viele Stunden mit Egoshootern, Actionspielen und Autorennen, online und offline, am PC oder mit der Spielekonsole. In der Nacht vernetzt man sich mit Freunden, telefoniert (über Skype) und liefert sich ausführliche Kämpfe in virtuellen Welten. Viele Jungen sehen sich aufgrund dieser Erfahrungen als Experten für Computer.

Mädchen mögen lustige und romantische Filme und haben dabei ein besonderes Faible für Filme, in denen "Jungs auch ganz anders sein können": zärtlich, romantisch, fürsorglich. Jungs mögen Lustiges, Actionund Hip-Hop-Filme. Filme werden aus Kostengründen v. a. im TV und im

Auszüge aus Hausaufgabenheften: WAS SIND DEINE LIEBLINGSFILME UND -SERIEN?
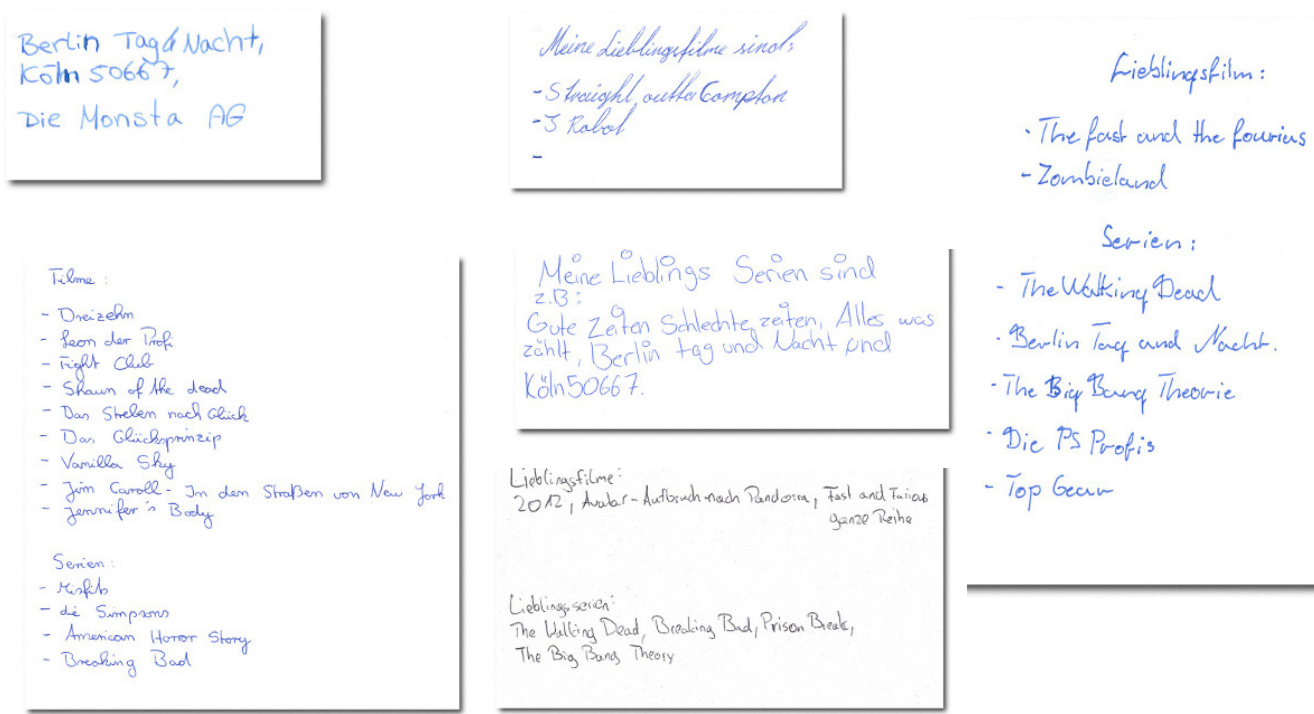

- The Wakkiny Dead

- Berlin Tan and Nacht.

- The Bick Bung Theorie

- Die Ps Profis

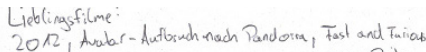

Top Gear ganze Reihe

Lieblings, secien:

The Walling Dead, Breaking Bud, Prison Break,

The Big Bang Theory 
Auszüge aus Hausaufgabenheften: WAS LIEST DU GERNE?

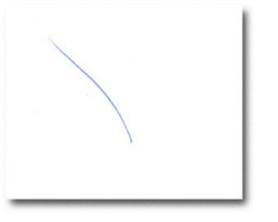

Ich bis generell nich begristert vom lesen und

(ic) eher teitschritten als Büher.

Moist lese ich teitschriften wilitulo Motor Spart" oder Artobild.

\section{Ich lese kaum etwas höhstens die Bücher aus der Shule}

\section{Ich Lese nicht gerne.}

Internet geschaut. Kinobesuche mit der Clique sind zwar beliebt, werden aber wie DVDs als zu teuer eingestuft.

Talk- und Reality-Formate sind ebenso angesagt wie Serien (Sitcoms, Zeichentrick), Soaps, Casting-Shows (DSDS) und Infotainment-Sendungen sowie Spielfilme und vereinzelt auch Nachrichten (RTL, n.tv), vor allem dann, wenn sie einen Sensationsgehalt aufweisen können.

Materialistische Hedonisten lesen nur sehr vereinzelt Bücher, meistens für die Schule. Aber sie blättern gerne mal beim Friseur oder im Wartezimmer in Zeitschriften über Stars, Mode, Autos oder Computerspiele.

In der Freizeit von Materialistischen Hedonisten ist kein Platz für "weiterführende" Bildung. Freiwillige Vor- und Nachbereitung des Unterrichts kommt nur dann in Frage, wenn dies "versetzungsnotwendig" ist. Selbst wenn man an einem Thema in der Schule interessiert ist, so würde man sein Wissen darüber kaum in seiner Freizeit vertiefen, da andere Aktivitäten wie das Fernsehen oder Facebook reizvoller sind und man außerdem nicht als "Streber" gelten möchte.

Für viele gehört das Jobben als Zeitungsausträgerln, im Fitness-Studio oder im Betrieb der Eltern dazu, um die Freizeitaktivitäten zu finanzieren. 
( Ich höre meistens Chartmusik, auch ältere Chartmusik, aber das geht manchmal von Hip-Hop zu Popmusik, zu Rapmusik, zu Techno. Schlager nicht so und Kultmusik auch nicht so. (männlich, 15 Jahre)

Typische Zitate zur Illustration

( Ich glaube, meinen Geschmack hat jeder, also haben auch andere. Der ist jetzt nicht so besonders. Ich bin ehrlich. (weiblich, 15 Jahre)

( Also ich höre gerne Deutschrap, Englisch Pop, Französisch Rap und Türkisch Pop, eher so. [...] Deutschrap höre ich eher Kool Savas. Was noch... Eco Fresh. Eher auch in die Szene von den Neueren, also Summer Jam. Das ist eher so ein Neuer. Aber der ist auch schon ein paar Jahre in der Rap-Szene. Dann Kollegah. Von den Englischen höre ich eher JayZ, Tyga. (männlich, 16 Jahre)

( Ich höre gerne Deutschrap, Englischrap und so Hip-Hop. Und nicht gerne halt diese Hardcoremusik. Heavy Metal und so. (männlich, 17 Jahre)

( Nach der Schule gehe ich nach Hause und esse was. Danach komme ich wieder mit dem Bus ins Jugendhaus. Dann chillen wir hier mit Freunden und machen halt so ein bisschen FIFA. Abends um 18 Uhr fahre ich dann wieder nach Hause. Und dann zu Hause halt chillen, sitzen und mit dem Handy spielen. (männlich, 17 Jahre)

( In meiner Kindheit fand ich X-Men, allgemein die Marvel-Comics, voll gut (...). Ich finde es voll cool, dass eben normale Menschen Superkräfte haben. Das finde ich voll cool. (männlich, 16 Jahre)

( I) habe ein Abo [Für DIE BRAVo]. Sonst lese ich eigentlich nichts. Nur die "Bravo". Da steht immer alles drin über die Stars. Und da sind immer coole Poster drin. Und da sind auch immer gute Tipps drin, so Schmink-Tipps, und was man gebrauchen kann. (weiblich, 15 Jahre)

( Naja. Ich habe vor einem Jahr oder so noch immer Gregs Tagebuch gelesen. Aber eigentlich lese ich fast nicht. Nur für Hausaufgaben und so. Da muss man ja lesen. (männlich, 16 Jahre)

Wir gehen halt so, bummeln ein bisschen herum, also ein paar Läden. Zum Beispiel am Alexanderplatz oder am Ku'damm, um zu gucken, was es da so Neues gibt. (männlich, 16 Jahre) 
( Am Wochenende treffen wir uns. Manchmal, keine Ahnung, da trinken die Jungs Alkohol. Dann sagen wir, lasst uns mal feiern gehen. Dann gehen wir feiern und manchmal trinken wir auch im Park. (männlich, 17 Jahre)

( Ich gucke mir in YouTube ein Video an. Und dann lade ich mir das auf mein Handy. Und dann kommen immer weitere Lieder also Videos, die so ähnlich sind. Und die höre ich mir dann an. (weiblich, 15 Jahre)

( Mir fallen immer verrückte Sachen ein. Wir gehen zum Beispiel einfach raus und machen Party. [INT: WIE MACHT IHR PARTY?] Wir hören draußen Musik. Oder wir gehen spontan irgendwohin. (weiblich, 15 Jahre)

(7) Lustig, wir sind alle lustig drauf. Mit denen kann man immer Spaß haben. [INT: WAS MACHT IHR DANN SO, WAS SPASS MACHT?] Naja, wir machen halt hin und wieder Blödsinn. Also nichts, was schlimm ist, aber wir lachen halt eigentlich über alles. Deswegen... manchmal bleiben wir nur sitzen und reden oder so. Manchmal gehen wir ins Stadion oder sowas, Fußball spielen, alles mögliche. [INT: Auf EINEM BolzPLATZ?] Ja, genau. Hier ist so ein Fußballplatz, da gehen wir öfters hin. Und letztens waren wir dann im Stadion, VfB gegen Manchester City. Sowas auch. (männlich, 16 Jahre)

\section{Pizza, Döner ist Standard. (männlich, 17 Jahre)}

( Wir unterhalten uns über alles mögliche. Über Fußball oft, Ergebnisse, Transfers und owas. Aber eigentlich über alles mögliche. Über Videospiele hin und wieder auch. (männlich, 16 Jahre) 
(7) Also ich mache jetzt seit zwei Monaten Fitness und in den Monaten habe ich mich schon recht intensiv damit befasst mit dem Thema. Für die Zeit kenne ich mich schon wirklich sehr gut mit dem Thema aus. Immer mehr Leute gehen jetzt ins Fitnessstudio, und da kann ich schon hin und wieder mal gute Tipps geben. (männlich, 16 Jahre)

\subsubsection{Vergemeinschaftung}

Wie auch Jugendliche anderer Lebenswelten legen die Materialistischen Hedonisten Wert auf einen soziokulturell homogenen Freundeskreis: Freunde sollten sich für die gleichen Themen interessieren, die gleiche Musik hören, sich für den gleichen Sport interessieren und dieselben Klamotten und Frisuren haben.

Materialistischen Hedonisten ist es wichtig, einen großen Freundeskreis zu haben. Man ist nur sehr ungern alleine, beschäftigt sich nicht gerne mit sich selbst. Im Kreis der Freunde, in größeren Gruppen fühlen sie sich am wohlsten und aufgehoben. Cool ist, wenn man bei allen bekannt und beliebt ist. Dieser Anspruch setzt unter Druck: Um den Erwartungshaltungen der Peers gerecht zu werden, muss man v. a. modisch up-to-date sein und die Gerüchteküche kennen. Trotz bzw. gerade wegen des hohen Peerdrucks werden die besten Freunde auch als "Brüder" und "Schwestern" bezeichnet. Ist das physische Zusammensein nicht möglich, wird die räumliche Distanz über Online-Netzwerke, Chat, SMS und Telefonate überbrückt und so die Teilhabe am Geschehen gesichert.

Ein bis zwei Handvoll „richtige" Freundinnen und Freunde trifft man täglich. Mit ihnen kann man etwas unternehmen, sie sind lustig, gut drauf, für die Freunde da, man hat Spaß und macht Blödsinn. So wichtig Freunde sind, so unsicher ist man sich manchmal jedoch hinsichtlich der Zuverlässigkeit und Beständigkeit der Freundschaften. Einige haben die Erfahrung gemacht, dass ein Streit zu einer unüberwindbaren Hürde mutieren kann und Konflikte schnell das Ende einer Freundschaft bedeuten können. Aggressives Konfliktverhalten und Machtkämpfe sind nicht selten innerhalb des oft stark hierarchisch strukturierten Freundeskreises. 
"Schlampen", die "vergebene Jungs" in der Disko abschleppen, "Schlägerweiber" oder pöbelnde Jugendliche und "Asoziale" werden ausdrücklich abgelehnt. Jugendszenen, insbesondere wenn ihr Style stark vom Mainstream abweicht, sind ihnen meist suspekt. Man mag keine eingebildeten oder arroganten Menschen. Abgrenzung findet sowohl nach unten ("Sozialschmarotzer" ,Dauer-Hartzer") als auch nach oben statt (,Bonzen“, ,Gymnasiasten“).

Im Vergleich der Lebenswelten berichten die Materialistischen Hedonisten am häufigsten und selbstverständlichsten von ethnisch heterogenen Freundeskreisen. Teilweise gibt es gegen Jugendliche mit Migrationshintergrund jedoch Vorbehalte - selbst wenn man selber einen Migrationshintergrund hat - wenn die "so ganz anders" oder "aufdringlich" sind.

Eine tolle Freundin oder einen tollen Freund „zu bekommen“, ist wichtig und steigert das eigene Ansehen im Freundeskreis. Die aktuelle Paarbeziehung hat eine sehr hohe Bedeutung: Ein Großteil der Freizeit wird gemeinsam verbracht, die Erwartungen des anderen sind Orientierungsgeber, und er bzw. sie ist wichtiges Gesprächsthema unter Freundinnen und Freunden.

Auch wenn die Mädchen sich wünschen, dass die Jungen ein wenig romantischer und zärtlicher sein könnten, orientieren sich die Materialistisch-hedonistischen Jugendlichen an stereotypen Geschlechterrollenvorstellungen: Jungen geben sich betont hart, stark und furchtlos. Vergleichsweise groß ist auch die Affinität zu Kampfsportarten und Fitness-Studios („Pumpen gehen“).

Insbesondere die Materialistischen Hedonisten, die in einer Großstadt leben, rekrutieren ihren Freundeskreis über das unmittelbare Wohnumfeld. Treffpunkte liegen oft im eigenen Viertel. Vielen ist es wichtig, dass Jugendliche aus dem gleichen Stadtteil kommen wie sie selbst. Bisweilen wird Jugendlichen aus anderen Stadteilen mit großem Mißtrauen begegnet ("Man muss wissen, wo man hingehört").

Sie treffen sich auch gerne auf den großen Einkaufsstraßen, in Shopping-Zentren, Sisha-Bars, Sportplätzen, Jugendhäusern, auf öffentlichen (Spiel-)Plätzen, vor Multiplex-Kinozentren und im Sportverein. Sie haben 
keine Affinität zu subkulturellen oder „exotischen“ Lokalitäten: Dort hängen nur die "Freaks und Spinner" ab; gemeint sind hier oft Punker, Emos, Goths. Teilweise grenzt man sich auch explizit von den Gymnasiasten ab.

(7) Man will nicht zu Hause abkacken, alleine. Das ist langweilig. Dann sagt man, hey, lass uns mal raus, lass uns mal irgendwo hin, lass uns mal ins Jugendhaus. (männlich, 17 Jahre)

Typische Zitate zur Illustration

(7) Wir gehen zum Alexanderplatz dort hinten. Ich weiß nicht, wie das heißt, Alexa [AnM.: EINKAUfSZENTRUM] oder so. Da sind richtig viele Jugendliche. Wir stehen da alle in so einem Park. Und da chillen wir alle. (männlich, 15 Jahre)

( Da treffe ich mich auch mit den Jungs. Dann sagen wir, was sollen wir heute machen. Manchmal gehen wir in Shisha Bars und rauchen eine Shisha. Oder wenn gutes Wetter ist, dann gehen wir in den Park und rauchen da Shisha. (männlich, 17 Jahre)

[INT: WIE VIELE FREUNDE HAST DU INSGESAMT?] Ich glaube schon eher viele, also sehr viele sogar. 80 oder so. [INT: UND DIE, DIE DU WIRKLICH ALS DEINE WAHREN FREUNDE BEZEICHNEN WÜRDEST?] Na ja, bei manchen ist es ja so, dass man denen nicht vertrauen kann, oder ich finde den Charakter von denen nicht ganz toll (...). Das sind dann halt die zehn [LEUTE], die dann auch nur so passen, mit denen ich dann auch so richtig im Kontakt bin. (männlich, 16 Jahre)

$>$ Meine Freunde sind gut drauf. Sie sind immer bereit, alles zu machen, jede Scheiße zu machen. Dann sage ich zu dem, komm, lass uns den mal hauen, so aus Spaß, den anderen Freund, der da sitzt. Dann sagt er, ja komm, dann stehen wir auf und hauen den. Wir sind alle ein bisschen krank im Kopf. (männlich, 17 Jahre)

I Ich mache nichts mit denen. Es sind nicht meine Typen. Sind halt alles Gymnasiasten meistens. Ich weiß auch nicht warum, aber das ist halt einfach so. (männlich, 16 Jahre) 
( In meiner Schule sind ein paar. Ich will jetzt nicht dieses Wort sagen. (...) Die sind so öko, aber die wollen auch nichts mit uns zu tun haben, das ist klar. Und wir wollen nichts mit denen zu tun haben. (weiblich, 15 Jahre)

Ich mag die nicht, weil das sind eingebildete Bonzen, die alles von Mama und Papa in den Arsch geschoben bekommen, aber denken, sie sind voll reich und so, obwohl das nur ihre Eltern sind, die Geld haben. Solche Leute mag ich nicht so. (weiblich, 17 Jahre)

(7) Kleidung finde ich schon ziemlich wichtig, weil in unserer Klasse haben wir auch welche, die, also ich weiß nicht, ob die sich nicht oft die Haare waschen, oder ob das nur so aussieht. (männlich, 14 Jahre)

Also 50\% meiner Freunde oder so spielen Basketball. Und wir treffen uns immer am Leopoldpark. Das ist so ein kleiner Park und da ist halt so ein Basketballkorb und da treffen wir uns meistens. Da sind eigentlich fast alle. (männlich, 16 Jahre)

( Ich rede immer sehr viel über Sport. Ich bin halt sportlich sehr aktiv. Meine Freunde sind auch alle Sportler. (männlich, 16 Jahre)

( Leute, die ich gar nicht mag, sind so Schlägertypen. Die wirklich einfach nur irgendwohin gehen und einfach nur schlägern wollen. So asozial und keine Freundschaften schließen können. Das mag ich gar nicht. Mit den Leuten will ich nichts zu tun haben. Meine Freunde sind halt so wie ich. (männlich, 16 Jahre) 


\subsection{Experimentalistische Hedonisten}

Die spaß- und szeneorientierten Nonkonformisten mit Fokus auf Leben im Hier und Jetzt.
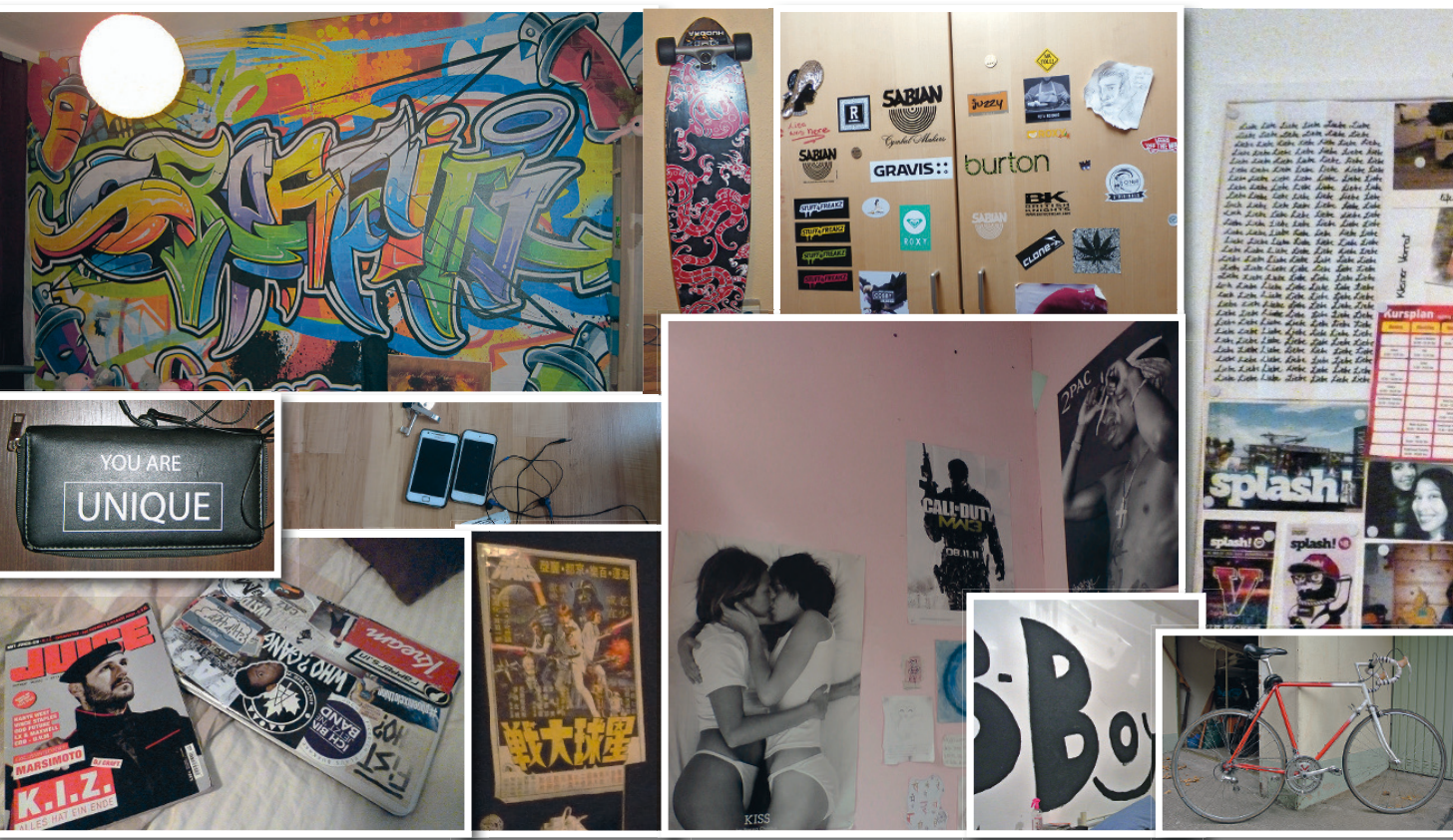

\subsubsection{Lebensweltliche Basisorientierungen}

Freiheit, Individualität, Selbstverwirklichung, Spontaneität, Kreativität, Risikobereitschaft, Spaß, Genuss und Abenteuer sind Ankerwerte der Experimentalistischen Hedonisten. Sie wollen das Leben in vollen Zügen genießen und sich den Ernst des Lebens möglichst lange vom Hals halten. Man lebt vor allem im Hier und Jetzt und mag es gar nicht, wenn das Leben nur aus Vorschriften besteht. Der Wunsch nach ungehinderter Selbstentfaltung ist groß. Sich Selbstdisziplin und Selbstkontrolle 
Werte-Universum der Experimentalistischen Hedonisten

POSTMATERIALISMUS

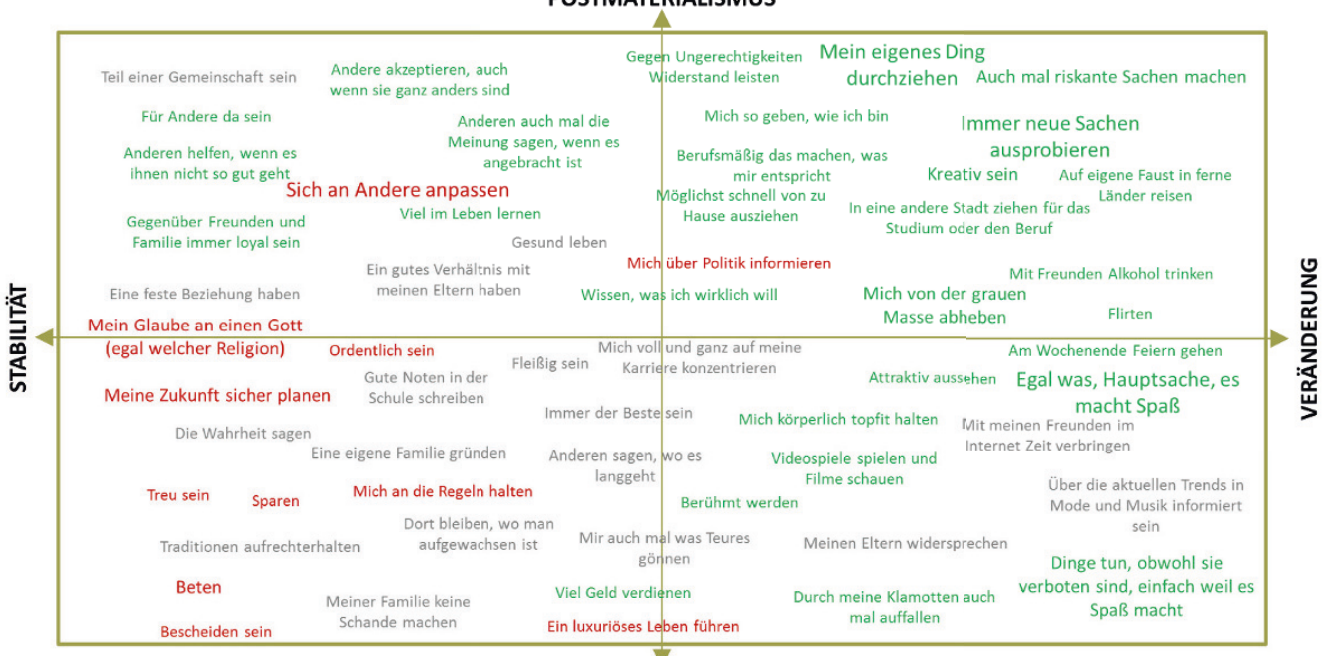

MATERIALISMUS

abzufordern, liegt Experimentalistischen Hedonisten oft fern. Man möchte Grenzen überschreiten, Regeln brechen, „es drauf ankommen lassen" und sich ins kalte Wasser werfen - nur so lernt und lebt man wirklich. Dass diese Jugendlichen manchmal für "aufsässig" gehalten werden, zeigt ihnen, dass sie auf dem richtigen Weg sind. Experimentalistische Hedonisten beschreiben sich häufig selbst als eigensinnig, eigenwillig und widerspenstig.

Zu typisch bürgerlichen Werten wie Bodenständigkeit, Bescheidenheit, Gewissenhaftigkeit, Gehorsam, Disziplin, Pflichtbewusstsein, Pünktlichkeit, Ordnung, Sauberkeit haben die Experimentalistischen Hedonisten im Vergleich der jugendlichen Lebenswelten die geringste Affinität. Das zeigt sich zum Beispiel daran, dass Schule für viele keine Priorität im Leben besitzt. Man macht für die Fächer, die einem gleichgültig sind nur das Nötigste. Brennt man aber für ein Thema, setzt man sich nicht selten auch in der Freizeit tief mit der Materie auseinander.

Soweit es ihnen möglich ist, versuchen sie sich von dem aus ihrer Sicht langweiligen Mainstream zu distanzieren und sich von den Vorstellungen 
einer bürgerlichen Normalperspektive zu emanzipieren. Jugendlichen in der Stadt fällt dies dabei leichter als Jugendlichen auf dem Land. Ältere formulieren ihren Anspruch auf Andersartigkeit deutlicher als Jüngere. Das Vorhandensein alternativer Lebensentwürfe im Sozialisationsumfeld bedingt hier wesentlich, wie selbstbewusst die Jugendlichen ihre Vorstellungen von einem ",anderen Leben“ formulieren.

Experimentalistische Hedonisten ecken mit ihrer Werthaltung oft an bzw. wollen bewusst anecken. So gibt es bisweilen Ärger sowohl mit Lehrerinnen und Lehrern als auch mit anderen Jugendlichen oder den Eltern. Es ist ihnen wichtig, sich durch eigenes kreatives Schaffen abzuheben, zusammen mit anderen etwas auf die Beine zu stellen und dabei einen eigenen bzw. szenespezifischen Stil zu verfolgen - "Selbermachen statt nur blöd konsumieren". Sie legen großen Wert auf kreative Gestaltungsmöglichkeiten, sind oft fantasievoll, originell, provokant.

Von allen Lebenswelten äußern die Experimentalistischen Hedonisten den Wunsch nach "anders leben" am deutlichsten. Das Subkulturelle, "Undergroundige", Abseitige fasziniert sie und zieht sie an. Man findet Leute spannend, die anders sind, die etwas Faszinierendes haben, weil sie sich den Konventionen verweigern. Das Spießbürgerliche, Normale, Karrieristische, Konventionelle langweilt sie hingegen. Man möchte "sich abgrenzen“, ",auffallen“, "dem Einheitsbrei der Gesellschaft etwas entgegenstellen", ",aus der Masse hervorstechen".

In dieser Lebenswelt ist die Affinität zu Jugendszenen daher auch am höchsten. Einige spielen mit bewusst eingesetzter "Hässlichkeit" als Provokationsmittel. Auffällige Kleidung und Accessoires sind ihnen wichtig. Viele sympathisieren mit Körpermodifikationen (Tattoos, Piercings, Ohr-Tunnel).

Auf einen individuellen Style legen Experimentalistische Hedonisten generell großen Wert - nach dem Motto "I don't want it if anyone can have it or has it already". Sie kennen sich mit den szenespezifischen Kleidungscodes aus. Viele kaufen in Szeneläden bzw. -Mailordern oder auf Flohmärkten und in Vintage-Stores ein.

Extreme Positionen einzunehmen finden Experimentalistische Hedonisten spannend. Dazu gehört auch, schon recht früh Alkohol, Zigaretten 
und weiche Drogen (v.a. Marihuana) zu probieren. Für andere wiederum ist der Konsum von Genuss- und Rauschmitteln ein jugendtypisches Verhalten (und somit Mainstream), von dem man sich demonstrativ abgrenzen möchte. Während einige Experimentalistische Hedonisten sich für subkulturelles Nightlife interessieren bzw. beginnen zu interessieren, verurteilen andere Diskos pauschal als langweilig und suchen sich andere Locations.

Mit Sexualität gehen Experimentalistische Hedonisten sehr offen und interessiert um. Typisch ist, dass man die Vielfalt sexueller Orientierungen ostentativ gutheißt und entdramatisiert. Sie wird als selbstverständlicher Teil einer offenen Gesellschaft verstanden. Dass man selbst „locker über Sex sprechen kann", sehen nicht wenige als Überlegenheitsmerkmal gegenüber den gleichaltrigen Peers.

Typisch für Experimentalistische Hedonisten ist eine sehr geringe Routineorientierung. Sie betonen, wie langweilig sie es finden, wenn Menschen immer auf Nummer sicher gehen möchten, sich am Bewährten orientieren und wenig offen für Veränderung sind.

Auszüge aus Hausaufgabenheften: WAS GIBT DeInEM LeBEN SinN?
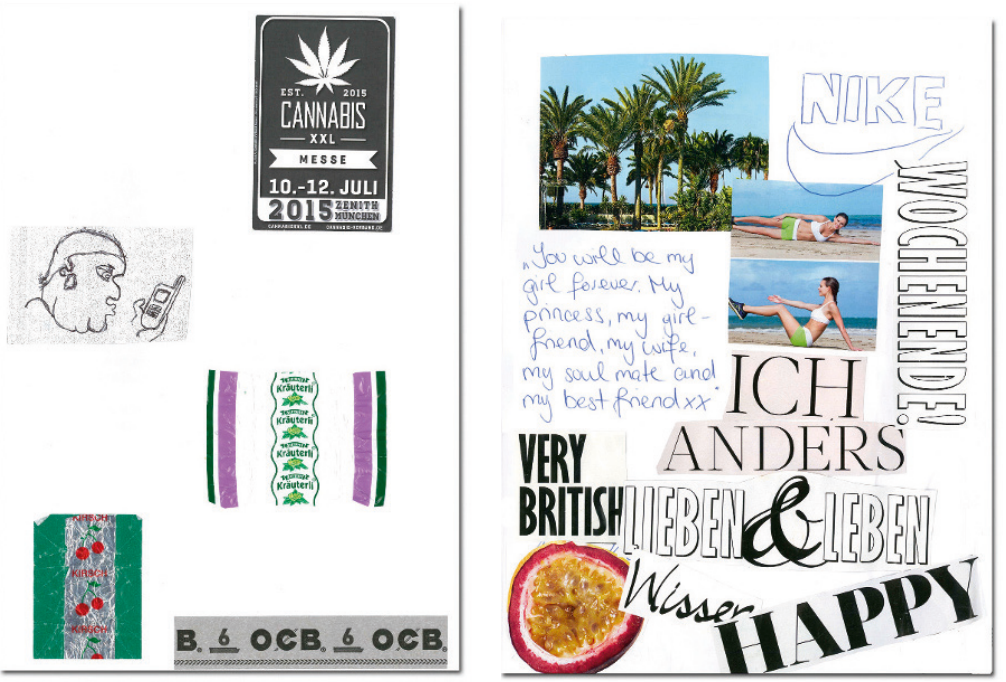
Auszüge aus Hausaufgabenheften: WAS GIBT DeINEM LeBEN SInN?
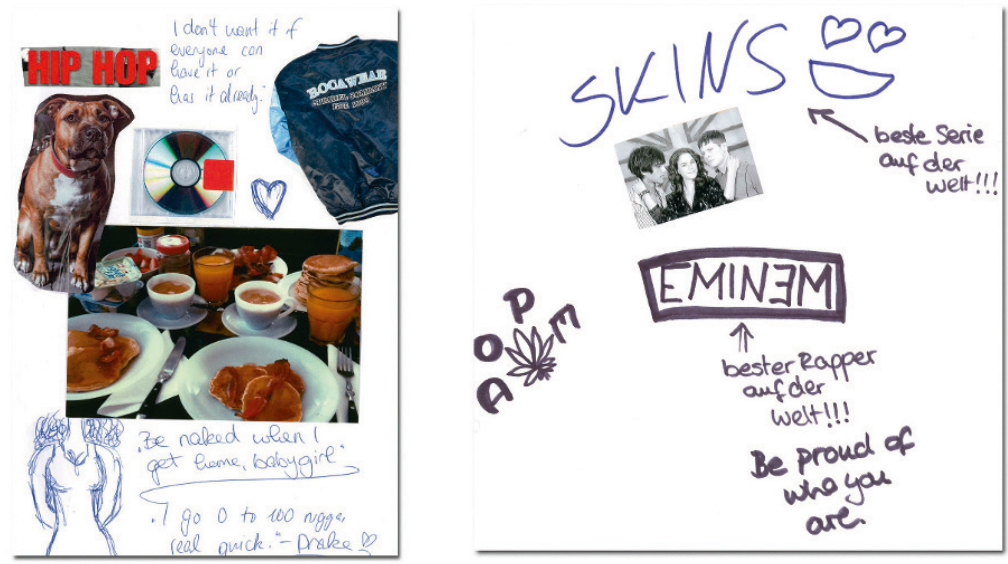

welt!!!
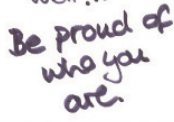

Zwar rebellieren die Experimentalistischen Hedonisten (am stärksten) gegen "spießbürgerliche“ Normalität, die eigenen Eltern entsprechen diesem Bild jedoch nur noch selten. Bei aller Wertschätzung von Familie - Familie wird oft als langweiliger Alltag verstanden; immer gleiche Routinen, alle kennen sich etc., - ist man daher bereits früh bemüht, sich immer mehr Freiräume von den Eltern zu „erkämpfen“ und v. a. die Freizeit möglichst unabhängig von den Eltern zu gestalten.

( Sein eigenes Ding machen, sich vom Aussehen her alleine schon von den anderen Menschen abgrenzen. Ich hatte auch mal so eine Zeit, in der ich als leichter Punker rumgelaufen bin, so komplett schwarz

Typische Zitate zur Illustration geschminkte Augen und zerfetzte Klamotten. Und ich finde es irgendwie toll, so Leute zu überraschen. Ich hab mir auch mal meine Haare fast blau gefärbt an den Spitzen, also einfach von dem einen Tag auf den anderen, und dann alle Leute so ,Oh mein Gott, du hast blaue Haare'. Und das ist halt ganz witzig. (weiblich, 15 Jahre)

( Meine Freunde sagen, dass ich sehr durchgeknallt bin, dass ich öfter mal was mache, wenn jemand sagt, du traust dich nicht. Aber auch nicht, dass ich mir alles gefallen lasse. Die meisten meiner Freunde sagen, dass ich eine verrückte Nudel bin. (weiblich, 14 Jahre) 
(7) In bin sehr eigenwillig, und ich wollte einfach nie das, was meine Eltern wollten. Und wenn meine Mutter gesagt hat: „Du bist um zwölf zuhause!", dann war ich um vier zuhause. Und dann habe ich zwar Ärger bekommen, aber irgendwie war es mir auch egal, weil ich mir dachte, ich hatte meinen Spaß. (weiblich, 17 Jahre)

( Also ein bisschen revolutionär, dass man halt ein bisschen wirklich aus der Reihe tanzt und nicht das macht, was man so vorgeschrieben bekommt. [...] dass man halt ein freieres Leben hat, auch dass man nicht so sehr von der Gesellschaft beeinflusst wird, finde ich ganz interessant. (männlich, 17 Jahre)

( Mein Geschmack ist auf jeden Fall anders. Ich bin jetzt nicht der, der den Geschmack hat wie viele andere hier auch. Ich bin jemand, der ein bisschen aus der Reihe tanzt. (männlich, 17 Jahre)

( Ich kenne echt wenige, die meinen Musikgeschmack haben. [...] Die hören eigentlich alles gemischt, kleiden sich auch ganz anders als ich. (weiblich, 17 Jahre)

(7) Mein Style, Klamottenstyle ist schon relativ individuell [...]. Sich den Leuten anzupassen, fand ich generell schon recht lächerlich, wenn alle mit den gleichen Klamotten rumlaufen. Ich ziehe eigentlich an, worauf ich Lust habe. Und es interessiert mich eigentlich auch nicht so viel, was Leute über mich denken, wenn sie mich sehen oder so. [...] Ich trage eher lässige, schlabbernde Klamotten, die zu groß sind. Auch eher so Jogginghosen und so viel zu große Pullis. (weiblich, 15 Jahre)

( I I hehe in Secondhandläden. Ich hole mir sehr selten neue Klamotten. (weiblich, 16 Jahre)

( Also worauf ich mich auf jeden Fall freue immer, also die Spontanität auch einfach Sachen zu erleben, die man nicht jeden Tag erlebt, wenn irgend etwas Unerwartetes passiert. Das kann was Schlimmes sein, aber das kann auch was Schönes sein, einfach wo man sagen kann, ja, jetzt habe ich was erlebt heute. (männlich, 17 Jahre)

Samstag ist man vielleicht auch nochmal feiern gegangen. Und dann Sonntag war eigentlich immer so ausnüchtern, runterkommen, so schauen, was auch so für die Schule zu machen ist. (weiblich, 15 Jahre) 
(1) Wenn ich mal einen Jungen habe, der mit Barbies spielt oder schwul ist oder meine Stöckelschuhe trägt, ist das kein Ding. (weiblich, 16 Jahre)

( ICh wäre lieber so jemand wie der professionelle LoL-Spieler Gosu. Den hat noch niemand jemals gesehen außer seinem Team. Keiner kennt sein Gesicht. Das finde ich cool. (weiblich, 16 Jahre)

(7) Also ich bin eigentlich jemand, der weniger Hausaufgaben macht, aber wenn es halt wirklich was Wichtiges ist, wie zum Beispiel in meinen Leistungskursen in Kunst, wo man echt viel Hausaufgaben auf hat, ja, dann mache ich sie halt. (weiblich, 17 Jahre)

(7) Als Blockupy stattgefunden hatte, da habe ich mich wirklich komplett mit dieser Mache befasst, von der ganzen Weise, wie halt die EZB vorgeht. Da waren wir halt wirklich in der Klasse beim Liveticker - ,Was ist momentan los?' Das war wirklich ein Ereignis, wo teilweise geschockt war, aber was auch wirklich mir eine andere Denkweise gegeben hat gegenüber Kapitalismus. Das war auf jeden Fall in der letzten Zeit was, was mich auch so ein bisschen geprägt hat. Da habe ich angefangen, mehr über Politik nachzudenken. (männlich, 17 Jahre)

\subsubsection{Zukunftsvorstellungen}

Die Zukunft spielt im Mindset der Experimentalistischen Hedonisten noch keine große Rolle. Man findet zwar spannend, was da so kommen mag, lässt den Dingen aber lieber ihren Lauf, als sie bis ins Detail zu planen und sich damit selbst jegliche Möglichkeit zur Spontaneität zu nehmen. Wenn man noch keine konkreten Ideen hat, stresst man sich nicht sonderlich. Wichtig ist jedenfalls, dass es nicht langweilig werden darf.

In den Zukunftsvisionen spielen Paarbeziehungen und Familiengründung zwar eine wichtige Rolle, man möchte aber nicht, dass künftig die eigene Unabhängigkeit und Freiheit darunter leidet. 
Auszüge aus Hausaufgabenheften:

WIE MÖCHTEST DU SPÄTER LEBEN? WAS MACHST DU DANN?

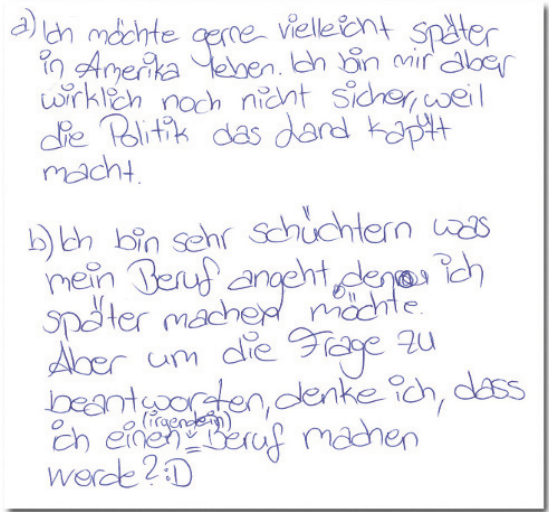

a) Ith moichte gerne vielleicht spatter in Amerika leben. Ion bin mir aber wirklich noch nicht sicher, weil die Politik das dand kaptt macht

b) Ich bin sehr schuchtern was mein Beruf angeht denor ich später macheld móchte. Aber um die Frage zu beantworten, denke ich dass werde?:D
Ich modite am liebsten mit meinem Freund in einer sußen wohnung in Friednishain leben. Vielleicht auch mit Kindem, aber dariber zerbreche ich mir noch nicht jetzt den kapt Ich mochle Reiren longueiligen Burojob haben, sondem mich fereatir ausleben Rönnen und mit vielen Mensehen in Kontekt sein. Am liebsten wurde ich ganz viel gleichzeitig machen. Als Moderatorn arbeiten, nebenbei schreiben und meiner Leidenschaft, Fitness, nachgehen. Anf schauspielern oder selbst Filme zo produzieren. biatte ich auch gust.

Wichtig ist vielen, möglichst schnell eine eigene Wohnung oder Wohngemeinschaft zu beziehen - am liebsten in einem Szeneviertel der Kreativen und (Überlebens-)Künstler.

Dass man als Erwachsener den Fuß vom Gaspedal nimmt, kommt für die Experimentalistischen Hedonisten nicht in Frage. Auch im (hohen) Alter möchte man sich jugendlichen Eigensinn bewahren und das Leben bis zum letzten Atemzug voll auskosten ("Young till I die").

Viel wichtiger als Karriere ist die Möglichkeit zur Selbstentfaltung, beruflich wie privat. Vielen graust es regelrecht vor Routinen und erwartetem Leistungsdruck der Arbeitswelt. Daher sympathisiert man mit einem Leben als Freelancer oder Eigentümer eines kleinen Betriebes, in dem man selbst der Chef ist und das Tempo und Pensum vorgeben kann. Man wünscht sich, im besten Fall die Freizeitinteressen zum Beruf zu machen. Einige versuchen auch, den Eintritt in den Beruf ("den Ernst des Lebens") noch möglichst weit hinauszuzögern, in dem sie Zeit in Bildung investieren (Zweitstudium, Langzeitstudium etc.).

Typische Zitate zur |llustration
Meine Zukunft sicher zu planen, mag ich gar nicht, weil ich eben total spontan bin und es gerne mag, Entscheidungen sehr kurzfristig zu treffen. (weiblich, 17 Jahre) 
( Ich habe immer noch keine wirkliche Richtung, was ich mal später irgendwie werden will. Es interessiert mich schon, aber auch wieder nicht so, dass ich mich wirklich zuhause hinsetze und mich wirklich damit befasse. (männlich, 17 Jahre)

Sobald ich mit der Schule fertig bin, werde ich sofort meine Sachen packen und eine eigene Wohnung wahrscheinlich nehmen. [...] Prenzlauer Berg, wobei es echt teuer ist, aber ich finde auch Friedrichshain richtig cool, generell Friedrichshain, Kreuzberg, Mitte. (weiblich, 17 Jahre)

I Ich weiß, dass ich das Fachabi noch machen will nach dem Realschulabschluss. Aber das mache ich größtenteils deswegen, weil ich nicht weiß, was ich in zwei Jahren machen würde. Ich habe noch keine Ahnung. Ich könnte mich auch dieses oder nächstes Jahr noch nicht bewerben, und ich würde auch nicht irgend etwas nehmen, was ich dann bereue. Deswegen lasse ich mir lieber noch ein bisschen Zeit. (weiblich, 16 Jahre)

( Ich bin ehrlich gesagt froh, wenn ich auf eigenen Beinen stehe und nicht mehr zuhause bin. [...] Ich fühle mich eingeschränkt in der Hinsicht, dass ich eben nicht alles so einrichten kann, wie ich möchte, dass ich das nicht alleine planen kann mit dem Abwasch und sonst was und dass mir immer vorgeschrieben wird, wer was macht. (weiblich, 17 Jahre)

( Ich liebe so Styling, Haare machen und alles. Aber es wird schon anstrengend den ganzen Tag bei der Arbeit zu sein. Und ich denke auch, dass es da ein bisschen anstrengende Kunden teilweise gibt. [...] Ja, und ich brauche das auch einfach als Grundausbildung, wenn ich zum Beispiel Kosmetikerin oder Stylistin machen möchte oder Maskenbildnerin. Ich hab das Ziel, einen eigenen Salon zu haben. [...] Als Frisör verdient man ja natürlich nicht viel, aber wenn ich dann auch einen Meister mach, wird das, glaube ich, schon sehr gut passen. (weiblich, 15 Jahre)

[INT: WAS GLAUBST DU DENN, WAS WIRST DU DENN MAL SO FÜR EIN MensCh SEIN?] Ein etwas fauler Mensch, der so in den Tag reinlebt, auch wenn er einen Beruf hat. Der später hoffentlich im Musik-Business sein wird oder halt in die Richtung. (männlich, 17 Jahre) 
( Ich will auf jeden Fall die coolste Oma aller Zeiten werden. Ich will mit 80 einen Roadtrip auf der Route 66 mit einem Bike machen. Und dann möchte ich verhaftet werden. Und ich möchte etwas klauen und dann behaupten, ich habe Alzheimer, ich kann mich an gar nichts erinnern. Und ich möchte Leute anmeckern, nur weil ich alt bin. [...] Vor allem will ich mich als Oma unbedingt nochmal tätowieren lassen. Also ich will auch vorher schon Tattoos, aber als Oma will ich unbedingt nochmal eins. (weiblich, 17 Jahre)

\subsubsection{Kulturelle Orientierung, Freizeit}

Freizeit ist für diese Jugendlichen in erster Linie Raum für kreative Selbstverwirklichung: Erlernen neuer Skateboard-Tricks, Spielen in einer Band, Nähen von eigenen Klamotten, Fotografieren, Zeichnen und Malen (z. B. im Rahmen einer Manga- oder Graffiti-Szene), sich selbst ein Musikinstrument beibringen, Video- und Bildbearbeitung für Material, das sie im Internet veröffentlichen. In ihren Freizeitaktivitäten zeigen sie einige Eigenschaften, von denen Experimentalistische Hedonisten behaupten, dass sie ihnen im schulischen Alltag abgehen: Ausdauer, Ehrgeiz, Zielstrebigkeit und auch Disziplin. Sobald sie eine Passion für eine Sache entwickeln, sind sie mit Herzblut dabei.

Experimentalistische Hedonisten beginnen schon früh, sich für subkulturelle Nischen und den Reiz des Verbotenen zu begeistern. Sie sind stark auf Abgrenzung von den "Normalos" und Jugendlichen in anderen Szenen bedacht. Unter ihnen finden sich viele Jugendliche mit einer großen Lust am Abseitigen, am Trash, am Schockierenden, am Kultigen, am Exzentrischen und bisweilen Plakativ-Geistlosen (z. B. B-Movies). Mit dem Massentauglichen und Domestizierten fangen Experimentalistische Hedonisten kaum etwas an.

Die kulturellen Interessen sowie der eigene Style haben häufig einen klaren Szenebezug. Dabei ist ihnen wichtig, dass sie tief in die Szenen eintauchen, also "nicht nur konsumieren“, sondern auch die szenespezifischen Lebenseinstellungen für sich erproben. So hört z. B. eine Experimentalistische Hedonistin, die eine Vorliebe für Mangas hat, auch 
vorwiegend japanischen oder koreanischen Rock und Pop, schaut sich asiatische Spielfilme an und versucht sich am Zeichnen eigener Mangas.

Experimentalistische Hedonisten verfügen über ein hohes Maß an szenebezogenem Expertenwissen im Besonderen und Popkultur im Allgemeinen. Dieses Wissen vertiefen sie durch Internet-Recherchen oder Lesen von "Szeneliteratur". Es ist " ihr" kulturelles Kapital, das seinen Wert durch die Distanz zur klassischen Hochkultur schöpft. Sie wissen, dass Erwachsene und viele Gleichaltrige gleichermaßen von ihren Ausdrucksformen und kulturellen Vorlieben nichts verstehen können, weil die Aneignung der entsprechenden ästhetischen Codes und Wissensbestände abseits klassischer Bildungseinrichtungen stattfindet. Man ist froh, kulturelle Freiräume zu haben. Wichtig ist auch, Events von und mit Gleichgesinnten zu besuchen (z. B. Games-Messen, Konzerte).

Vorbilder sind häufig Schlüsselpersonen aus den Szenen, für die sie sich interessieren (z. B. Musiker wie Bob Marley, Kurt Cobain, Eminem). Auch unangepasste Personen der Zeitgeschichte findet man spannend (z. B. Ghandi).

Auszüge aus Hausaufgabenheften: WofÜR INTERESSIERST Du DICH?

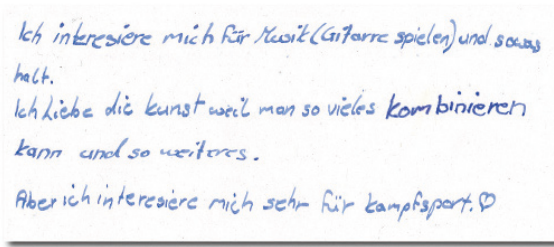

Korea Jopan, Sprachen, Musik, fashion, stylinf, musere Galaxy, Ge schichte, Politik, unwertsomitz, chrenautliche Arbat, rocken

thpltoplRap, gesundes Essen, Fitness, Mode, Sprechen, Beauty, Soziale Medien wie Instegram, YouTube, Facebook, meine zukunft und mich selbst, sex, Moderetionsjobs, Zertschisten, feien, Festivals, cocketerils, Hunde \& kertzen, snedeer..

$$
\begin{aligned}
& \text { Tanzen } \\
& \text { Mosik }
\end{aligned}
$$


Auszüge aus Hausaufgabenheften:

Nenne eine erwachsene Person: A) Deren Lebensgeschichte Du Dir gerne ERZÄHLEN LASSEN WÜRDEST. B) VON DER DU GERNE WAS LERNEN WÜRDEST.

a) Eminem. Aber ouf Deutich, damit ich auch alles zo $100 \%$ verstele

b) lch wurde geme auch in Zuteunft von mir selbst lemen. Wem ich von anderen lemen mölite, kamn ich sie ja einfech fragen. Das ist eangweilig. Von sich selbst lemen lingegen, kostet eine Menge zeit. Erfehrongen, Tehler, Tranen und auch schone Momente.

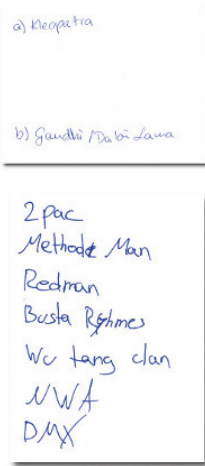

Q) ich warde gerne ebwas über Eminems cebensgeschichte hören. Er istr für mich eive sehr bedentende Person, weil er viele sachen durdigemaeht hat, die idn aud durdigenadit hab. b) Ebenfalls Eminem, da idigerve lerven warde, wie er trotz seiver vergongenheit, wie Aufgegeben hat and inmer an sich geglaubt lat, egal was andere gesagt haben. id finde das mega stark.

Die Experimentalistischen Hedonisten haben oft einen sehr differenzierten Musikgeschmack. Sie benennen verschiedene Genres, suchen gezielt nach neuer Musik, sind dabei auch sehr an neuen, experimentellen Musikstilen interessiert. Künstlerische Grenzüberschreitungen und Provokation finden sie gut.

\section{Auszüge aus Hausaufgabenheften: WAS HÖRST DU GERNE FÜR MUSIK?}

Ich hore hauptsächlich thp Hop, RnB und Trep. Hin und wieder ench etwes Reggae oder Pop, aber das keommt elor selten vor Enen dieblingsmusitzer habe ich nicht. konnte micle bei den ganzen guten Kunstlem einfach nicht entscheiden. Dazu gehoren zum Beispiel Kendrick Lamar, Dralee, I cole, Eminem, Kanye West, Pusha T, Jay Z. Joey Bada \$ \&a Rremmurd, ASAP Rockey, Scttoolboy Q, Lupe Fiasco, French Montana Danny Brown, Travit Scott, Flathash Zombies, Isciah Rashad, The Underaclievers, G-Eazy, Odd Future Wolftrang, Lil Wayne, Cluedish Gambino, Little Simz. Boogie, Vince Staples, Dipset, Skepth, Denzel Curry, Young simmie, The weelend, SBTRUT, thene Ako, Curren Sy, Rick Ross, Mac Mieler, Kellani, SCA, Chance The Rapper, Action Bronson Franke Ocean, PARTYINEXTDOoR und so weite und so fort. Zum Gluck reidat glench der Platz nicht mehr
Da ich ein alsoluter nusiffan bin, bin ich piir alle weviknichtengen offen und häre vor allem viel postHardeore-Metal, Trash Motal, Techno, DoutsadRap und Altema tive- Indie Rock. wax ich ïberhaupt nicht hivenkam, istder ganze mainstream-Poy, welcher tagriaglich in Radio raut und ranter lault.

Lieblingsüntler: Bring ne the horizon Metullica Enter Shinai cosper Paut kalkbremer Suenväth R.1.2. Billy Talent 
Auszüge aus Hausaufgabenheften: WAS SIND DEINE LIEBLINGSFILME UND -SERIEN?

\begin{abstract}
Meine Lieblinesserle ist Skius. Aber unr die britische Fassung. Im Femsehen

schane ich oft Two and a half wen, how I wet your mother, Mike and Molly oder Big Bang Theory. Mein Ciebiling film ist Straight Outta compton der bald im deutschen kive ausgestrahlt wird!
\end{abstract}

How High street Style stomp the Yard

Meine lieblingstilme sind Inception und Intersfellar von Christopher Nolan und die Fulme "der Herr der Ringo Triologio.

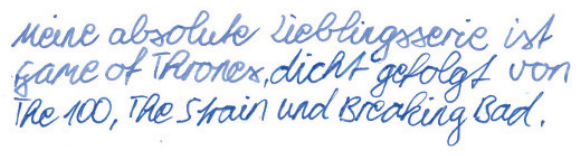

Von der klassischen Hochkultur und deren Einrichtungen (klassische Oper, Theater, Museen) distanzieren sich Experimentalistische Hedonisten deutlich ("Mozart und so"). Im Hinblick auf ihre kulturelle Orientierung nehmen diese Jugendlichen eine sehr klare Position ein. Es werden strikte Grenzen gezogen, die kaum verhandelbar sind.

(7) Ich würde schon sagen, dass ich individuell bin, auch so von den Sachen, die mich interessieren. Ich kenne zum Beispiel ein, zwei Leute bloß, die auch die Serie gucken, die ich gucke. Oder die Musik, die ich höre, die

Typische Zitate zur Illustration hören auch nicht viele. Die meisten hören Charts und so etwas, aber ich finde, da klingt alles gleich. Das ist nicht so meins, diese Musik. (weiblich, 16 Jahre)

ICh höre wirklich nicht das, was die ganze Zeit im Radio läuft, weil es mich einfach nur nervt. (männlich, 17 Jahre)

(1)h laufe oft locker herum mit so einem dicken T-Shirt, also wie der HipHop-Style in Amerika zum Beispiel. Das finde ich voll schön. Das gefällt mir. Aber das gehört auch irgendwie zu meiner Tanzrichtung, Breakdance. (männlich, 17 Jahre) 
Bei uns gibt es ein paar Zehntklässler, die gucken mich immer schief an und sagen zu mir: lih, das ist hässlich! Aber ich habe auch nie mit denen geredet oder so. Die finden mich seit dem ersten Tag an schon scheiße, und das war mir eigentlich auch immer relativ. Ich ziehe an, was mir gefällt, und wenn es denen nicht gefällt, ist das ja nicht mein Problem. (weiblich, 14 Jahre)

(7) Ich bin auch viel im Internet unterwegs und gucke, was sind so Newcomer-Bands hier in Deutschland, dann höre ich mir immer die Lieder an und auf einmal macht es klick und mir gefällt das ganze Album. Dann sage ich immer zu meinen Freunden: ,Ey, hört euch mal die an, supportet die mal ein bisschen auf Facebook.' Ich gucke wirklich die ganze Zeit nach, was es für neue Musik gibt. Auch komplett neue Musiksparten, also Reggae-Metal bis hin zu, was weiß ich. (männlich, 17 Jahre)

( Als ich meiner Mutter erzählte, dass ich jetzt Mangas lese und Animes schaue, war sie entsetzt. [...] Ich glaube, viele Menschen haben ein falsches Bild von der ganzen Materie. Das ist von Asien hier herüber geschwappt, und viele dachten sich, das gebe ich mir nicht. Das ist was für 18+. Aber wenn man die richtigen und vor allem die neuen Animes kennt, weiß man genau, das ist nichts für Kinder. Aber nicht wegen der Erotik, sondern wegen der Splasher und dem Blut. Das klingt jetzt gewalttätig, ist es aber nicht. Und es kämpft auch immer nur einer gegen einen. Das sieht man auch in der Welt. Da haben wir den IS und alles. Alle sagen immer nur, dass es total schlimm ist. Neulich sagte eine sogar, das ist doch Satanismus. (weiblich, 16 Jahre)

8 Ich bin sehr von Asien begeistert. [INT: Du LIEST AUCH GERN MANGAS?] $J a$, ich lese ganz viel Mangas. Und ich höre auch viel K-Pop. Ich bin auf diesem Gebiet arg aktiv. Und ich lerne nebenher auch ein bisschen japanisch und koreanisch. Und chinesisch habe ich ja auch in der Schule. [...] Ich mache auch Cosplay. Ich habe hier auch ein Foto von der letzten Gamescom in Ludwigshafen. Ich wollte eine Maid machen. Aber eine einfache Maid ist ja langweilig. Das macht ja jeder. Also habe ich die tote Maid gemacht. Die fanden das dann alle cool. (weiblich, 16 Jahre)

Ich lese mehr irgendwelche Zeitungsartikel im Internet oder irgendwelche Blog-Einträge oder meine Lieblingszeitschrift, die Juice, weil es eben auch um Hip-Hop und Rap geht. (weiblich, 17 Jahre) 
(7) Also wenn es um Musik geht, dann stecke ich da echt viel Zeit rein. Ich habe alle meine Künstler auf Playlists gepackt, damit ich das immer parat habe. (weiblich, 17 Jahre)

(7) Ich hasse shoppen abgrundtief. Das ist Käse. Man geht hin, gibt Geld aus, was man nicht ausgeben will, kommt nach Hause und denkt sich: Scheiße. Wenn ich shoppen gehe, dann weiß ich genau, was ich will. Ich gehe in den Laden rein, hole mir das und gehe gleich wieder raus. Zehn Minuten und fertig ist es. Ich habe auch nur drei Paar Schuhe. Ich bin wohl die Einzige in meinem Freundeskreis, die nicht gern shoppen geht. (weiblich, 16 Jahre)

(7) Hip-Hop ist für mich, dass man den Lifestyle auch lebt, von dem gesungen wird. Dass man sich so anzieht, sich der Texte annimmt, die Musik viel hört. (weiblich, 16 Jahre)

(7) Ich finde an den 1990ern gut, dass sie rebelliert haben und gesagt haben, was sie denken, auch gegen die Polizei, weil die ja früher mit ganz schöner Brutalität auch gegen die Schwarzen vorgegangen sind. Das finde ich gut, dass sie das in ihrer Musik zum Ausdruck bringen. (weiblich, 16 Jahre)

( Am liebsten fahre ich Longboard, das ist etwas, was ich wirklich ständig machen könnte. Einfach raus mit dem Longboard und mit ein paar Kumpels fahren. (weiblich, 14 Jahre)

\subsubsection{Vergemeinschaftung}

Aufgrund ihrer starken Anbindung an Jugendszenen verfügen Experimentalistische Hedonisten oft über einen großen Freundes- und Bekanntenkreis. In der Peergroup haben die meisten die gleichen Interessen und Vorlieben.

Die eigenen Freunde beschreibt man als lustige, verrückte, ironische, manchmal auch als sarkastische Menschen. Für "Streber" ist im Freundeskreis der Experimentalistischen Hedonisten kein Platz. Man mag Außenseiter, mit denen man immer mal wieder auch etwas Nervenkitzel 
in der Freizeit haben kann. Von den "Normalos" und den "Leuten mit viel bling bling" distanziert man sich hingegen. Die Experimentalistischen Hedonisten haben einen feinen "Marken-Sensor", d. h. sie wissen, welche Marken in ihrem Umfeld "klargehen" und welche nicht. Besonders deutlich grenzt man sich von Leuten ab, die die klassischen Luxus-Marken (Louis Vuitton etc.) tragen ("voll peinlich“, "Angeber").

Experimentalistische Hedonisten haben oft typische "Hangouts" - Orte, wo sie mit hoher Wahrscheinlichkeit auf Gleichgesinnte treffen (Jugendhäuser, Festivals, Szenecafés etc.). Häufig vergemeinschaften sie sich im öffentlichen Raum, weil sie auffallen möchten. Auch Jugendhäuser stehen hoch in ihrer Gunst. An Jugendhäusern schätzt man die Gemeinschaft und die Möglichkeit, sich mit eigensinnigen und eigenwilligen Projekten einbringen zu können und ernst genommen zu werden. Experimentalistische Hedonisten finden es jedoch langweilig, die eigene Freizeit immer am gleichen Ort zu verbringen. Abwechslung und Bewegung ist ihnen wichtig. So zieht man gerne einfach durch die Gegend, lässt sich treiben. Sie mögen Orte, wo sich nicht die breite Masse trifft. Beliebt sind auch Wohnungen von Freunden, die bereits ausgezogen sind - die Eltern somit nicht stressen können.

Insbesondere die Jugendlichen, die sich in einer Szene vergemeinschaften, zeichnen sich durch ein hohes Maß an Binnenkommunikation aus. Man ist innerhalb der Szene sehr gut vernetzt und nutzt sämtliche Kanäle, um Kontakt zu halten. Gerade Jugendliche, die in ländlichen Gegenden leben und spezifischen Szenen angehören, kommunizieren online über die gängigen und szenespezifischen Plattformen. Wichtig ist, sich mit Jugendlichen auszutauschen, "die einen verstehen", die die eigenen Ansichten teilen, die wissen, „warum man eine bestimmte Mütze auf eine ganz bestimmte Art und Weise trägt" - also mit Jugendlichen, die die Codes der Szene kennen. 
Mit Leuten, die sich wirklich nur für Noten interessieren und über nichts anderes reden können und nur am Lernen sind. Mit solchen Leuten kann ich nicht viel anfangen. So etwas würde mich stören. Ich will ja auch mal abschalten von der Schule, wenn ich da schon den ganzen Tag drin sitze. (weiblich, 16 Jahre)

(7) Ich finde, Kiffer an sich sind eine komplett eigene Gesellschaft. Das sind komplett andere Leute. Natürlich ist es ein Nervenkitzel, weil es spannend ist, weil es illegal ist. So ein großes Thema ist es jetzt nicht wirklich, aber ja. [INT: FüHLST DU DICH DENN AUCH DIESER SZENE ZUGEHÖRIG? ODER ERLEBST DU DAS NUR SO MIT?] Also schon ein wenig, also nicht wirklich, aber ich habe mit den Leuten zu tun, und sie sind auch teilweise meine Freunde, ja. (weiblich, 15 Jahre)

( Wir haben keine Lust, uns so ein Eck zu machen und in irgendeinen Club zu fahren. Und dann kauft man sich ein Bier mit ein paar Leuten und zieht entweder so umher, so Wandersaufen zum Beispiel, oder man geht auf Haus-Parties. (weiblich, 15 Jahre)

( Also zu ein paar Leuten kann man immer hingehen und dann da chillen [...]. Bei einer Freundin zum Beispiel, die wohnt hier zehn Minuten entfernt, da kann man sich auch hinchillen, die hat eine Schmiede, da kann man sich reinhartzen, das ist sowas wie ein Raucherkeller sozusagen, und da kann man entspannt sitzen und sich die ganze Zeit unterhalten. (weiblich, 15 Jahre)

[INT: UND WAS SIND ZUM BEISPIEL LEUTE, DIE DU GAR NICHT MAGST? WIE SIND DIE?] Hm, verklemmt oder pöbeln oder lügen die ganze Zeit, also labern irgendeine Scheiße oder billige Mädchen, pack ich auch gar nicht. Die schmeißen sich an irgendwelche Kerle ran und tragen einfach den Burner-Ausschnitt, die kürzesten Hosen und lauter so Sachen. (weiblich, 15 Jahre)

[INT: Wie würdest Du Deinen Freundeskreis beschreiben?] Hm, weiß ich nicht... lustig oder hm... verrückt vielleicht, individuell. Ich habe zum Beispiel einen Freund, der macht irgendwelche komplett komische Scheiße, die dann echt witzig ist. (weiblich, 15 Jahre) 


\section{Wenn ich dann immer die Leute in meiner Schule sehe mit Louis Vuitton} Täschchen und Gucci hier, Prada da, das ist nochmal eine ganz andere Welt [...] und das finde ich ganz ganz furchtbar. (weiblich, 17 Jahre)

(7INT: WIE SIND DENN SO LEUTE DRAUF, DIE DU NICHT MAGST?] DasS man einfach nur nach Geld geht. Also dass man wirklich nur sagt: ,Ich bin jetzt cool, weil ich das da anhabe und weil ich auf die Festivals gehe oder weil ich mir das da jetzt anhöre.' Die sollen sich lieber mal mit was anderem befassen und halt mehr so ein bisschen die Welt entdecken und nicht nur auf das hören, was andere ihnen vormachen oder was cool ist. (männlich, 17 Jahre)

(7) Also meine zwei besten Freundinnen, die kenne ich vom Feiern und uns hat verbunden, dass wir alle so spontan sind und mutig. [INT: WAS MEINST DU MIT MUTIG?] Zum Beispiel bei diesem Schwimmbad-Einbruch, da habe ich meine beste Freundin kennengelernt. [...] Wir waren 15 Leute, glaube ich, und meine beste Freundin und ich waren die einzigen, die dann auch wirklich schwimmen gegangen sind, die einfach alles ausgezogen haben, reingesprungen sind und dann hatten wir eine super schöne Zeit zusammen. (weiblich, 17 Jahre)

[INT: WIE SIND DENN LEUTE, DIE DU ÜBERHAUPT NICHT ABKANNST?] Also ich könnte jetzt eigentlich ganz viele Leute aus meiner Schule beschreiben, die sehr oberflächlich sind, sehr auf Marken fixiert sind und sich damit profilieren. (weiblich, 17 Jahre)

Entweder man akzeptiert mich so, wie ich bin - oder man kann gehen. Ich brauche solche Leute nicht. Ich glaube, ich bin dabei sehr strikt. Aber umso enger ist dann auch mein Freundeskreis. (weiblich, 16 Jahre)

( Also wir haben letztes Jahr auf dem Splash-Festival Leute kennengelernt, und mit denen sind wir dieses Jahr wieder gefahren. Wir haben auch noch Neue dazu kennengelernt, am Ende waren es wirklich 20 Leute, mit denen wir da gezeltet haben. Und die haben dann natürlich alle den gleichen Musikgeschmack. (weiblich, 17 Jahre) 


\subsection{Sozialökologische}

Die nachhaltigkeits- und gemeinwohlorientierten Jugendlichen mit sozialkritischer Grundhaltung und Offenheit für alternative Lebensentwürfe

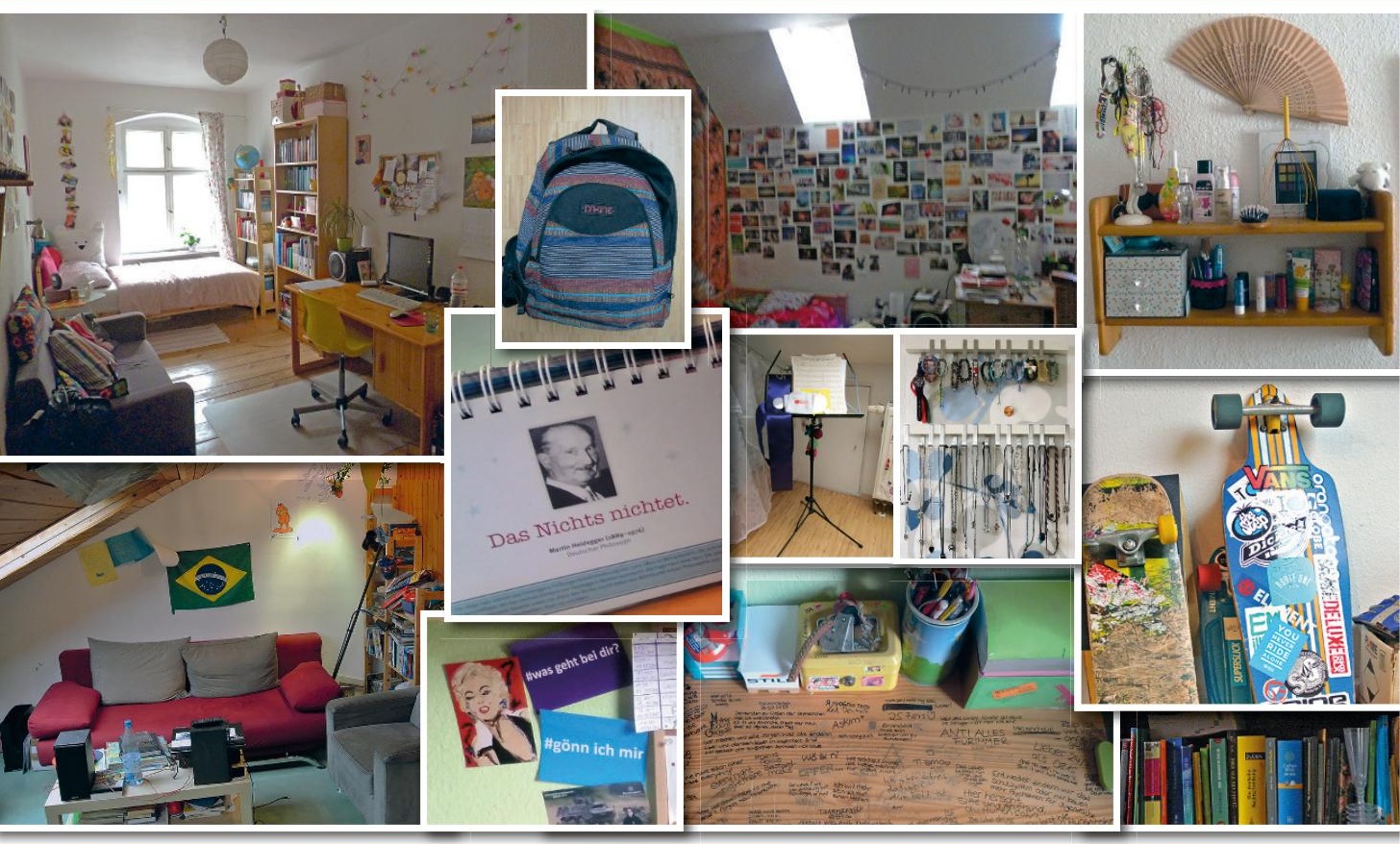

3.6.1 Lebensweltliche Basisorientierungen

Sozialökologische Jugendliche formulieren bereits recht deutlich den für sie relevanten, stark postmateriell geprägten Wertekatalog: Demokratie, Freiheit, Pazifismus, Toleranz, Gerechtigkeit, Gleichberechtigung aller Lebensweisen, Sorgsamkeit gegenüber Mensch, Tier und Umwelt sowie Nachhaltigkeit sind Maximen, nach denen sie ihr Leben ausrichten wollen. Sie haben ein vergleichsweise starkes "Sendungsbewusstsein" 
- andere von ihren Ansichten zu überzeugen, ist ihnen wichtig. Entsprechend typisch ist es daher, dass Sozialökologische sich als Schüler- bzw. Klassensprecher oder für Sozialprojekte engagieren oder bei Poetry Slams oder Debattierclubs mitmachen.

Solidarität ist ein weiterer wichtiger Wert. Man reflektiert die eigene meist sozial privilegierte Position in der Gesellschaft und fordert vor diesem Hintergrund Chancengleichheit für alle. Man sieht sich verpflichtet, Verantwortung für die vermeintlich Schwächeren zu übernehmen und deren Rechte einzufordern. Erfolg definieren viele nicht über persönliche Karriere, sondern darüber, was man Gutes in der Welt tut. Sozialökologische Jugendliche sind sehr altruistisch motiviert und am Gemeinwohl orientiert. Sie sind von der Gleichheit der Menschen überzeugt und wünschen sich, dass dies nicht nur auf dem Papier, sondern in der Wirklichkeit Bedeutung hat. Sie sind aufgeschlossen für andere Kulturen und empfinden Abscheu, wenn Menschen wegen ihres Aussehens nicht akzeptiert werden und „ein Keil zwischen die Menschen getrieben" wird. Ganz eindeutig ist die Ablehnung von Arroganz und Rassismus sowie von „aufgesetzten Szene-Leuten“.

Wohnbilder Sozialökologische Lebenswelt

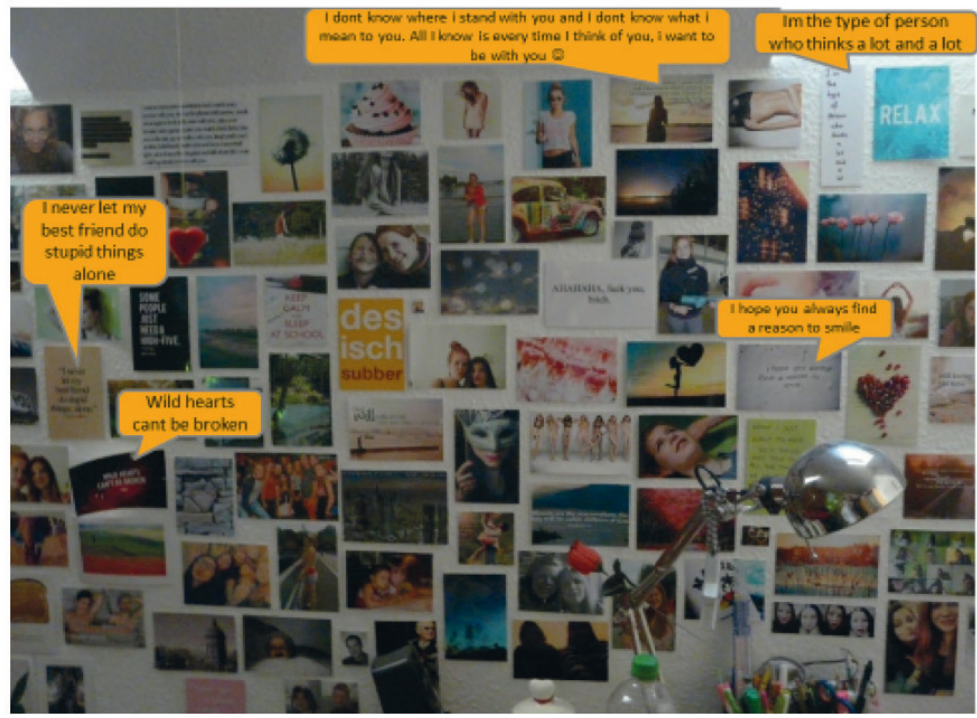


Sozialökologische Jugendliche verfügen über ein großes Repertoire sozial- und systemkritischer Positionen. Man empfindet Sympathie und Solidarität mit einer - etwas romantisch verklärten - "Unterschicht". Man übt teilweise fundamentale Kritik am politischen und sozialen System und befürwortet Bürgerprotest, lehnt jedoch "Stress" und Rechtswidrigkeiten ab. Einige pflegen die traditionelle postmaterielle amerikakritische Grundhaltung.

Die Sozialökologischen Jugendlichen bewundern glückliche Menschen, die selbstbestimmt das Leben genießen, ihren eigenen Idealen folgen, ihre Träume leben und sich nicht "vom großen Geld" leiten lassen. Vorbilder sind einerseits häufig Intellektuelle (Schriftsteller, Künstler, Politiker etc. der Zeitgeschichte) oder Alltagshelden und Überlebenskünstler, die trotz widriger Umstände das Beste aus ihrem Leben machen. Die Sozialökologischen Mädchen haben besonders großen Respekt vor starken, durchsetzungsfähigen Frauen (aus ihrem Umfeld, aber auch Personen der Zeitgeschichte).

Insbesondere von materialistischen Werten distanziert man sich ausdrücklich. Luxus und materieller Überfluss werden verurteilt, weil sie den

Wohnbilder Sozialökologische Lebenswelt

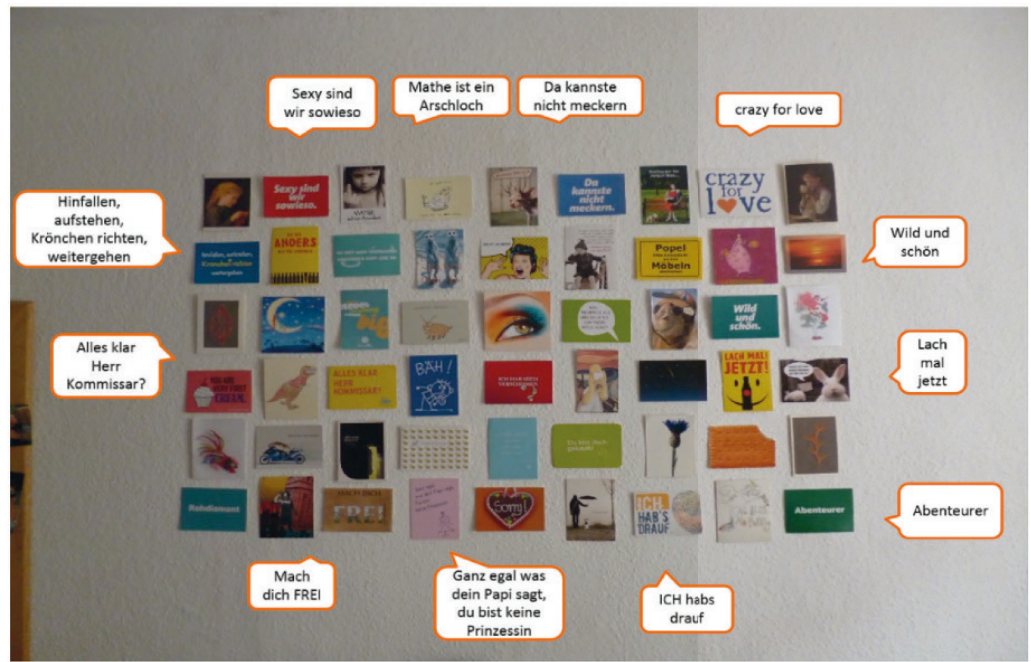


Auszüge aus Hausaufgabenheften: Nenne eine erWachsene Person: A) Deren Lebensgeschichte Du DIR GERNE ERZÄHLEN LASSEN WÜRDEST. B) VON DER DU GERNE WAS LERNEN WÜRDEST.

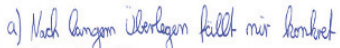
leider heine Persom em dwen felemgerschichte ich germe erfahen wiride. Helerding interemicien mich generell becorden Gendidh con Mensoen, die in Selen auf die rchige Babin geratem sind 2. B. uon Oldach. losen. Suchtronden doder krominellen.

b) Th wrinde geme von der Mutter

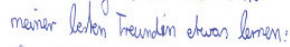

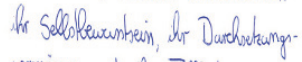
vermogen wnd ihe Taftheit. a) kebendin Meine Urana (95)

$\rightarrow$ ken würde gene ihre eigne soliberung inter Ftucest as der slowatei nach

Dentschiand haren.

a) scew getorben

- Theodor Vleuss

b) - Joachin Gauk,

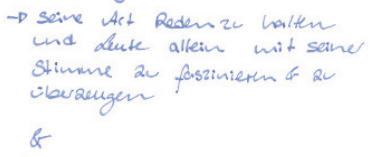

Sandra Butaken

$\rightarrow$ Solrauspieleri
Mir sind dazu jetzt spontan Menschen einge fallen, ohne groß daniber nach zu denten.

a) (ch worde mir gerne die Lebensgeschichte von Ad olf Hitler er zählen lassen. lch findees interessant und zugleich beangstigend, wie ein Mensch sich so eine Meinung bildet und ein Hass gegen Menschen entwickelt, nur weil sie zu einer anderen "Rasse" gehōren.

b) Lernen worde ich gerne etwas von Albert Einstein, da er ein sehr schlaver Mann har und mit vielen Aussagen recht hatte, die er gemacht hat.

einige Sozialökologische betonen demonstrativ, dass der "Markenwahn nervt". Luxus-Markenklamotten haben keine Bedeutung. Extravaganzen belächelt man, gibt es doch weitaus wichtigere Herausforderungen als die Inszenierung des Selbst in der globalisierten Welt.

Auszüge aus Hausaufgabenheften: Wofür INTERESSIERST Du DICH?

- Tiere (Tienrechle / Tienhallung)

- Musih (Goa)

- Reviem

- unternshiedliche Laindar und lalturen

- Prychologie

- Gule Bucher

- Serien

- Meerschueinchen

Treunde

Jung

Jungpgenchiclten meiner Freundinnen

Bucher scheiben

- Musik

- Fotografie

- Gosprache mat interessanten Menschen

- Sport

- karinutie

- Ruttur verschieclever Manschen \& Lander
- För diteratur \&e das Solveiben

- eigne Gedicate

- Bucher a Filme

- Sport

- Volleyball \& Schwimmen F Farstball

- Musik - Quefilizke, Pop

- Debatten (Jugend degattiest)

$\rightarrow$ bin 4 Landessregerin

- Freunde

4 reden, Bider machen, was zusammen unternesmen, lachen

- Reit mit de Familie av veloringen

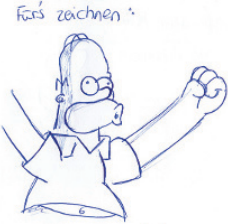

Furs Kendama spieten \& firs long boanden 
Sozialökologische sind sehr bildungsaffine Jugendliche. Ihnen ist es wichtig, ihr Wissen, den eigenen Horizont und die Fertigkeiten zu erweitern. Sie haben großes Interesse an anderen Ländern bzw. Kulturen und globalen Zusammenhängen. Das geht einher mit einem Lernverständnis über das schulische Lernen hinaus; neue Erfahrungen bedeuten für diese Jugendlichen immer auch einen Erkenntnisgewinn im Hinblick auf ihr Weltbild. Dieser Aspekt ist oft vorrangig gegenüber dem Spaßfaktor.

Schule als Bildungsort, an dem die Voraussetzungen für die zukünftige beruflichen Perspektiven geschaffen werden, hat im Alltag der Sozialökologischen Jugendlichen eine hohe Priorität und nimmt viel Zeit ein. Weil man jedoch nicht zu den Strebern gehören will, zeigt man trotz Interesse an einzelnen Schulfächern, hoher Lernbereitschaft und Wissenshunger demonstrativ eine gelassene Distanz zur Schule, insbesondere gegenüber den Mitschülerinnen und Mitschülern.

Sozialökologische Jugendliche wollen gerne an die Wurzel vordringen, wenn sie sich mit einem Thema beschäftigen. So setzt man sich kritisch mit Nachrichten, Konsum oder auch Verschwörungstheorien auseinander. Und auch im Hinblick auf die religiöse Orientierung will man nicht einfach vorgegebenen Glaubenssätzen folgen, sondern den eigenen Glauben ergründen und (er)finden.

Auszüge aus Hausaufgabenheften: WofÜR INTERESSIERST Du DICH?

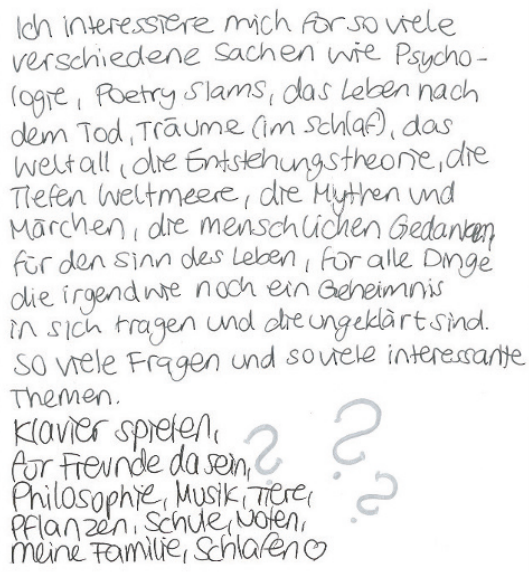


Eltern sind enge Vertraute. Man ist ihnen dankbar für eine schöne Kindheit und die Freiheit, die ihnen von ihren Eltern oft gelassen wurde. Im Alltag spielt die Zeit mit der Familie im Vergleich zu den anderen Aktivitäten aber eine untergeordnete Rolle. Deutlich mehr Zeit wird mit dem Freundeskreis verbracht, den man als genauso wichtig erachtet wie die Familie. Man ist glücklich, wenn die Freunde auch glücklich sind.

( Ich denke sehr sozial. Ich finde Rastalocken schön, ich finde es gut, wie vegetarische Menschen leben und will das vielleicht selber mal ausprobieren. Ich achte auch auf meine Umwelt, wenn jemand einen Becher wegschmeißt, ich so: Heb den bitte auf oder gib ihn mir, ich schmeiß den in den Müll. Ich will auch Blutspenden gehen, und dieses Knochenmark will ich auch spenden. Ich will mir auch später einen Organspendeausweis holen und so etwas. Also, viel für andere leben und für unsere Welt, damit die erhalten bleibt. (weiblich, 15 Jahre)

(1) Da gibt es doch dieses Sprichwort von Ghandi "Sei du selbst die Veränderung, die du dir für diese Welt wünschst", also das finde ich schon eigentlich gut. (weiblich, 17 Jahre)

(1) Wirklich wichtig im Leben ist mir meine Familie, meine Freunde, mein Glauben und dass ich frei bin, also dass ich nicht eingesperrt bin. Egal ob das in einer Zelle ist oder in Sachen Meinungsfreiheit. (männlich, 15 Jahre)

(7) Also wenn ich jetzt meiner Kreativität einfach mal freien Lauf lassen würde, dann würde ich am liebsten mit dem Wohnmobil fahren. Das finde ich ziemlich cool. Ich hätte sowas auch ganz gerne. Hinten einen Wohnwagen dran und vorne einfach fahren, das finde ich am praktischsten und am abenteuerlichsten. (weiblich, 16 Jahre)

Ich liebe verreisen. Auch super gerne weltweit. (weiblich, 16 Jahre)

( Ich finde halt, das ist interessant mit den Kulturen, wie die Leute so leben und die Traditionen und so. Also ich glaube, in fast allen Ländern und Kontinenten ist das anders als hier. Weil ja jeder eine andere Kultur hat. Und die Menschen kennenlernen und so. Also wir sind ja irgendwie da so schon verwöhnt. Zum Beispiel, wenn man jetzt nach Indien 
oder so gehen würde, es gibt Leute, die auch mit weniger glücklich sind. Sowas finde ich interessant und schön zu beobachten. (weiblich, 17 Jahre)

( Also ich mag es so Reden zu halten, Leute zu überzeugen, auch gerade "Jugend debattiert", oder ich bin ja auch Schülersprecherin. Ich mag es einfach, mit der deutschen Sprache umzugehen. Ich habe auch ein paar Gedichte geschrieben. Die haben auch etwas gewonnen beim JugendLyrik-Preis in Stuttgart. Ich würde jetzt nicht sagen, dass ich jetzt so voll, keine Ahnung, nur auf Gedichte und Lyrik stehe, aber so ein bisschen cool ist es schon. (weiblich, 16 Jahre)

( Weil ich ja ein Teil der Gesellschaft bin, und dann gehöre ich ja dazu, und dann interessiert es mich eben auch, darüber zu reden und meine Meinung dazu zu äußern. (weiblich, 15 Jahre)

Und auch trotzdem finde ich, ist es so, dass Frauen immer noch als Sexobjekt gesehen werden und die Werbung so viel falsch macht, das geht gar nicht. Das ist einfach sexistisch bis zum geht nicht mehr, dass man nur junge schöne Frauen im Fernsehen sieht. Und generell sind überall Brüste und Pos zu sehen, egal worum es geht [...]. Und die ganzen Klischees auch, dass das Mädchen klein und zart sein soll [...]. Das finde ich kacke. (weiblich, 16 Jahre)

( Damals, als diese Wörter Hipster und so aufkamen, wollte ich immer mit der Mode gehen und immer das Neueste tragen. Aber jetzt ist mir das so ziemlich egal geworden. Ich habe meinen eigenen Kleidungsstil. Ich kann den jetzt nicht so einer Gruppe zuordnen, aber ich trage eben das, was mir gefällt und was mir bequem ist. (weiblich, 15 Jahre).

Ich habe einen richtig schlimmen Eisenmangel, so dass der schon nicht mehr messbar ist. Und deswegen muss ich manchmal Fleisch essen, aber das versuche ich so selten wie möglich zu machen. (weiblich, 16 Jahre)

Also ich muss sagen, Tierschutz ist mir schon am wichtigsten. Und Menschenrechte auch. Also ich will das jetzt nicht so darüber stellen. Aber es interessiert mich halt am meisten. (weiblich, 16 Jahre) 
(1) Auf der Schule, auf der ich bin, die ist halt sozial ausgerichtet. Also das ist halt mit Psychologie und Pädagogik und so. Und wir machen auch immer relativ viel Projekte und sowas. Deswegen habe ich mir die Schule auch ausgesucht, weil mich das halt interessiert. (weiblich, 16 Jahre)

\subsubsection{Zukunftsvorstellungen}

Die Sozialökologischen Jugendlichen gehen davon aus, dass ihnen vielfältige berufliche Optionen offen stehen. Sie können und wollen sich noch nicht auf eine berufliche Perspektive festlegen. In jedem Fall soll es ein anspruchsvoller und sinnstiftender Beruf sein, wo man gerne hingeht und Eigeninitiative zeigen kann. Beruf bedeutet für sie idealerweise Berufung und Selbstverwirklichung.

Die Affinität zu Berufen, mit denen man „etwas bewegen kann", ist hoch (soziale Berufe, Politiker). Es ist ihnen wichtig, mit Menschen zu tun zu haben und helfen zu können. Die Bezahlung ist dabei eher zweitrangig. Karrierismus liegt Sozialökologischen eher fern. Man möchte kein typischer "Boss", "Chef im Ledersessel" sein.

Auszüge aus Hausaufgabenheften: WIE MÖCHTEST Du SPÄTER LEBEN? WAS MACHST DU DANN?

Ich mochte später in meiner eigenen wohnung leben, am beste ein eigenes Haus. Ob mit Freunden eine Wa gronden oder alleine, dass ist noch offen. Auf jeden Fall mòchte ichein Haustier haben. (tund oder katze) Beruflich mōchte ich das machen has mir gefallt und wo ich Spaßs dran habe, damit ich den Benf auch die nàchsten Jahrzehnte aus halte. Auserdem möchte ich ein spannen des leben fichren und jeden Tag etwas neves erleben. Ich will nicht, dass mir der grave alltag zu viec und 20 langweilig wird. Ich mochte in fremde länder reisen und andere kulturen und sitten kennen lerren.

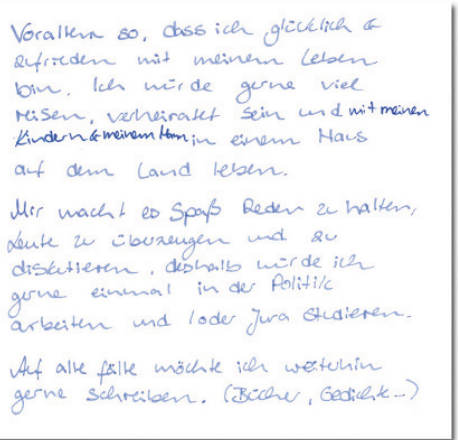

ich möchte Sonderpadagogik studieren Danach Möhte ich ein Familie granden. Mein Trown ware en Hows in Amsterdam.

Ich habe keinen Genauen Rlon we ich spater einmol leben will. Ich möble eine eigue Familie und genuy zat fur meine Hobbys. Was ich dam mache weis ich noch nicht. 
Sozialökologische Jugendliche betrachten es als Horrorvorstellung, ein Leben lang das Gleiche machen zu müssen. Mehrgleisige Berufswege und Patchwork-Karrieren finden sie spannend, da man so vor immer wieder neue Herausforderungen gestellt wird, neue Menschen kennenlernt und eigene Fähigkeiten weiterentwickeln kann.

Eigentlich ist man sich sicher, einen guten Schulabschluss hinzulegen und blickt daher optimistisch in die Zukunft. Wenn man erst weiß, wo es hingehen soll, will man sich voll reinhängen und erwartet, dass es dann auch klappen wird. Vor Eintritt in das Berufsleben träumen Sozialökologische typischerweise von einem langen Auslandsaufenthalt (zum Beispiel mehrere Monate mit dem Rucksack durch die Welt, Au-Pair-Job in den USA, Work\&Travel-Experience in Neuseeland). In der Zukunft will man neben dem Traumberuf auch weiterhin viele fremde Länder sehen. Sich mit unvertrauten Kulturen auseinandersetzen zu können sieht man als eine wichtige Lebenserfahrung. Gesund bleiben und eine eigene Familie zu gründen sind ebenfalls wichtig Zukunftsziele, wenngleich man sich vorstellen kann, Familie und Kinder zunächst zu vertagen, weil man vorher noch vieles anderes tun möchte. Eine eigene Familie mit Kindern ist zwar ein wichtiges Lebensziel, diese Jugendlichen romantisieren aber das traditionelle Familienmodell nicht, sondern sind durchaus offen für alternative Lebensmodelle, zumindest für eine gewisse Lebensphase.

Sorgen bereitet momentan lediglich die Frage, ob man sich richtig entscheiden wird oder möglicherweise nie oder zu spät die wahre Berufung entdeckt. Die Chancen, auf dem Arbeitsmarkt Fuß zu fassen, werden kaum thematisiert. Dies kann als Hinweis darauf gelesen werden, dass Misserfolg in diesem Kontext keine Option darstellt - sich beruflich nicht etablieren zu können, rangiert außerhalb des Vorstellungsvermögens. Das mag auch daran liegen, dass ein Studium für die allermeisten absolut gesetzt ist.

Man möchte zwar ein Leben in geordneten und sicheren Verhältnissen, jedoch abseits des Spießbürgerlichen und Kleinkarierten (zum Beispiel kann man es sich gut vorstellen, mit dem Partner auch lange nach Studiumsabschluss noch in einer Wohngemeinschaft zu leben). 
Erwachsenwerden bedeutet für diese Jugendlichen v.a. Freiheit und Selbstbestimmung hinzu zu gewinnen. Während es für viele andere Jugendliche auch die (unliebsame) zwangsläufige Übernahme von mehr Verantwortung und Pflichten bedeutet, steht das für die Sozialökologischen nicht so sehr im Vordergrund, da verantwortungsvolles Handeln auf vielen Ebenen ohnehin schon zu ihrem Anspruch an sich selbst gehört. Im Vergleich zu den meisten anderen Lebenswelten thematisieren Sozialökologische auch die Möglichkeit, sich als Erwachsene politisch und sozial (besser) engagieren zu können: Zum einen, weil ihnen als Volljährige das Wahlrecht zusteht, zum anderen weil man als Erwachsener ernster genommen wird.

( Pläne? Es kommt ja immer alles anders. Aber was ich mir am liebsten vorstellen würde: Erst mal eine WG mit vielen Freunden, vielleicht aber auch mit Leuten, die ich noch nicht kenne. [...] Und dabei studiere ich halt. Was, das weiß ich selbst noch nicht, vielleicht Psychologie oder so etwas. [...] Also sowas wie Wirtschaft oder sowas, das geht gar nicht. (weiblich, 16 Jahre)

( Ja, ich freue mich eigentlich darauf, wenn ich dann endlich mein Abi habe und studieren kann, dass man dann sich mehr so selbst einplanen kann, nicht so wie bei Schule, da kriegt man ja den Stundenplan. Dann muss man kommen und dann kann man sich ja so die Vorlesungen und so selbst einteilen und kann auch gucken, ob man in eine WG zieht oder alleine lebt und so, ja. Also ich will auf jeden Fall ausziehen. (weiblich, 17 Jahre)

Auf was ich mich freue, ist ganz klar die Volljährigkeit. Das bringt einfach sehr viele Freiheiten mit sich wie zum Beispiel Autofahren. Und man kann dann so lange draußen bleiben, wie man Lust hat. Man darf auch wählen gehen. Das heißt, man kann sich dann Gedanken machen und auch etwas in Deutschland bewirken. (männlich, 15 Jahre)

(1) Mich interessiert der Beruf Grafikdesigner oder Mediengestalter. (männlich, 15 Jahre) 
I Ich denke, ich kann mich gut in Menschen hinein versetzen und die verstehen. Deswegen will ich auch so einen sozialen Beruf wählen, das wäre da ganz nützlich. (weiblich, 15 Jahre)

(7) Wenn ich ein gutes Abi habe, würde ich auch Jura studieren. Aber da braucht man erstmal ein gutes Abi dazu. Eigentlich will ich Sonderpädagogik studieren. Ich kann mich eh nie entscheiden. (weiblich, 17 Jahre)

Ich würde gerne mal zu Greenpeace. Also wir zahlen da schon ein bisschen was für, aber ich würde da gerne aktiv mitarbeiten. Und vielleicht werde ich auch später Tierschützer. Das kann ich mir auch vorstellen. (weiblich, 16 Jahre)

( Mit 20 bin ich entweder verreist und mache vielleicht irgendein Projekt wie Work\&Travel. Wobei, das mache ich ja vielleicht früher, mit 19. Vielleicht studiere ich auch schon mit 20. Das weiß ich noch nicht. Und dann möchte ich auch schon ausgezogen sein. [...] Ja wahrscheinlich in einer WG mit meiner Freundin. [...] Mit meinem Freund möchte ich da noch nicht zusammengezogen sein. [...] Das ist mir irgendwie zu früh. (weiblich, 16 Jahre)

( Und dass ich halt auch etwas mache, das Spass macht, auch im Beruflichen und nicht nur, keine Ahnung, wo man gut verdient oder was alle machen, oder wo man denkt, das passt, was halt wirklich gut für einen ist. Dass ich halt glücklich bin mit meinem Leben. (weiblich, 16 Jahre)

I Ich würde später auch gerne reisen, wenn man dann mal so Urlaub hat. So in fremde Länder reisen und fremde Sachen erfahren und kennenlernen. (weiblich, 15 Jahre)

\subsubsection{Kulturelle Orientierung, Freizeit}

Sozialökologische Jugendliche haben ausgesprochen vielfältige Freizeitinteressen: Freundinnen und Freunde treffen, Lesen, Kino, Internet, Sport, alternative Kultur, Musik, Reisen, Psychologie, Kochen und Backen. Sie sind auch sportlich vielfältig aktiv. Gesundheits- und fitnessorientierte 
Sportarten wie Joggen und Krafttraining werden genauso praktiziert wie Kampfsport (letzteres mit dem Ziel der Körperbeherrschung, nicht der Gewaltanwendung), Leistungssport im Verein oder Randsportarten (z. B. Bogenschießen).

Konzerte, Musikfestivals (z. B. Festivals wie Splash, Fusion, Melt, Haldern) und mit netten, offenen Menschen tanzen gehören zu den coolen Dingen im Leben. Musik und die aktuelle Lieblingsband sind wichtig, weil sie positive Energie verbreiten und man Druck ablassen kann. Eine hohe Aufmerksamkeit gilt den Texten, die mal lyrisch-lustig, mal sozialkritisch oder auch sinnlos sein dürfen.

An Kunst sind Sozialökologische sehr interessiert, insbesondere "alternative Kunst" (Street-Art oder Graffiti, Poetry Slams). Kunst ist dann besonders spannend, wenn sie eine sozialkritische Message hat. Im Vergleich aller Lebenswelten ist das Interesse an der klassischen Hochkultur bei den Sozialökologischen am stärksten ausgeprägt. Sie gehen z. B. häufiger ins Theater und sind klassischer Musik und Jazz nicht so abgeneigt wie viele ihrer Altersgenossen. Einige spielen selbst klassische Instrumente. Und auch Museumsbesuche, welche in den meisten anderen

Auszüge aus Hausaufgabenheften: WAS GIBT DeINEM LeBEN SinN?

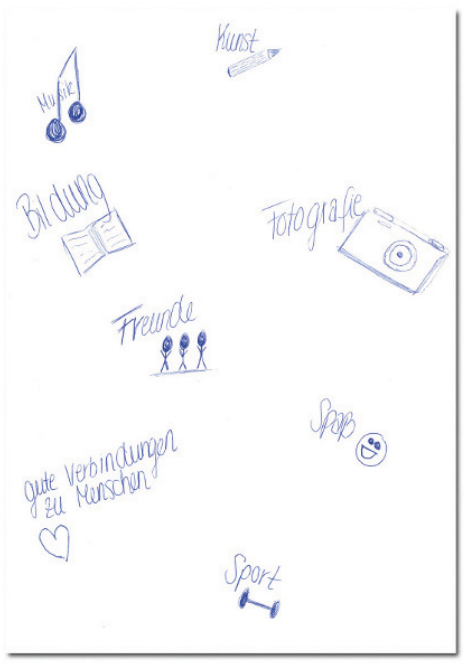

\section{Und naturlich} mèn Glaube:

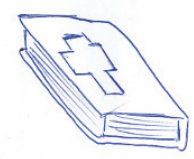

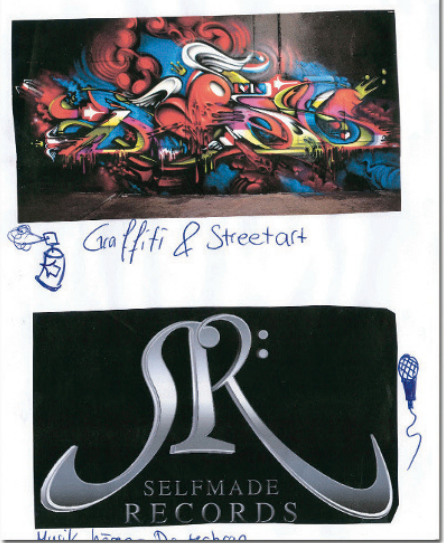


Auszüge aus Hausaufgabenheften: WAS HÖRST DU GERNE FÜR MUSIK?

Die aktuellen charts höre ich gerne, aber auch ab und zu Rap und HipHop.

Ich mag tiefgrundige Lieder und Texte die eine Bedeutung haben.

Mein momentanes Lieldingslied

ist Lieblingsmensch von Namika.

Jazz, Rap, Pop, Techno
Groptenteils:

- Goa

- Techno

- Elehtro

- manchmal Dubstep

Verheler:

- Paul Icalkbenner

- Neelix

- krama

- Travis Bath

- Cucumbers

- Unseer Dimension

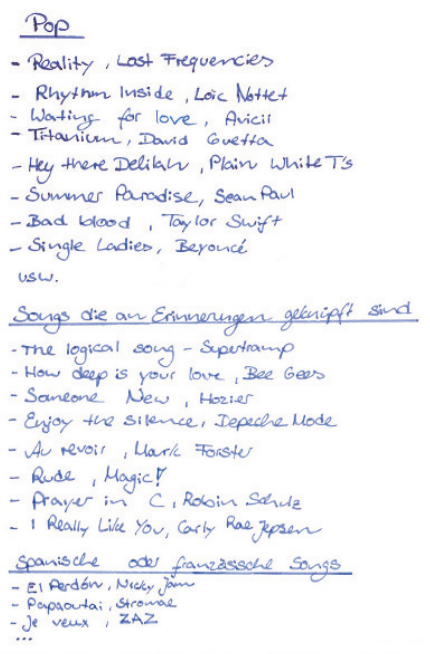

jugendlichen Lebenswelten auf (bisweilen starke) Ablehnung stoßen, sind in diesem Milieu durchaus beliebt.

Filme im Kino und Fernsehen werden aus einem breiten Spektrum sehr bewusst ausgewählt und zeichnen sich durch filmische Qualität oder eine besondere Thematik aus. Der Fernsehkonsum beschränkt sich weitgehend auf interessante Reportagen und Dokumentationen. Casting- und Reality-Shows finden kaum Anklang. Einige beginnen bereits, sich für Produktionen zu interessieren, die in besonderem Maße sozialpolitisch engagiert und/oder künstlerisch ambitioniert sind (z. B. Wolf of Wall Street, Das Schicksal ist ein mieser Verräter). Auch Kultfilme bzw. moderne Klassiker finden bei vielen Anklang. (z. B. Shawn of the Dead, Pulp Fiction, Vanilla Sky, Lost in Translation, Star Wars).

Sozialökologische sind von allen Jugendlichen die größten Leseratten. Bücher werden verschlungen, nicht nur gelesen. Das Themenspektrum ist dabei äußerst breit: Lyrik, populäre Bestseller, Trivial- und Horrorliteratur. Auch Sachbücher stehen hoch in der Gunst, um sich in Themenfeldern wie Politik, Geographie oder Geschichte Expertenwissen 
anzueignen. Und wenn man „von der Muse geküsst" wird, fängt man an, eigene Gedichte und Geschichten oder gar ein Buch zu schreiben, in denen Tagträume, eigene und fremde Biographien verarbeitet werden.

Sozialökologische träumen von einem Leben als Globetrotter. Sie haben großes Interesse an fremden Ländern ("Land und Leute") und Sprachen. Daher belegt man auch gerne Sprachen an der Schule oder bildet sich in seiner freien Zeit in Fremdsprachen weiter. Viele beklagen, dass sie von der Welt noch viel zu wenig gesehen haben - das Fernweh ist groß. Man möchte zukünftig entsprechend so viel wie möglich reisen. Dabei möchte man die Ziele spontan auswählen, z. B. auf einer Tour mit dem Interrail-Ticket. Ebenso kann man sich für Natur und Wandern und den Abend am Lagerfeuer begeistern. Die Natur ist ein Ort der Ganzheitlichkeit und Kraftquelle. Einen bis ins kleinste Detail geplanten Urlaub in "Hotelbunkern" findet man schrecklich. Spannend sind die typischen Destinationen des Rucksack-Tourismus (Indien, Thailand, Interrail durch Europa) sowie Städtetrips.

Auszüge aus Hausaufgabenheften: WAS LIEST DU GERNE?

Damals habe ich gerne solche mädchenbücher gelesen, nie Die diei!!! oder Freche Mädchen.

Heute lese ich sehr gerne thriller, da man sich richtig in das Buch vertiefen kann und sich dre spannung aufbaut, hie zum Beispiel bei dem Buch Noah

Aber auch andere Bücher gefallen mir sehr, zum Beispiel:

Bevor ich Sterbe, Junkgirl, Eine nie Alaska

Ich lese sehr gerne Bucher, da ich finde, dass man so in eine andere welt mit rein gezogen wird und sich entspannen kann.
Eigentlich alles....

- The favlt in our stars

- Margos Spurm

- Eive wir Alaska

- Seden

- Die welle

- Prem (Gamze Reine)

- Der Hobloit

- Alday Lyun CGanze Buchreine

L 1 Band. Verbaunt ans Ende du Welt

- Götlicer verdarmmt

(t Fortactzuy der Buchoine)

- Das lapislazeli Herz

- City of Bones

(ganze Reine)

Ich lese gerne Comics, aber auch gerne Biographienund Romane.

Zum Beispieli, $F$ ist wieder da" 
Auszüge aus Hausaufgabenheften: WAS GIBT DeInEM LeBEN SInN?
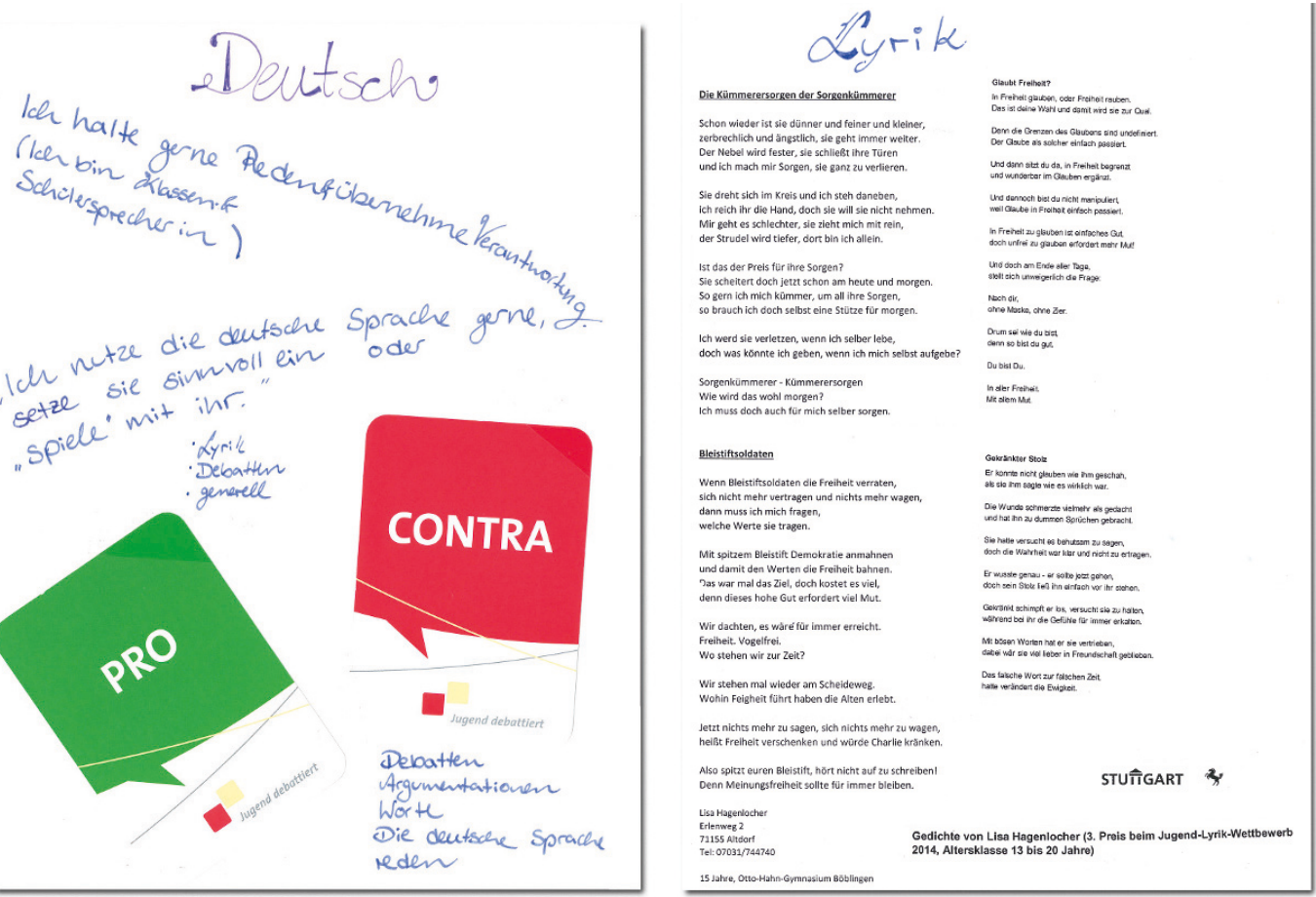

Sozialökologische Jugendliche sind zufrieden mit ihrer verbleibenden Freizeit. Sie brauchen keine zusätzlichen Angebote, weil sie sich ihre Aktivitäten selber organisieren und kaum Langeweile kennen. Es wird zwar "manchmal eng", aber sie wollen ihre Zeit auf keinen Fall "vergeuden und verplempern".

Typische Zitate zur |llustration

(7) Also ich mag halt auch spannende Sachen. Also nicht solche Hausfrauenserien wie Desperate Housewives oder so. Das gucke ich überhaupt nicht. (weiblich, 16 Jahre)

7 Meistens habe ich noch AGs nach der Schule, also ich spiele Querflöte. Entweder habe ich dann noch Unterricht oder Jam AG, da spielen wir alle zusammen [...]. Und ich bin in so einer AG, die heißt "Jugend 
debattiert" Und wenn ich dann nach Hause komme, dann lerne ich meistens und mache Hausaufgaben. (weiblich, 16 Jahre)

( Also ich fotografiere voll gerne, ich habe in meinem Zimmer so eine Fotowand und ich unterhalte mich halt gerne mit Leuten. (...) Ist eigentlich egal was, aber ich führe gerne, wie sagt man, nicht so oberflächliche Gespräche. Sport mag ich auch, aber ist nicht so, dass ich jetzt für Sport lebe. [LACHT] Klarinette spiele ich echt gerne. Und ich reise sehr gerne und ich will auch später mal so ganz viele Länder besuchen, am besten alle Kontinente mal. (weiblich, 17 Jahre)

ICh bin jetzt auch Klassensprecherin und für nächstes Schuljahr auch Schülersprecherin, das heißt irgendwo muss ich bestimmt streichen. Ich spiele jetzt schon Querflöte seit der 5.. Ich merke schon so ein bisschen, ich spiele zwar gern, aber ich habe auch nicht so viel Zeit zum Üben. Aber sonst so läuft es ganz gut. (weiblich, 16 Jahre)

(7) Ab und zu höre ich [ANM.: MusIK] auch gerne in anderen Sprachen, also Französisch und Spanisch, weil ich das mag, wie sich das anhört, auch wenn man es nicht gleich versteht. Ich habe jetzt zwar Französisch seit zwei Jahren als dritte Fremdsprache gewählt, aber man versteht es trotzdem nicht gleich. Und Englisch versteht man jetzt eigentlich sofort, was die so singen. Aber ich mag das auch mit Spanisch, das gefällt mir. (weiblich, 16 Jahre)

(Dann gibt es noch Wattpad. Da kann man selber Geschichten posten, also schreiben. Das ist für junge Autoren. Ich lese dort vor allem englische Stories, einfach weil es mehr gibt, aber Deutsch geht schon auch [...]. Ich bin da nicht so aktiv, aber manchmal schreiben wir zusammen ein Kapitel. (weiblich, 16 Jahre)

(1ch lese gern die STYLEFILE. Das ist ein Graffiti-Magazin. Und bei Büchern lese ich gern spannende Biografien. (männlich, 15 Jahre)

( Ich habe noch ein etwas anderes und etwas ausgefalleneres Hobby. Das kennen nicht viele. Das ist diese Sache hier. Das nennt sich Kendama. Das kommt aus dem Japanischen und ist praktisch so ein Geschicklichkeitsspiel, wo man verschiedene Tricks machen kann. (männlich, 15 Jahre) 


\subsubsection{Vergemeinschaftung}

Sozialökologische haben einen vergleichsweise hohen Anspruch an den eigenen Freundeskreis. Mit Jugendlichen, "die völlig anders drauf sind" als sie selbst, d. h. kein Interesse oder Verständnis für sozialökologische und kulturelle Themen mitbringen, hat man kaum etwas zu tun. Man sucht Freunde mit "Niveau und Tiefe". Über die eigenen Freunde sagt man, dass sie oft etwas „verrückt", "künstlerisch begabt" und „extrem klug" sind.

Im eigenen Freundeskreis ist es wichtig, dass man "geradeaus sein kann“, "heftig diskutiert" - jedoch stets respektvoll miteinander umgeht. Sozialökologische suchen die intellektuelle und persönliche Herausforderung, möchten sich mit Leuten umgeben, die eine starke und kritische Position einnehmen. Freundschaft bedeutet für sie, in einen kontinuierlichen bereichernden Austausch zu treten.

Sozialökologische bewegen sich in Jugendszenen, in denen die gemeinsamen Interessen eher auf Umwelt- und Naturbewusstsein basieren und/oder als konsumkritisch gelten können. Man grenzt sich von den "sorglosen Verschwendern" und den „Umweltsündern" deutlich ab.

Man möchte sich gerne mit unterschiedlichen Menschen verschiedenen Alters und verschiedener sozialer und nationaler Herkunft umgeben. Idealisiert wird die Freundschaft mit Menschen aus sozial schwächeren Verhältnissen, wenngleich viele faktisch kaum Kontakt zu dieser Gruppe haben. Man geht davon aus, dass der Zusammenhalt und die gegenseitige (auch finanzielle) Unterstützung bei ärmeren Menschen stärker und die Dekadenz geringer ist.

Gute Gemeinschaftserfahrungen machen Sozialökologische außer im Freundeskreis auch in Vereinen, die ihnen wie riesige Familien erscheinen, bei großen nicht-kommerziellen Festivals, Ferienlagern oder an jugend-religiösen Orten wie zum Beispiel Taizé. Unter den Religiösen dieser Gruppe spielt Glaube als Gesprächsthema und Vergemeinschaftungsanlass eine wichtige Rolle. 
(7) Was für Menschen ich nicht mag? Also, das ist ein Mensch, der keine anderen Meinungen zulässt, der fanatisch im Denken ist. Und denkt, die Meinung von sich ist die richtige Meinung und es gibt keine anderen

Typische Zitate zur Illustration Meinungen, die vielleicht auch richtig sein können. Also ein Mensch, der starrsinnig ist, unreflektiert [...]. So herzlose Menschen kann ich nicht leiden, oder falsche Menschen. (weiblich, 16 Jahre)

( Ich habe einige afrikanische Freunde. Also viele, die hier geboren sind, aber auch welche, die wirklich aus Afrika kommen. Und ich habe auch eine Freundin, die aus dem Libanon hierher gezogen ist. Und das ist klar ein Unterschied. Vor allem kulturell gesehen. Aber trotzdem ist es kein Grund, nicht befreundet zu sein. Weil so lange derjenige nett ist und man gut miteinander klar kommt und sich respektiert, geht das klar. (weiblich, 16 Jahre)

( Ich habe auch noch eine Freundin in Italien. Sie kommt eventuell nächstes Jahr zum Deutschlernen. (weiblich, 16 Jahre)

( Naja, ich weiß nicht, ich komme halt nicht mit so Leuten klar, die ihre Meinung nicht sagen können und keinen Charakter haben. Ich weiß nicht, so was macht mich richtig aggressiv. [LACHT] Wenn ich dann irgendwo auf einem Geburtstag bin oder so und dann sitzen da so Leute, die sich nur mit den Leuten unterhalten, die sie kennen und alle anderen sind sowieso Scheiße. Sowas kann ich nicht leiden, wenn man so verschlossen ist. (weiblich, 17 Jahre)

( Also die meisten Freunde sind Christen. Sie sind auch hilfsbereit, nett und zu den meisten Menschen höflich. Und sie sind so, wie man sich Jugendliche halt vorstellt. Sie haben auch Unfug im Kopf. Aber nicht so, dass es ausartet. (männlich, 15 Jahre) 


\subsection{Expeditive}

Die erfolgs- und lifestyleorientierten Networker auf der Suche nach neuen Grenzen und unkonventionellen Erfahrungen.

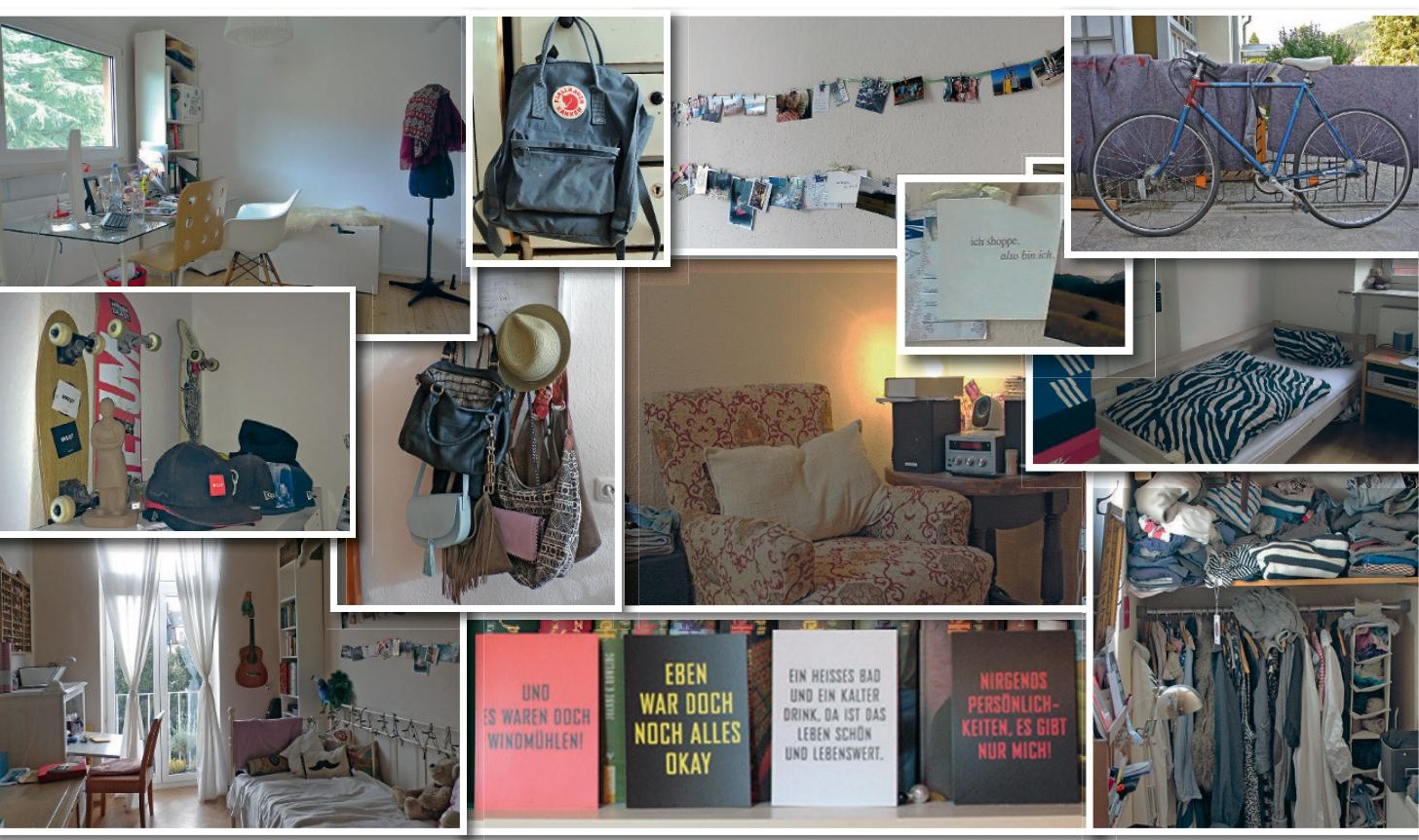

3.7.1 Lebensweltliche Basisorientierungen

Typisch für Expeditive ist ein buntes Wertepatchwork. Sie legen groBen Wert auf eine Balance zwischen Selbstverwirklichung, Selbstentfaltung, Selbständigkeit sowie Hedonismus einerseits und Pflicht- und Leistungswerten wie Streben nach Karriere und Erfolg, Zielstrebigkeit, Ehrgeiz und Fleiß andererseits. Von allen Jugendlichen sind sie mit die flexibelsten, mobilsten, pragmatischsten, innovativsten. Viele sind auch sehr kompetitiv und akzeptieren die Wettbewerbsgesellschaft. Den 
Werte-Universum der Expeditiven

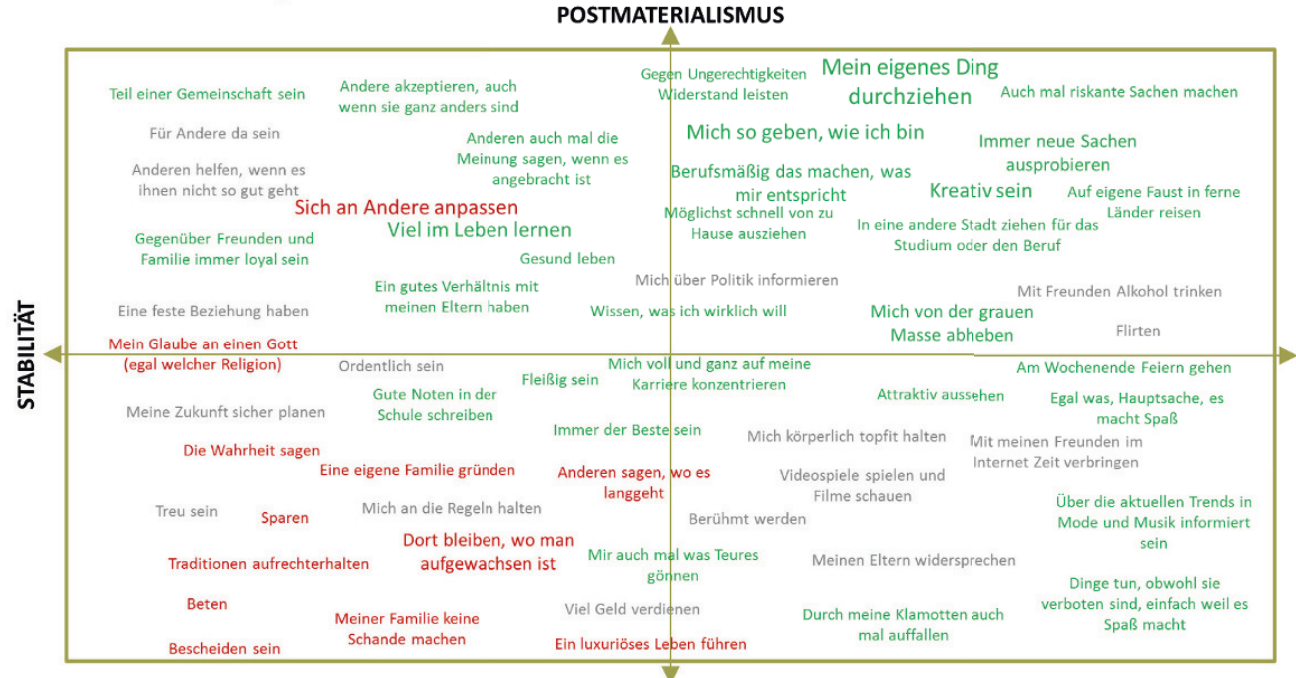

MATERIALISMUS

\section{eigenen Erfahrungshorizont ständig zu erweitern, ist eine wichtige Lebensmaxime.}

Sie möchten sich nicht in ideologische Korsette zwängen lassen, haben eine geringe Kontroll- und Autoritätsorientierung. Zu Fügsamkeits- und

\section{Auszüge aus Hausaufgabenheften: WAS GIBT DeINEM LeBEN SinN?}

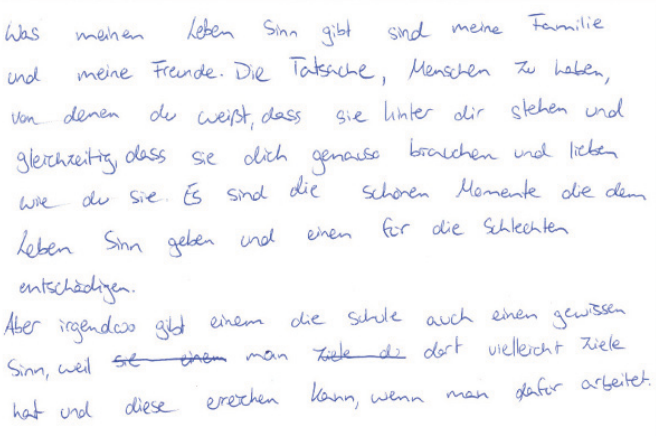

"Meine Zeit, sinnvoll" nutreu, also zum Beispiel eire gute zeit mit Freundeu/ dem Portrer habeu

- Menschen guidelicl llacheud seheu

Das Gefühl au haber, iu seineur kebeu etwas eneicheu ru könneu (Zubunfschanceu)

- Möglichst viele Ote dieser Welt sehou zu Röhnen

- Sich selbst frei eutfalten zu Rörnen

Familie

Waluscheinlich (so geht es zumindest mir) weip niemand so gare genau, was seinem kebeu deu Sinn gibt. 
Auszüge aus Hausaufgabenheften: WAS GIBT DeINEM LeBEN SinN?
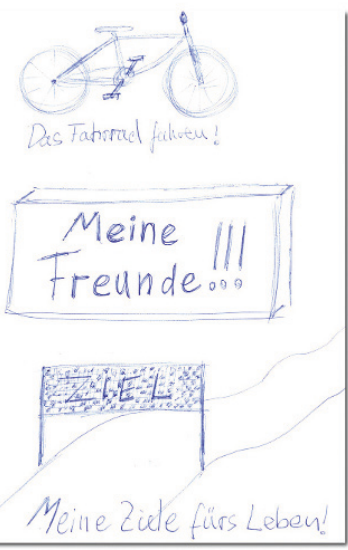

Meine Familie selbstverständlich (ich habe leider gerade kein gutes Bild)

Meine Freunde auch

Das ich die Möglichkeit habe meine Interessen, wie das Theater spielen, das Ballett, das Klavier spielen und noch vieles mehr so ausleben zu können wie ich das möchte.

Teil einer Gemeinschaft zu sein

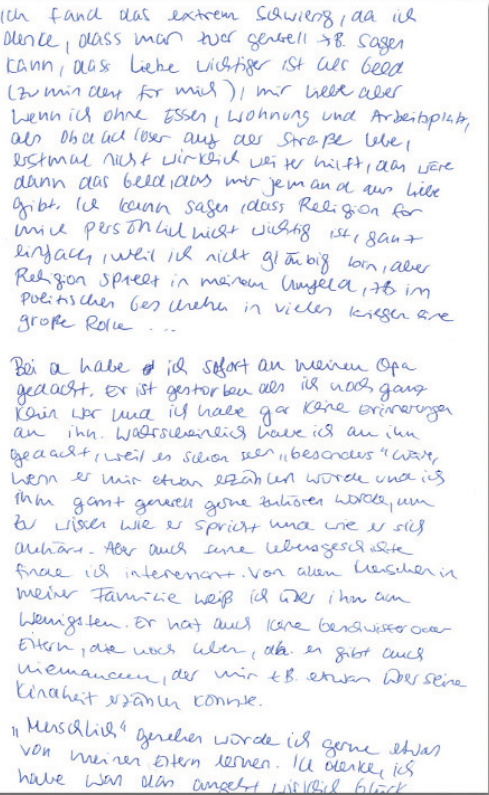

ich fand das extrem SQwieng, aa il dence, dass man tuer gerbell $\rightarrow B$. Sagen cann, acss liebe vichtiger ist wes beed (zumin dent for mic) / mir liebe aber als obclacl loser aut aer strape we, estmal nicht wirkeic vei ter hilft, ala ware dann als beed, alos mir jemand an hile gibt. la coun sagen class Religion for chick pers on aul hick vikng ist, sant gi an bis lorn, ale infera, is in grope Rofter Wrehe in vieles kieger are

Boi a habe il sefort an meiren opa geaacht. Er ist gestor beu als il noos gang roin sor wa ils habe gar kone erimerngen an inh. Woorshentig have is an inn

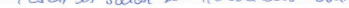
b visen bue sprich una vie sto auhars. Aler auch ane ubenseschiste finoe is interenont von aken cuerseler in meiner Familie weip ia aber ihn am

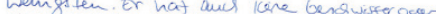
Ettern, die woes wben, ab. In gint aucs niemancuen, der mir EB. enwan Deerseine

von hutinen bitern lemen. I le derke ics have wan das angest wirigie blanck

Unterordnungswerten haben Expeditive eine ebenso große Distanz wie zu asketischen Werten und konservativ-religiösen Moralvorstellungen. Steht die freie Entfaltungsmöglichkeit Einzelner in Frage werden Expeditive Jugendliche skeptisch, wenden sich jedoch eher ab als zu rebellieren. Expeditive Jugendliche brauchen kreative Gestaltungsspielräume, um sich wohlzufühlen. Egal ob in der Schule, im Internet, im Sport oder in der Musik, sie wollen selber entscheiden, wann sie was in welcher Form tun oder lassen.

Expeditive grenzen sich von den Merkmalen bürgerlicher Etabliertheit ab: unhinterfragtes Verfolgen von Konventionen, Unterordnung von Spaß und Selbstverwirklichung zugunsten von Sicherheit, Angst vor Auffallen und Veränderung. Expeditive haben klare Ziele für ihr Leben, möchten aber nicht an sondern weiterkommen. Ein erwachsenes Leben ohne Aufbrüche scheint (noch) unvorstellbar. Das erste Ziel besteht darin, die Freiheiten zu erreichen, die eigentlich das Erwachsenenleben 
Auszüge aus Hausaufgabenheften: WAS SIND FÜR DICH DIE WICHTIGSTEN SACHEN DER WELT?

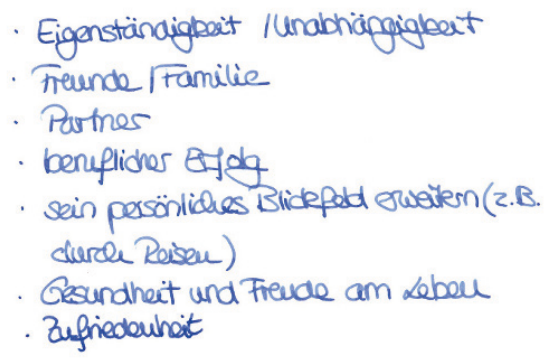

- Eigenständigbest / Unabhängigleent

- Treunde Familie

- Partner

- sein persönlidues Blidefeld erwetern (2.B. clurde Reisen)

- Zufriedeuhit

Ich kann gar nicht so genau sagen welche die wichtigsten Sachen für mich in der Welt sind. Ich denke aber das es nichts materielles ist. Viel wichtiger sind solche Dinge wie Freundschaft und das man eine Familie hat auf die man sich verlassen und der man vertrauen kann. Ich finde gute Erziehung auch sehr wichtig und vorallem, dass man lernt sich eine eigene Meinung über das Leben und die Welt zu bilden. Man sollte unabhängig sein.

auszeichnen: finanzielle Spielräume, eine eigene Wohnung, größere Mobilität, Teilhabe am kulturellen Leben, selbstbestimmte Sexualität.

Viele sehen sich als urbane, kosmopolitische "Hipster". Dem eigenen Selbstverständnis nach stellen sie die kulturelle und stilistische Avantgarde unter den Jugendlichen und schöpfen daraus viel Selbstbewusstsein. Sie verfügen über ein ausgeprägtes Selbstdarstellungs- und Durchsetzungsvermögen und haben ein elitäres Grundverständnis von sich selbst. Selbstbeschreibungen muten teilweise narzisstisch an: Man charakterisiert sich als interessant, einzigartig, eloquent, stilbewusst, stilsicher und "Gewinner-Typ". Dass andere Jugendliche dies bisweilen als Arroganz deuten, nimmt man durchaus wahr - deutet es aber nicht zuletzt als Bestätigung der eigenen Überlegenheit.

Expeditive haben oft Vorbilder aus dem Feld der Kunst (Fotografen, Schriftsteller usw.) oder "Machertypen" (Politiker, Entrepreneure). Auch historische und "jugenduntypische" Persönlichkeiten gelten einigen als Vorbilder.

Expeditive feiern Vielheit und Differenz, distanzieren sich von allem, was "gleichgeschaltet" daherkommt. Unverhandelbare Ordnungen und Konventionen sowie "genormte Identitäten" sind ihnen ein Gräuel. Sie lieben das Unkonventionelle, wenden sich demonstrativ vom „bürgerlichen Muff", von "spießbürgerlicher Gemütlichkeit" und von "steifem Bürokratismus" ab. Ein „austauschbarer Mustermensch“ zu sein, bezeichnen Expeditive als eine fürchterliche Vorstellung, entsprechend groß sind die 
Auszüge aus Hausaufgabenheften: Nenne eine erWachsene Person: A) DEREn Lebensgeschichte

Du DIR GERNE ERZÄHLEN LASSEN WÜRDEST. B) VON DER DU GERNE WAS LERNEN WÜRDEST.

a) Willy Brandt

Er entebte beinahe das gane, ereignisteiche 20. Jamilundert und besingastesselbst mit.

Seine Biggraphie istäußest sparneud, and noch iuteressantes wäre es sicherich, wenn er mir seine kebensgeschichte pesconilich erähleu wirde.

b) Das Fotographiereu von Diane Arbus odes eiseus andereu intemational betannteu Fotographer.

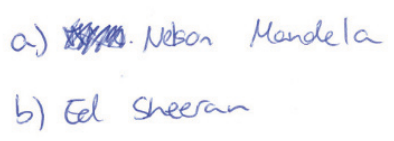

Die meines Großvaters mütterlicherseits. Ich habe ihn nämlich nie kennen gelernt da er schon tot war als ich geboren bin. Ich weiß nur sehr sehr wenig über ihn.

Abgrenzungsbemühungen zum Mainstream. Sie sind dabei aber weniger "verbissen" und rigoros als die Experimentalistischen Hedonisten. Ihre Distinktionsbestrebungen gestalten sich weniger als rebellisches Kämpfen, sondern ergeben sich quasi selbstverständlich aus der doch "offensichtlichen" intellektuellen und stilistischen Überlegenheit (vor allem gegenüber Gleichaltrigen).

Expeditive sind begeisterte und anspruchsvolle Konsumenten mit einem ausgeprägten Marken- und Trendbewusstsein (Mode, Musik, Kulinarik, Technik). Man greift (noch) auf Läden wie H\&M, COS, Mango und Zara zurück - „für Basics sowieso", versucht aber bereits, Stangenware möglichst zu vermeiden. Einige shoppen auch bereits in Läden, die gezielt qualitätsbewusste ältere Käufer adressieren (z. B. COS). Damit möchte man sich von den Gleichaltrigen absetzen und einen exklusiveren Kleidungsstil verfolgen. Auch beginnt man, sich für kleine Designerstores zu interessieren, wo sich der Wunsch nach Individualität besser einlösen lässt. Aus diesem Grund sind auch Flohmärkte und Second-HandLäden beliebte Einkaufsstätten und die eingemotteten Kleider der Eltern beliebte Fundgruben. Der eigene Stil wird als „zwischen elegant und extravagant", "kreativ", "anders als in der grauen Masse" beschrieben. 
Expeditive genießen es, für ihren Kleidungstil von anderen bewundert zu werden.

Für die Ästhetik der Expeditiven ist das ironische Spiel mit unterschiedlichen Stilen typisch. Dabei bedienen sie sich selbstbewusst und frech vieler Klischees und greifen neue Trends schnell auf, zitieren, was sie in internationalen (Mode-)Blogs aufstöbern und ergänzen die Styles (College-Style, Tomboy-Style, 80ies Vintage) um eigene Ideen.

Einige Expeditive verkörpern einen "Belanglosigkeitscharme", inszenieren sich ästhetisch z.B. demonstrativ nachlässig aber stilsicher. Man liebt Kleidung, Accessoires und Möbel mit einer "trashigen Aura“. Auch minimalistisches Design kommt gut an. Expeditive haben oft ein groBes Vintage-Faible. Wichtig ist, dass der eigene Stil nicht "angestrengt" rüberkommt. Alles soll mühelos und beiläufig wirken. Bei der Selbstinszenierung, v.a. über Mode und Möbel, ist man jedoch durchaus detailversessen. Bereits in der untersuchten Alterskohorte zeigt sich, dass Expeditive für popkulturelle Verfeinerungstaktiken sensibilisiert sind. Ästhetische Kleinstunterscheidungen wirken spannend auf Expeditive.

Expedive sind viel unterwegs. Es zieht sie nach draußen, in die angesagten Locations, dorthin, wo die Musik spielt, wo die Leute spannend und anders sind.

Bei aller Begeisterung für Spaßhaben in der Freizeit möchten sie jedoch auch im beruflichen Leben etwas reißen ("mover \& shaker"). Sie leben nach dem Motto "Work hard, play hard".

Die Familie ist Expeditiven (wie allen Jugendlichen) wichtig, in den Alltagsbeschreibungen spielt sie jedoch eine geringe Rolle - die Familie ist der sichere Hafen, hin und wieder unternimmt man etwas mit den Eltern oder einzelnen Geschwistern, das „wirkliche Leben“ spielt sich jedoch außerhalb der Familie ab. Expeditive Jugendliche fiebern der räumlichen Ablösung vom Elternhaus entgegen - dem Beginn eines neuen Lebensabschnitts. 
Typische Zitate zur Illustration

Ich möchte später zumindest zeitweise weg aus [MITTELGROSSE STADT IN OstdeutsChland]. Ich finde es wichtig, die eigene Komfortzone zu verlassen. Ich treffe auch heute schon Leute oder mache Sachen, die ich nicht jeden Tag mache, mein Leben ist also nicht langweilig, aber im Moment habe ich schon das Gefühl, dass ich nur so vor mich hinlebe. Das ist nicht direkt vegetieren. Aber dadurch finde ich es wichtig, dass ich später mal in eine andere Stadt gehe und dort die Möglichkeit habe, neue Wege zu laufen. Ich möchte die neue Stadt für mich selber entdecken. (weiblich, 15 Jahre)

Mir ist natürlich wichtig im Leben, dass ich Bezugspersonen habe, auf die ich mich verlassen kann, bei denen ich so sein kann, wie ich bin: Familie, Freunde, Partner. Dass ich trotzdem unabhängig bin, dass ich mein eigenes Leben führen kann, wie ich das möchte. Dass ich gute Zukunftschancen habe. Dass ich das Gefühl habe, ich kann mich weiterentwickeln, dass ich irgendwie eine Perspektive habe. Dass ich viel reisen kann, das ist mir sehr wichtig, was sehen. Und ich finde, man sollte sich schon sich anstrengen: Work hard - play hard. Dass man so den Ausgleich dazu findet. Dass man auf der einen Seite sich wirklich anstrengt, aber auch dann wieder so Ruhephasen hat, dass man runterkommt oder feiern geht oder sonst irgendwas. (weiblich, 17 Jahre)

Ich denke nur, man sollte alles nicht so ernst nehmen oder streng, einfach so ein bisschen locker immer bleiben und runterkommen erst mal. So unbeschwert auf die Sachen zugehen und dann wird das alles schon. Ich glaube, man muss immer vor allem an sich selber denken und man darf nicht so sehr an andere denken dabei, wenn man wirklich etwas erreichen will. Weil ich glaube, es denken nicht so viele wirklich an die anderen. Und wenn du für dich zwar an die anderen denkst, aber keiner denkt dann mehr an dich, das bringt dir dann auch nichts mehr. Ich glaube, man muss schon ein bisschen egoistisch sein in vielerlei Hinsicht und vor allem auch selbstbewusst und eine eigene Meinung über die Dinge haben. (weiblich, 16 Jahre)

( Ich glaube, sie würden sagen, dass ich relativ unabhängig bin für mein Alter, dass ich nicht so drauf Wert lege, was andere über mich sagen, aber dass ich schon relativ ehrgeizig bin, glaube ich. Dass ich auch ziemlich stur sein kann, vielleicht auch ein bisschen nachtragend. Dass 
ich auch - das hört sich jetzt doof an, aber zukunftsorientiert bin, dass ich mir viele Gedanken über meine Zukunft mache und auch sehr viel Wert darauf lege. (weiblich, 17 Jahre)

(ICh glaube, sie würden sagen, dass ich selbstbewusst bin und sehr laut (...) und mich gerne präsentiere und im Mittelpunkt stehe. Aber auch, dass ich über ernste Themen sprechen kann und auch mal nicht so albern immer bin. Vielleicht würden auch viele sagen, dass ich immer so Anführerin gerne bin, weil ich immer gerne das Sagen habe in vielen Dingen einfach so. (weiblich, 16 Jahre)

( Manchmal langweilt mich das ein bisschen, wenn ich zum dritten Mal bei H\&M war und die haben irgendwie nichts Besonderes. (weiblich, 17 Jahre)

(1) Das ist eher so ein exquisiter Schuhladen, also keine Kette. Das macht einer alleine. Und der hat auch einen Kleiderladen nebenan. Und der hat auch oft Schuhe, die sonst kein Laden in Stuttgart hat. Der hat ziemlich viele Connections und kriegt auch exquisite Schuhe. Ich finde den Laden einfach cool, also auch die Mentalität. (männlich, 16 Jahre)

( Bei Klamotten, was mir gefällt, das kauf ich immer alles. Nicht immer ultraschick oder so. Das gefällt mir auch nicht und gerade für die Schule ist es blöd, wenn man sich da so auftakelt. Was immer so locker ist und so ein bisschen hipster, das gefällt mir eigentlich alles immer sehr gut. (weiblich, 16 Jahre)

( Wenn ich etwas angefangen habe, dann versuche ich, das wirklich durchzuziehen, dass ich nicht sage, ich mache zum Beispiel jetzt jeden Tag Sport, und dann sag ich am dritten Tag, ich habe keine Lust mehr. Das ziehe ich dann schon durch. (weiblich, 17 Jahre)

( Wenn ich viel Geld kriegen würde, würde ich mir ein Haus kaufen, in Paris am liebsten. Oder ich hatte immer so einen Traum, dass ich mal Medizin in Harvard studiere. Vielleicht würde ich mir das davon bezahlen, weil das ist ja echt richtig teuer, so das Studium sichern, sag ich mal. (weiblich, 16 Jahre) 


\subsubsection{Zukunftsvorstellungen}

Expeditive blicken recht optimistisch, entspannt und selbstbewusst in die Zukunft. Sie gehen davon aus, dass sie das Rüstzeug mitbringen, um in einer globalisierten (Arbeits-)Welt Karriere machen zu können. Sie beobachten im Bekanntenkreis, dass man heute (v.a. in der von ihnen präferierten Kreativbranche) mit Originalität, Eigeninitiative und Unkonventionalität ("kreativer Differenz") weit kommen kann. Das sind Eigenschaften, die sie sich selbst in hohem Maße zuschreiben. Außerdem verfügen sie über gute "Connections" und in der Regel die notwendige Unterstützung im Elternhaus. Expeditive können sich gut selbst inszenieren, sich verschiedene "Masken" aufsetzen, wenn sie das Gefühl haben, dadurch im Leben schneller, besser voran zu kommen. Diese Fähigkeit ist ihnen als Vorteil bewusst, wenn es darum geht, sich selbst zu verkaufen.

Ein "guter" Beruf ist Expeditiven äußerst wichtig, wird aber nicht als der einzige zentrale "Sinnstifter" verstanden. Leben ist mehr als nur Arbeit. Spaß ist ein wichtiger Faktor in den Beschreibungen der beruflichen Zukunftsvorstellungen: Man möchte sich nicht an den Arbeitsplatz quälen müssen, sich Hierarchien blind unterordnen (immer "machen müssen, was andere sagen"). Man wünscht sich eine berufliche Zukunft mit möglichst großen Freiheitsgraden (Auswahl aus Themenvielfalt, flexible Arbeitszeiten und interessante soziale Kontakte) an einem attraktiven urbanen Standort.

Man geht einerseits davon aus, relativ problemlos „irgendeinen Job" finden zu können, andererseits fürchtet man, dass man beim Wunsch nach kreativer Selbstverwirklichung möglicherweise Abstriche machen muss. Expeditive beschäftigt weniger die Frage, ob sie einen Job finden, sondern für welchen Job sie sich entscheiden sollen, wie viele Fehlversuche man sich leisten kann, ob der derzeitige Traumberuf auch in der Zukunft spannend bleibt. Wirkliche Sorgen um ihre Zukunft machen sie sich nicht.

Man träumt davon, lieber früher als später auf eigenen Beinen zu stehen, das Elternhaus zu verlassen und eine eigene Lebensform zu finden. Dies kann sowohl eine Ehe mit Kindern als auch eine lose Beziehung oder eine 
Auszüge aus Hausaufgabenheften: WIE MÖCHTEST Du SPÄTER LEBEN? WAS MACHST DU DANN?

Es gibt fier micht nielt genau eire Mögtichbeit I

vorstellung, wie mein kebeu ice 20 jahreu ausston muss.

in erster linie möchteich mit beideu Beireu iur Kebeu stheu und finanziell unabhängig seir.

Das wird wohl die Gnendlage fir alles weitere, wie ein tolles Zzhause und Familie (mit kandern, wobei ich mir hierbei setr unstcher bin) sein. th mö̈nte mitmeinem Postrer zusammeu lebeu. aber immernoole genug zait für mide und meine Habbys tabeu. Es sollte einau guteu Job und ännidu zueungtopläne wie ide habeu. Ob ide lieber in der Stadt oder auf dem zand woluneu will kamich dersit noch nibertsagen.

Wiadig ist mir, dass ich effolgreich iu Job bin, micl salbst dabei aber niclit verändere oder vernadilissige. Es soll auch immer àreu dusgleich zur Arbeit gebeu $(\rightarrow$ Fieunde, Porther, Diseu (audu in exolisone (ander)).
Ich würde gerne später in Paris oder Berlin leben. Entweder in einer großen alt bau Wohnung oder in einem Stadthaus. Ich würde dann gerne als Ärztin arbeiten und einen Mann heiraten der entweder auch Arzt ist oder einen anderen guten Job hat. Am liebsten würde ich drei Kinder haben einen Jungen und zwei Mädchen. Außerdem würde ich diese Kinder gerne zweisprachig erziehen. Mein Leben sollte immer ganz unbeschwert sein. Natürlich würde ich viel arbeiten und bestimmt gibt es auch manchmal stress aber ich werde versuchen auch als Erwachsene ganz unbeschwert und glücklich zu leben.

WG sein. Eine Partnerschaft ist nur dann attraktiv, wenn beide fest auf eigenen Beinen stehen und jeder das eigene Leben leben kann.

Bevor Bindungen oder Verpflichtungen eingegangen werden, wünscht man sich jedoch, erst einmal Freiheit und Unabhängigkeit zu genießen. Auslandsaufenthalte sind selbstverständlich und für verschiedene Lebensphasen (noch während der Schulzeit, danach, während des Studiums oder als lange Reise) vorgesehen.

Expeditive haben oft eine recht lange Phase des „Ausprobierens" eingeplant. Das Leben auch mit fortschreitendem Alter flexibel und spontan zu gestalten ist für sie wichtig.

( Ich glaube aber, dass man teilweise gar nicht wissen muss, was man möchte. Es ist auf der anderen Seite auch wichtig, im Jetzt zu leben und nicht ständig nur vorauszuplanen. Manchmal muss man einfach damit

Typische Zitate zur Illustration zufrieden sein, dass man nicht genau weiß, was man hat und was man macht. Man sollte die Dinge so nehmen, wie sie kommen. (weiblich, 15 Jahre)

( Also eine Familie möchte ich nicht so früh. Das weiß ich schon. Mein Halbbruder hat früh Kinder bekommen. Der hat jetzt schon zwei Kinder 
und ist erst, glaube ich, 28. Ich finde, das schränkt einen einfach ein. Ich finde, das muss man nicht gleich am Anfang seines Lebens machen. Lieber sollte man erst mal Dinge machen, die man später nicht mehr machen kann, zum Beispiel reisen oder feiern oder was auch immer. (männlich, 16 Jahre)

I Ich glaube, dass ich so ganz unbeschwert weiter sein werde und auch so durchs Leben gehen werde, weil ich glaube, dass das auch eine gute Einstellung ist. Aber dass ich auch mal so eine gewisse Machtposition, was meinen Job angeht, haben möchte. Aber dass ich auf jeden Fall wahrscheinlich immer ganz gestresst sein werde, weil ich immer ganz viele Sachen zu tun habe und mich das ein bisschen vielleicht auch überfordern wird, aber ich das trotzdem irgendwie schaffen werde. (weiblich, 16 Jahre)

Wenn man alles selber machen muss und seine eigene Wohnung hat, da freue ich mich auf jeden Fall drauf. Wenn man so alleine wohnen kann und selber mit den Sachen umgeht und immer machen kann, was man will. Vor allem, wenn man gerade studiert: Du entscheidest jetzt, was du machst und nicht mehr deine Eltern. Du musst nicht mehr deine Eltern fragen. (weiblich, 16 Jahre)

(1) Ich werde mit 18 zum Beispiel auch ausziehen. Da ist man auf sich allein gestellt. Das kann man natürlich auch mit 17 oder 19 machen. Aber 18 ist einfach auch so eine symbolische Zahl. Mit 18 ist man erwachsen. (weiblich, 15 Jahre)

( Ich möchte auf jeden Fall einen hohen Lebensstandard haben, dass man sich nicht immer Gedanken machen muss ums Geld: Kann ich mir jetzt das leisten oder das? Dass man einfach viel verreisen kann, das ist mir auch sehr wichtig, dass man etwas von der Welt sieht. Dass man eine ordentliche Wohnung hat oder später vielleicht mal ein Haus. (...) Dass sich mein Leben nicht nur um die Karriere dreht, dass es einen wichtigen Teil einnimmt, aber dass ich auch einen Rückzugsort habe. (weiblich, 17 Jahre)

$>$ Ich hoffe, dass ich studiere. Ich habe überlegt, Psychologie zu studieren, also eher in die Wirtschaftsrichtung so mit BWL, weil ich finde es eigentlich das interessanteste Fach, wo man auch am meisten lernen kann. Ich hatte mir auch Mathe überlegt, aber ich glaube, das wird zu trocken. 
Germanistik oder so interessiert mich gar nicht. Politik finde ich interessant, aber ich weiß nicht, wie gut da die Zukunftschancen mit dem Job sind. Lehramt auf gar keinen Fall. Ich glaube, irgendwann würde es mich nerven, wenn ich zum 103. Mal den Kindern beibringen muss, wie das jetzt funktioniert. Nein, und wenn die so laut sind und dann muss man jeden Tag das Gleiche machen, nein. (weiblich, 17 Jahre)

(7) Jobwahl ist immer schwierig. Ich will auf jeden Fall keinen Bürojob oder so etwas. Ich möchte nur ungern immer das Gleiche machen müssen. Ich möchte lieber mit den Händen arbeiten, also entweder etwas Handwerkliches oder im Design. Oder ich würde auch Fotograf werden wie mein Vater. (männlich, 16 Jahre)

I Ich stelle es mir so vor, dass ich nach dem Abi nach Berlin gehe und dann anfange zu studieren, Medizin, und dann bin ich da gerade dabei mit 22. (weiblich, 16 Jahre)

(7) Mit 30 hätte ich schon gern die Familienplanung in Sicht. Ich sehe das so: Bis 30 hat man Zeit sich auszuprobieren. Und ab 30 ist dann so... Klar ist das dann kein Muss. Und wahrscheinlich sehe ich das anders, wenn ich selber 30 bin, weil ich dann gar nicht das Gefühl habe, $30 \mathrm{zu}$ sein. Aber im Moment sehe ich das so, dass ich ab 30 einen Job und eine Wohnung haben sollte. Und irgendwie sollte ich auch wissen, was ich machen will. Klar hat man auch später noch Zeit. Man kann ja auch theoretisch noch mit 45 umschwenken. Ich fände es aber schön, wenn ich mit 30 wüsste, wie es vorerst weitergeht. (weiblich, 15 Jahre)

( Ich wäre gern eine gute Mutter, also nicht so eine überstrenge, aber doch eine gute Mutter. Ich möchte auch nicht so langweilig sein. Ich wäre nicht gern nur - in Anführungsstrichen - eine Hausfrau, die den ganzen Tag nur zu Hause ist und ab 30 nicht mehr feiern geht. (weiblich, 17 Jahre)

\subsubsection{Kulturelle Orientierung, Freizeit}

Bei den Expeditiven zeichnet sich bereits früh eine kulturell universalistische Orientierung ab. Man ist bereits in jungen Jahren auf der Suche 
nach vielfältigen kulturellen Erfahrungsräumen, z. B. modernes Theater, Kunst und Malerei. Entsprechend ist das kulturelle Kapital der Expeditiven von allen Lebenswelten am stärksten flexibel-multikulturell ausgeprägt. Mit dem Mainstream-Geschmackskanon möchte man nicht in Verbindung gebracht werden. Von Rockkonzerten bis hin zu klassischer Hochkultur erscheint vieles interessant, solange man einen gewissen "Anspruch" darin eingelöst sieht.

Expeditive nutzen ihr breites, flexibel-multikulturelles Kapital als Statusmarker, um Distinktionsgewinne gegenüber dem Mainstream zu erzielen. Dabei geht es nicht nur darum sich zu unterscheiden, sondern auch darum, sich als "kultivierter" abzuheben: durch ein gepflegtes und der Situation angemessenes Äußeres, eine adäquate Ausdrucksweise, charmantes Auftreten und einwandfreie Manieren wenn nötig - jugendlicher Trotz, Schnodder und Slang werden an anderer Stelle gezeigt. Man weiß um seine Wirkung und den Einfluss auf das Umfeld.

Musik ist für Expeditive mehr als nur Musikrezeption. Sie ist Lebensgefühl, Soundtrack für ihren Alltag, einerseits etwas sehr Persönliches und

Auszüge aus Hausaufgabenheften: WAS HÖRST DU GERNE FÜR MUSIK?

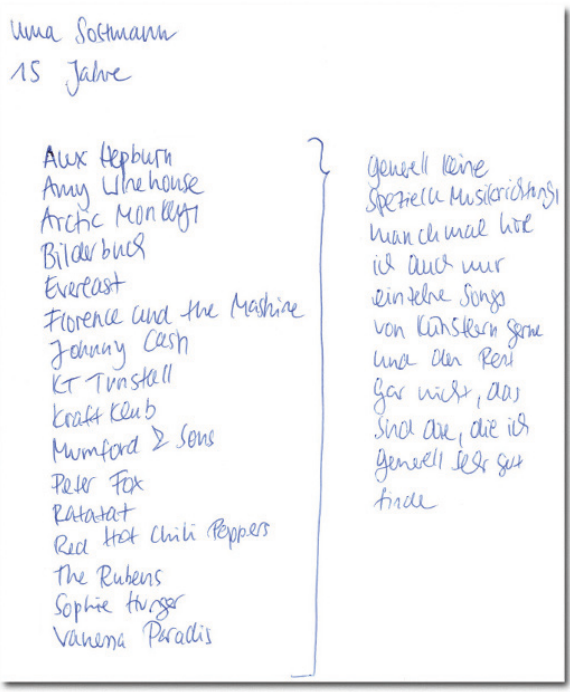

Una Sottmann
- Electronic

- (Deep)house

- Techno

- Tropical House

sonst jo nach Stimmung (Rap; Jazz; (ndie; mandhmal Klassik; ...)

Nidnt so gerne höre ich Top-Songs (Katy Pery; Torglor Swift; ... ).

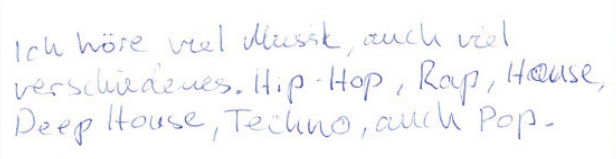


andererseits eine wichtige Voraussetzung der Vergemeinschaftung. Der eigene - aus Sicht der Expeditiven ungewöhnliche, distinguierte, Geschmack ist auch ein Mittel, um den Peers zu signalisieren, dass man erwachsener, reifer ist. So reicht ihr Musikgeschmack von den klassischen Stücken Mozarts über elektronisch-minimalistische Klänge bis hin zu satirischen Skandalrappern - Hauptsache etwas Besonderes und nicht zu sehr im "Mainstream". Expeditiven ist es wichtig, nicht auf eine Musikrichtung oder eine Szene reduziert zu werden. Sie interessieren sich für die Protagonisten und Ursprungsmythen bestimmter Genres, verfolgen die entsprechenden Nischenmedien, die darüber berichten. Musik ist auch Raum kreativer Selbstentfaltung: Man konsumiert nicht nur, sondern legt auch selber als DJ Platten auf oder würde das zumindest gerne in Zukunft tun. Oder man bringt sich selber ein Musikinstrument bei: Klavier, Synthi, Gitarre.

Expeditive sind "kulturelle Wilderer". Sie bedienen sich nach Lust und Laune aus dem reichhaltigen Reservoir der Popkultur und fügen Versatzstücke verschiedenster historischer und kultureller Provenienz zu einem neuen Ganzen zusammen: Remix, Bricolage, Sampling sind typische Kulturtechniken dieser Jugendlichen.

Expeditive lassen sich von einem elaborierten Sprachstil, komplexen Argumentationsketten, anspruchsvoller Kunst etc. beeindrucken. Das Banale, Triviale, Volkstümliche wird verunglimpft und entwertet. Man kann nicht nachvollziehen, dass Menschen (insbesondere Jugendliche) sich für Volksmusik, Schlager, DSDS-Sternchen oder Musicals begeistern können.

Die "normalen Bücher", die man in der Schule lesen muss, langweilen eher. Man trifft eine eigene Lektürewahl (z. B. Thriller, Sachbücher oder auch mal Klassiker). Lesen ist vergleichsweise beliebt, auch wenn zunehmend die Peergroup interessanter wird und weniger freie Zeit für dieses Hobby bleibt. Viele dieser Jugendlichen haben eine relativ große Büchersammlung, können von Lieblingsautoren berichten und erleben das Lesen als genussvoll.

Auch mit Hinblick auf Fernsehen und Kino folgt man viel seltener als Gleichaltrige dem Mainstream. Bevorzugt werden amerikanische und 
Auszüge aus Hausaufgabenheften: WAS LIEST Du GERNE?

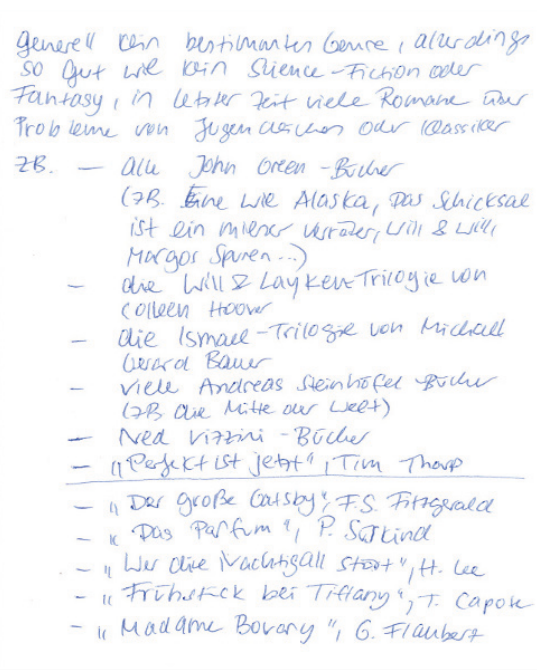

Joh 1 Greene

Die Bücher die meine Mutter empfiehlt

Bücher mit Themen die sich mit dem 3. Reich beschäftigen das finde ich interessant

Lieber Sachbücher ats kiebesromaue, Thriller sind is Ordnung.

Ich lese gerne etwas ausgefallenere Sacheu, mit, 50 shades of Grey" bann ich nix anfangen.

britische TV-Serien (Dr. House, Dr. Who, Simpsons, Skins, Misfits). Gerade weil man weiß, dass das "total doof und ätzend" ist, amüsiert man sich auch mal darüber, wie Menschen in Realty TV-Formaten zur Schau gestellt werden, verurteilt diese Form der Unterhaltung jedoch gleichzeitig. Dokumentationen, Magazinformate und "anspruchsvolle" Spielfilme auf ARD, Arte oder den dritten Programme schaut man sich auch mal an. Streaming-Portale werden ebenfalls frequentiert. Im Kino achtet man eher darauf, dass die Story stimmt und es eine anspruchsvolle Produktion ist (Drama, Psychothriller, Horrorfilm).

Reisen steht hoch im Kurs bei den Expeditiven. Fremde Länder, etwas Neues sehen und andere Menschen kennenlernen sowie Naturerfahrung sind die Motive, um auf Tour zu gehen. Expeditive sind fasziniert von dem pulsierenden Leben der Großstädte. New York, Berlin, London, Tokyo, Stockholm sind Orte, für die man sich begeistert, von denen man viel gehört hat und die man besuchen möchte.

Bei den Expeditiven Jugendlichen ist bereits recht deutlich die Vorliebe für das exzessive Partyleben zu erkennen, (Techno-)Partys und 
Auszüge aus Hausaufgabenheften: WofüR INTERESSIERST Du DICH?

Für vieles. Was in der Welt so passiert. Über die großen Probleme aber natürlich auch für die kleinen eigentlichen unwichtigen Probleme die ich selber oder meine Freunde haben. Für Jungs interessiert man sich als 16 jähriges Mädchen ja auch und dazu eben interessiert man sich für die Liebe. Für Mode und so was interessiere ich mich auch, ist ja auch teilweise wichtig.

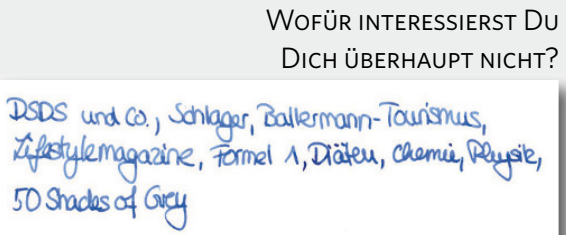

WOFÜR INTERESSIERST DU

DICH ÜBERHAUPT NICHT?

DSDS und Co., Schlager, Ballermann-Tounismus, Tifestylemagazine, Formel 1, Diäteu, Chemie, Deysile, 50 Shades of Grey

$$
\begin{aligned}
& \text { Musik } \\
& \text { Bucher } \\
& \text { meine Freunde }
\end{aligned}
$$

Gesolischaft, Politik I dehueltes Geschelueu, Probleme meiner Preunde, meuschlidues Handein / Deubeu, Reiseu, Städte, Fime, Fernsehseudungeu, gutes Esseu, klamotter, Musik, Fotographic, bestimmte Sportarteu, Extremsportarteu (Bungee - Jumping; Skydiving)

Clubbesuche rangieren - insofern realisierbar - schon recht weit oben auf der Liste der liebsten Freizeitbeschäftigungen. Die Optionen, die Großstädte hier bieten und auch die Freizügigkeit wirken auf Expeditive besonders anziehend. Im Duktus der Selbstverständlichkeit wird über ausschweifende Touren ("24 Stunden unterwegs") und ekstatische Erlebnisse berichtet: „Sex ist wichtig, das gehört ja praktisch zu Musik und Party dazu."

Viele Expeditive gehen Trend-und Extremsportarten sowie kreativen und musischen Hobbies nach.

Expeditive sind sehr bildungsaffin. Bildung findet in dieser Lebenswelt sowohl bewusst in der Freizeit als auch en passant statt. Interessiert man sich für ein bestimmtes Thema, so empfindet man es als selbstverständlich, sich auch darüber zu informieren bzw. weiterzubilden, indem man z. B. ein Sachbuch liest, im Internet recherchiert oder eine Ausstellung besucht. Wie auch bei den Sozialökologischen kann ein Museumsbesuch für Expeditive eine reizvolle Freizeitgestaltung darstellen. 
Typische Zitate zur |llustration
(7) Feiern gehen am Freitag- oder Samstagabend. Und wenn keine Klausuren anstehen vielleicht auch an beiden Abenden. Während der Klausurphasen lerne ich eigentlich den ganzen Tag. (weiblich, 17 Jahre)

( Ich würde schon gern häufiger ins Theater gehen. Aber ich mache schon ziemlich viel, also ich habe viel mit Theater zu tun. Meine beiden Onkel sind beispielsweise Regisseur und Schauspieler. Und mein Patenonkel macht Dokumentarfilme. Deshalb schaue ich mir auch solche Filme an. Impro mache ich zum Beispiel schon seit vier Jahren. Und das will ich auch weitermachen. Im Bereich des normalen Theaters probiere ich mich noch aus. Ich war bisher in drei verschiedenen Vereinen. Die haben mir aber alle nicht zugesagt. Letztes Jahr habe ich bei einem Kurzfilm mitgemacht. Der hatte vor einem Monat Premiere. Im Herbst werde ich bei einem anderen Kurzfilm mitmachen. (weiblich, 15 Jahre)

(Die ganzen Serien, ich finde so etwas schrecklich. Germany's Next Topmodel und so. (weiblich, 17 Jahre)

( Entweder gehe ich zum Theater oder zum Klavierunterricht oder zum Tanzen. Ballett, zweimal in der Woche, und einmal ist es so Modern Ballett eher und dann noch einmal so klassisch. (weiblich, 16 Jahre)

(8) Das ist nicht so klassisches Theater, das ist postdramatisch. Ich finde das irgendwie viel cooler. Ich war auch mal in der Schule in der Theater-AG, und das war ganz typisch das Schultheater, Jugendtheater. Und das fand ich ein bisschen doof, wenn man einfach seinen Text bekommt, seine Rolle einfach auswendig lernen soll. Und in der Theatergruppe, wo ich bin, im Haus der Jugend in der Weststadt ist das ganz besonders. Das geht immer so auf einen selber ein, weil man auch ganz viel Biografisches immer reinbringt und auch manchmal selber seine Texte dazu fügt oder seine Gedanken eben. Und unsere Leiterin sagt auch immer, wir sollen die Rolle verkörpern, aber immer wir selber sein auf der Bühne und immer als wir selber spielen. (...) Und das ist eben auch eine neue Herausforderung, weil es nicht so leicht ist, das dann so rüberzubringen, dass es auch authentisch wirkt. Aber es macht auf jeden Fall richtig viel Spaß. (weiblich, 16 Jahre)

Mein Freund und ich haben jetzt beide das Musikmachen für uns entdeckt. Also wir rappen. Und das machen wir schon oft. Wir schreiben Texte und rappen diese auf irgendeinen Beat. (männlich, 16 Jahre) 
(1) Schön finde ich meistens, wenn Freitag ist. Dann fahren alle zusammen nach Hause, dann weiß man: Ja, jetzt ist Wochenende! Dann gehe ich noch mal zum Ballett, das habe ich immer freitagabends, danach treffe ich mich aber noch mit meinen ganzen Freunden, weil wir dann abends natürlich etwas machen. Das ist dann immer so, wenn alles noch mal so abfällt von einem. Dann weiß man zwar, Montag geht eh wieder alles von vorne los, aber es ist trotzdem jetzt einfach so der Moment. (weiblich, 16 Jahre)

( Ich höre fast ausschließlich elektronische Musik. Sonntagmorgen oder so finde ich es auch nicht schlimm, wenn man da mal Klassik hört. Ich weiß nicht, ich finde es irgendwie entspannend. Ich finde auch, es ist ein bisschen anspruchsvoller als die elektronische Musik. Das ist halt eher so eintönig, und dann Klassik. (weiblich, 17 Jahre)

( Dokumentationen schaue ich hauptsächlich im öffentlich-rechtlichen Fernsehen, weil ich finde, im Free-TV kommen eigentlich zum größten Teil Sachen, die mich nicht interessieren. Wenn ich mal schaue, schaue ich lieber Dokumentationen, wo ich wenigstens das Gefühl habe, dass es einen nicht total verblödet. (weiblich, 17 Jahre)

Ja. Ich höre sehr viel Musik. Ich laufe jeden Tag eine halbe Stunde zur Schule und zurück, und dabei höre ich immer Musik. Ich höre auch oft so nebenbei über die Anlage. Mein Musikgeschmack ist gar nicht festgelegt. Ich höre das, was mir gefällt. Das beschränkt sich nicht auf ein Genre. Das ist dolle durch meinen Vater geprägt. Ich habe früher ganz viel Musik mit ihm gehört. Er bekommt die Rolling Stone, also so ein Musikmagazin. Da ist jedes Mal eine CD dabei mit zehn Tracks, die wild zusammengewürfelt sind. Und wir machen das ganz oft so, dass wir im Auto fahren und uns gegenseitig sagen, wie uns diese Musik gefällt und woran sie uns erinnert. Ich nehme mir auch ganz oft einfach irgendeine CD von ihm und höre sie mir an. Den Rest der Musik empfehlen mir Freunde. Oder ich mag einfach einen Song. Aber das ist oftmals gar nicht das Bekannte oder die Musik, die andere Leute in meinem Alter hören. (weiblich, 15 Jahre) 


\subsubsection{Vergemeinschaftung}

Vernetzung und Verflechtung sind die zentralen Vergemeinschaftungsmaximen der Expeditiven. Sie sind Networker - online wie offline. Neben engen Freundschaften pflegen sie große, lose Bekanntenkreise. Freunde und Bekannte beschreibt man als spannende und interessante Zeitgenossen mit einem ähnlichen Lebensstil und ähnlichen kulturellen und ästhetischen Präferenzen. In den Netzwerken der Expeditiven finden sich oft ältere Jugendliche und junge Erwachsene. Man findet es cool, auch von Älteren akzeptiert zu werden.

Expeditiven ist es wichtig, sich aus den jeweiligen Cliquen kurzzeitig ausklinken zu können: Einerseits um Zeit für sich zu haben und anderen zeigen zu können, dass man alleine zurechtkommt, andererseits erkennen diese Jugendlichen einen Wert darin, zwischen verschiedenen Gruppen frei zu flottieren.

Expeditive sind zwar in große Netzwerke eingebunden, fühlen sich aber in kleinen, durchaus elitären Zirkeln am wohlsten. Sie mögen ein Umfeld, in dem ein intensiver und intellektuell herausfordernder Austausch stattfindet. Sie suchen nach spannenden Kontakten, die sie weiterbringen, von denen sie profitieren können (die ihnen Gästelistenplätze auf Partys verschaffen können, von denen sie Musik und Filme bzw. Serien kopieren können, die wissen, wo was abgeht, die ihnen Mobilität ermöglichen oder erleichtern, die ihnen Einblicke in Jugendszenen geben und szenespezifisches Wissen vermitteln können).

Auch wenn Expeditive den Wert und Nutzen großer Netzwerke betonen, unterscheiden sie recht deutlich zwischen "Bekannten“ in ihrem weit verzweigten Netzwerk und den "wahren“, "echten“, "besten“ Freunden. Es sind die Freundinnen und Freunde, denen man sich bedingungslos anvertraut, mit denen man Tag und Nacht verbringen könnte, für die man sein letztes Hemd geben würde, weil sie es genauso tun würden.

Deutlicher als andere Jugendliche betonen die Expeditiven den Wert des Single-Daseins - feste und lange Paarbeziehungen sind hier vergleichsweise seltener, tiefe (platonische) Freundschaften zwischen 
Mädchen und Jungen hingegen häufiger zu beobachten als in anderen Lebenswelten.

Expeditive sehen sich oft mit dem Vorwurf konfrontiert, aufgrund ihres anspruchsvollen Kulturgeschmacks und ihres individualistischen Auftretens "auf Teufel komm raus anders sein zu wollen“. Sie werden als verkrampft, exzentrisch, "too cool for school" wahrgenommen. Ihre Expeditionen in jugendkulturelle Szenen werden von anderen Jugendlichen oftmals als opportunistische Streifzüge wahrgenommen und als mangelndes commitment gedeutet. Sie selber sehen sich jedoch als „Allrounder", die in verschiedenen Szenen unterwegs sein können.

Ihr breites kulturelles Interesse ist für sie eine wichtige strategische Ressource: Es dient ihnen als Marker von Überlegenheit gegenüber den kulturell weniger Versierten und als Selbstvergewisserung, dass man bereits erwachsener ist als viele Altersgenossen. Die oft ostentativ formulierte Offenheit und kulturelle Toleranz kennt bei vielen jedoch klare Grenzen. Auffällig ist, dass viele sich vom kulturellen Geschmack der bildungsbenachteiligten oder stark traditionell orientierten Jugendlichen distanzieren.

Expeditive selbst distanzieren sich von Menschen, die sie als zu langweilig, gleichgeschaltet, banal, kindisch und spießig verstehen: „Reihenhausbesitzer", "Ballermann-Touris", "Normalos", „Prolls", "Kleintierzüchter". Auch von weniger leistungsfähigen und -willigen Jugendlichen grenzt man sich $a b$ - v. a. wenn sie ihnen persönliche Nachteile bereiten, z. B. im Kontext von Schule und Lernen. Dies kommt zum Ausdruck in einer deutlich kritischen Haltung gegenüber "Hartzern" oder der Aussage, dass man mit Haupt- und Realschülern lieber nichts zu tun haben möchte. 
Typische Zitate zur Illustration
Ein paar Freunde von mir sind deutlich älter. (weiblich, 17 Jahre)

( Ansonsten ist der Großteil meines Freundeskreises erst im letzten Jahr entstanden. Das ist schon ziemlich krass, denn ich habe das Gefühl, dass ich sie schon ewig kenne. Dabei kenne ich sie noch gar nicht so lange. (weiblich, 15 Jahre)

( Das erste Mal bin ich mit einer Freundin aus meiner Klasse hingegangen. Die kannte dort ganz viele Leute und hat mich auch gleich ganz vielen Leuten vorgestellt. Am Anfang waren es für mich ganz viele neue Leute, und man hat jeden Abend jemand Neues kennengelernt. Es waren auch immer neue Leute dabei. (weiblich, 15 Jahre)

( I I glaube, in diesen fünf Monaten, in denen ich in Spanien war, habe ich mich auf jeden Fall verändert, weil ich da ja auch die ganze Zeit so alleine war. Das hat mich schon reifer werden lassen, auf jeden Fall. Und auch so unabhängiger und alles. [...] Als ich da so die ersten zwei Monate war, war es schon immer ziemlich schwierig für mich, weil ich halt auch die Leute nicht verstanden habe und einfach nicht wusste, warum ich das denn gemacht habe und so. Das hat mich auch weitergebracht, weil ich mir dann selber sagen musste, du schaffst das, du bleibst noch mal hier zwei Monate, dann wird es bestimmt besser. Und das war dann auch so. Weil ich da eben ganz auf mich allein gestellt war und das dann selber alles in die Hand nehmen musste. (weiblich, 16 Jahre)

\footnotetext{
Open Access Dieses Kapitel wird unter der Creative Commons Namensnennung - Nicht kommerziell 2.5 International Lizenz (http://creativecommons.org/licenses/by-nc/2.5/deed.de) veröffentlicht, welche für nicht kommerzielle Zwecke die Nutzung, Verbreitung und Wiedergabe in jeglichem Medium und Format erlaubt, sofern Sie den/die ursprünglichen Autor(en), den Titel des Werks und die Quelle ordnungsgemäß nennen, einen Link zur Creative Commons Lizenz beifügen und im Falle einer Abwandlung durch einen entsprechenden Hinweis deutlich erkennbar machen, dass Änderungen vorgenommen wurden.

Die in diesem Kapitel enthaltenen Bilder und sonstiges Drittmaterial unterliegen ebenfalls der genannten Creative Commons Lizenz, sofern sich aus der Abbildungslegende nichts anderes ergibt. Sofern das betreffende Material nicht unter der genannten Creative Commons Lizenz steht und die betreffende Handlung nicht nach gesetzlichen Vorschriften erlaubt ist, ist auch für die oben aufgeführten nicht-kommerziellen Weiterverwendungen des Materials die Einwilligung des jeweiligen Rechteinhabers einzuholen.
} 